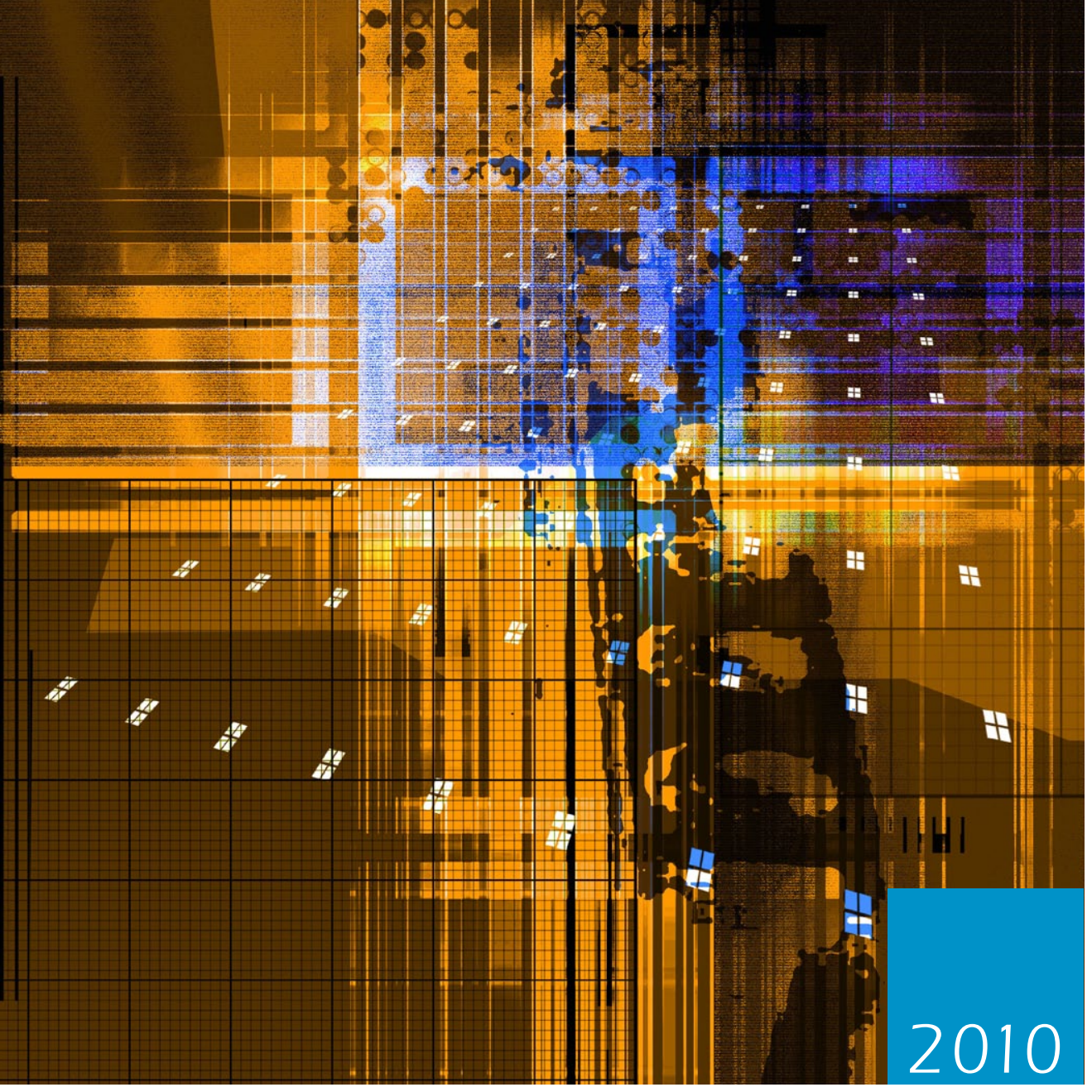

\title{
Modelling \\ Load Shifting Using \\ Electric Vehicles \\ in a Smart Grid \\ Environment
}

International Energy Agency

SHIN-ICHI INAGE

WORKING PAPER 
The International Energy Agency (IEA), an autonomous agency, was established in November 1974. Its mandate is two-fold: to promote energy security amongst its member countries through collective response to physical disruptions in oil supply and to advise member countries on sound energy policy.

The IEA carries out a comprehensive programme of energy co-operation among 28 advanced economies, each of which is obliged to hold oil stocks equivalent to 90 days of its net imports. The Agency aims to:

- Secure member countries' access to reliable and ample supplies of all forms of energy; in particular, through maintaining effective emergency response capabilities in case of oil supply disruptions.

- Promote sustainable energy policies that spur economic growth and environmental protection in a global context - particularly in terms of reducing greenhouse-gas emissions that contribute to climate change.

- Improve transparency of international markets through collection and analysis of energy data.

- Support global collaboration on energy technology to secure future energy supplies and mitigate their environmental impact, including through improved energy

efficiency and development and deployment of low-carbon technologies.

- Find solutions to global energy challenges through engagement and dialogue with non-member countries, industry, international organisations and other stakeholders.

IEA member countries:

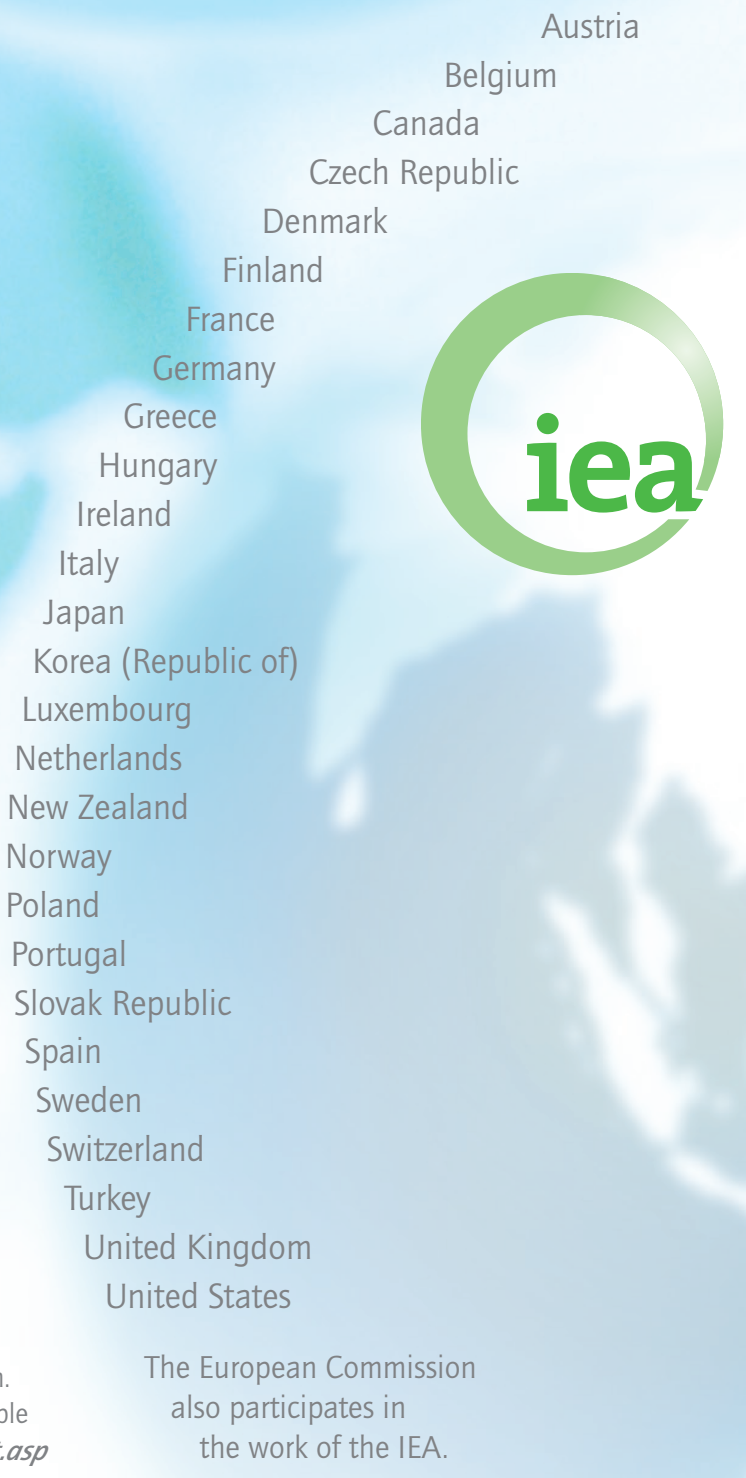

\section{(c) OECD/IEA, 2010 \\ International Energy Agency \\ 9 rue de la Fédération \\ 75739 Paris Cedex 15, France}

Please note that this publication is subject to specific restrictions that limit its use and distribution. The terms and conditions are available online at www.iea.org/about/copyright.asp
International Energy Agency

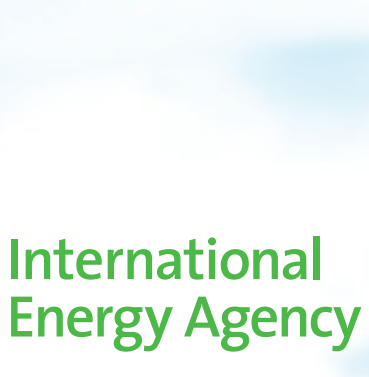




\section{Modelling \\ Load Shifting Using \\ Electric Vehicles \\ in a Smart Grid \\ Environment}

The views expressed in this working paper are those of the author(s) and do not necessarily reflect the views or policy of the International Energy Agency (IEA) Secretariat or of its individual member countries. This paper is a work in progress, designed to elicit comments and further debate; thus, comments are welcome, directed to the author at: shinichi.inage.wk@hitachi.com or David Elzinga at david.elzinga@iea.org

International Energy Agency

SHIN-ICHI INAGE 



\section{Table of contents}

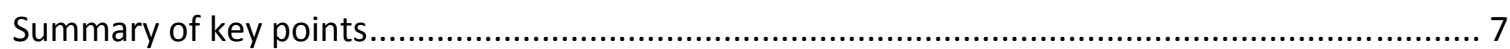

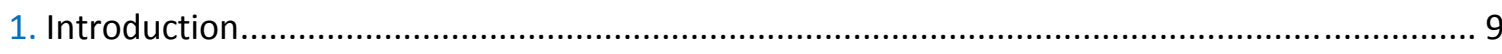

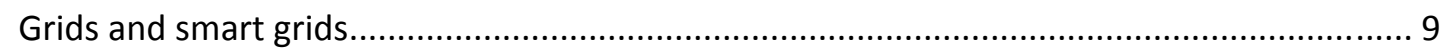

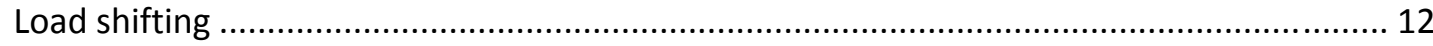

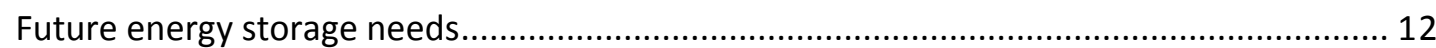

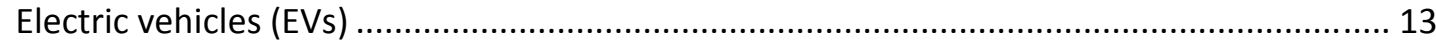

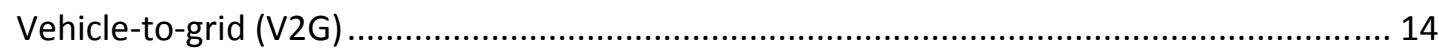

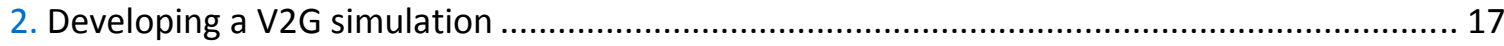

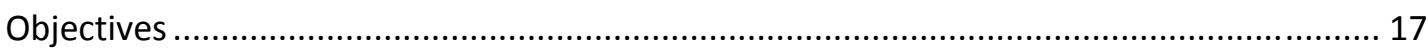

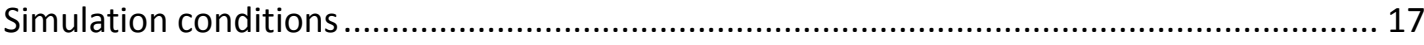

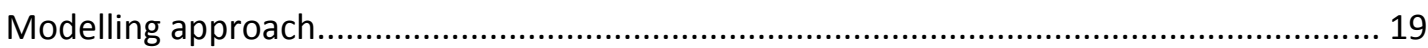

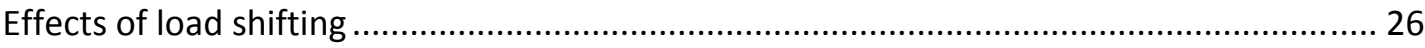

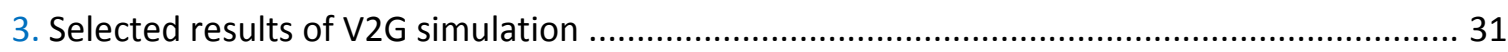

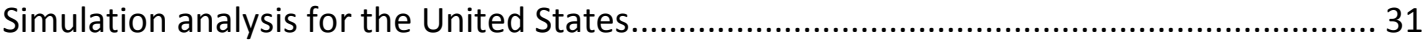

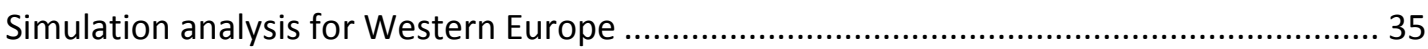

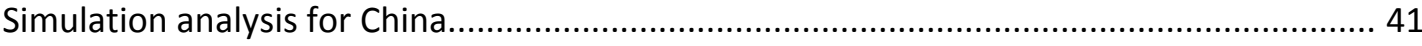

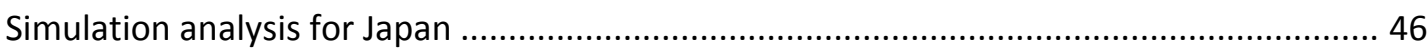

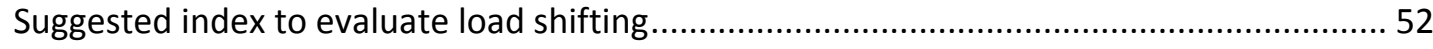

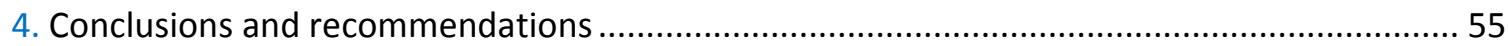

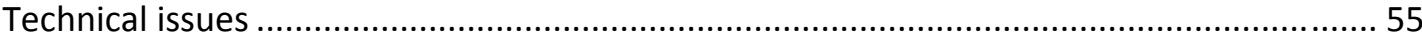

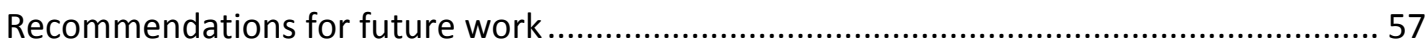

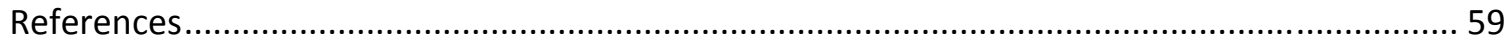

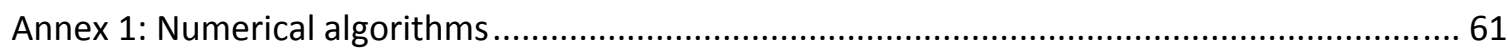

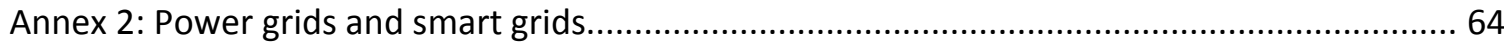

\section{List of figures}

Figure 1: $\mathrm{CO}_{2}$ emissions reduction during 2005-50 based on the BLUE Map scenario................... 9

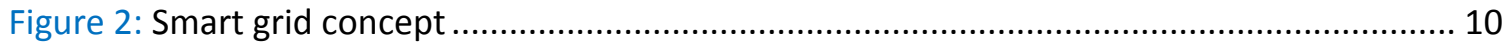

Figure 3: Growth of necessary energy storage capacity worldwide during 2010-50 .................. 13

Figure 4: Potential growth of plug-in EVs in key markets through 2050 .................................... 14

Figure 5: Typical daily travelling patterns of gasoline-fuelled cars in Japan ................................. 15

Figure 6: Trend of generation mix in the United States ............................................................ 18

Figure 7: Forecast of annual total demand in the United States ............................................... 18

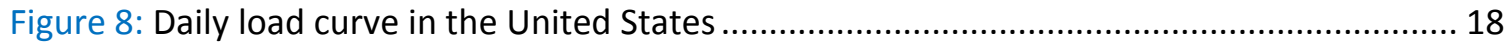

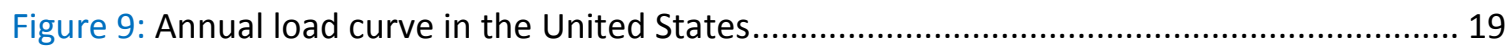

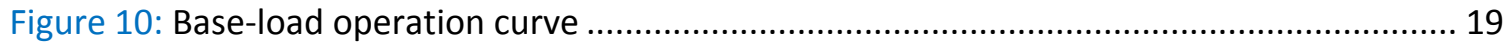

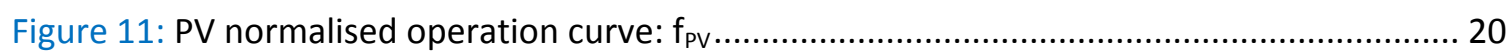

Figure 12: Actual wind speed distribution, New Mexico, United States...................................... 21 


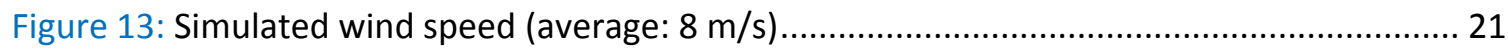

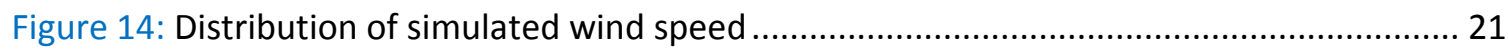

Figure 15: Normalised operational curve for wind power model............................................... 22

Figure 16: Wind farm smoothing effect on power fluctuation ................................................... 23

Figure 17: Comparison of simulated wind power with different sample numbers,

Page | 4 for 35 samples (left) and 10 samples (right) ......................................................................... 24

Figure 18: The relationship between number of samples and net variation................................ 24

Figure 19: Fundamental concept of the simulation method ...................................................... 25

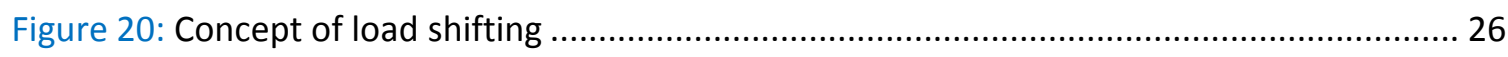

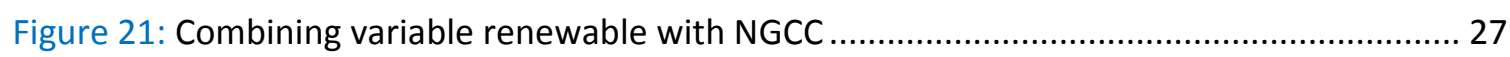

Figure 22: Adjustable speed rate and operational load range of NGCC …................................ 27

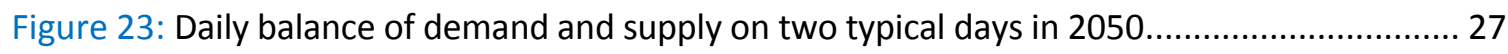

Figure 24: Comparison of daily trend of middle load in a typical day under minimum load........ 28

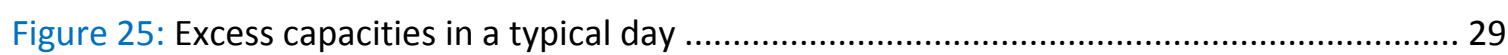

Figure 26: Decreasing effect of the requiring energy storage capacity ....................................... 30

Figure 27: US demand-supply balance in minimum demand months (April, September) ........... 32

Figure 28: US demand-supply balance in maximum demand months (August, December) ........ 33

Figure 29: US demand-supply balances during maximum demand with various V2G ratios in 2045 ... 34

Figure 30: Daily trend of middle-load generation in the maximum demand months in the

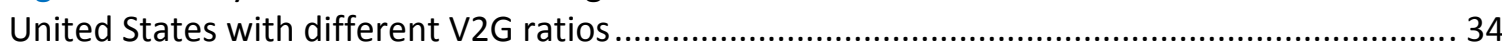

Figure 31: Relationship between V2G ratio and the maximum middle-load capacity in the United States 35

Figure 32: Trend of generation production mix in Western Europe............................................ 35

Figure 33: Growth of annual energy demand in Western Europe ................................................. 36

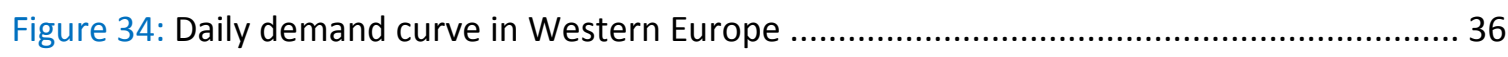

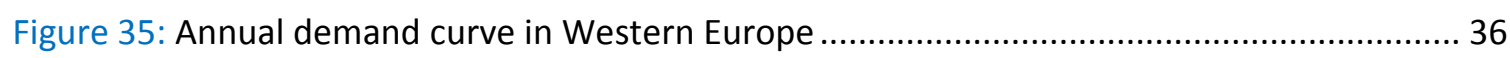

Figure 36: Western Europe demand-supply balance in minimum demand months (June, July) . 38

Figure 37: Western Europe demand-supply balance in maximum demand months (January, December) ....39

Figure 38: Comparison of effect of V2G in 2045 in Western Europe.......................................... 40

Figure 39: Daily trend of middle-load generation during maximum demand months in

Western Europe with different V2G ratios

Figure 40: Relationship between V2G ratio and the maximum middle-load capacity in Western Europe...41

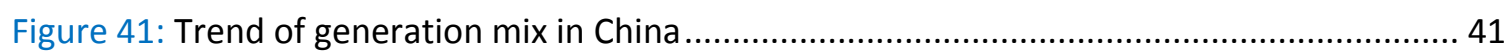

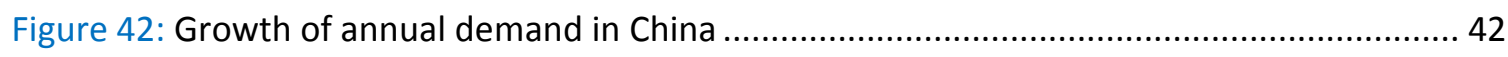

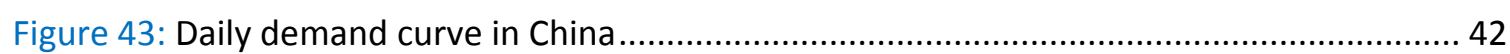

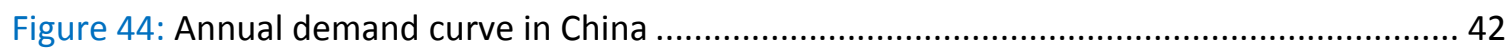

Figure 45: China demand-supply balance in minimum demand month (February) ...................... 43

Figure 46: China demand-supply balance in maximum demand month (August)......................... 44

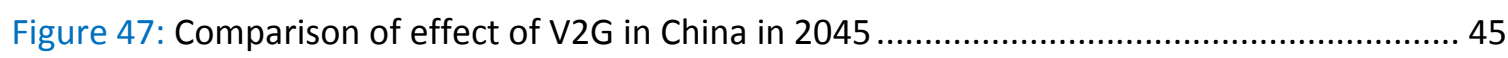

Figure 48: Comparison of daily trend of middle load in the maximum demand season in China ..... 45

Figure 49: Relationship between V2G ratio and the maximum middle-load capacity ................. 46

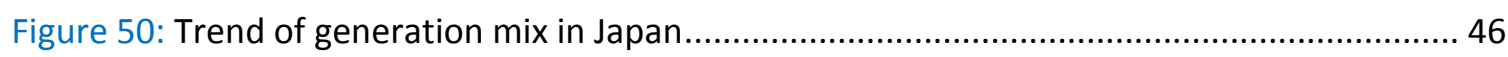

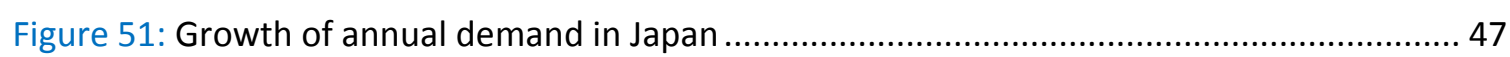

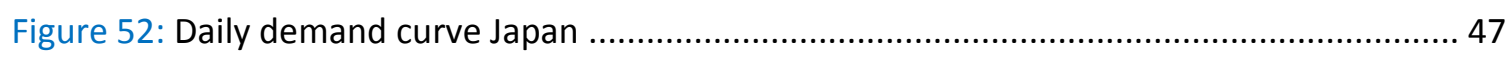


Figure 53: Annual demand curve in Japan 47

Figure 54: Japan demand-supply balance in minimum demand months (May and October) ..... 49

Figure 55: Japan demand-supply balance in maximum demand month (August) ........................ 50

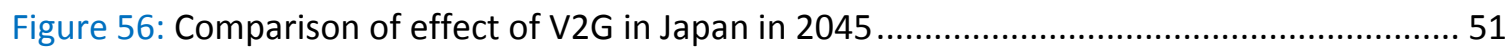

Figure 57: Comparison of daily trend of middle load in the maximum demand season in Japan ..... 51

Figure 58: Relationship between V2G ratio and the maximum middle-load capacity in Japan ... 52

Figure 59: Load shifting situations with a shortage (left) and excess (right) of EV generation capacity. 52

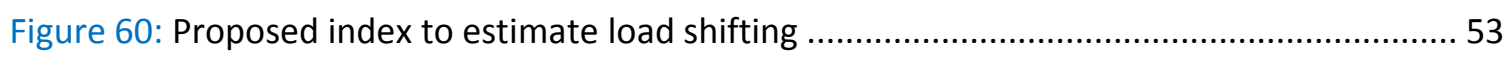

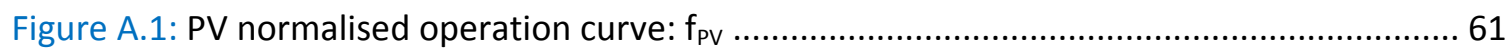

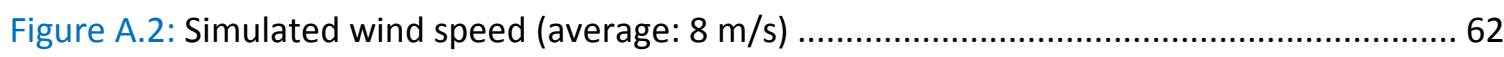

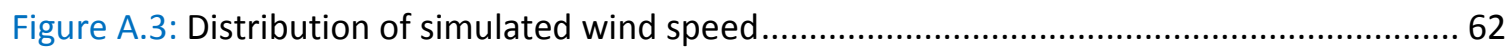

Figure A.4: Normalised operational curve for wind power model ............................................ 63

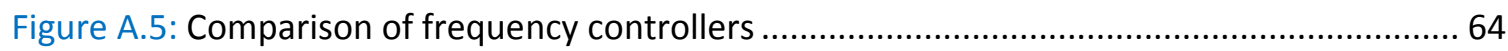

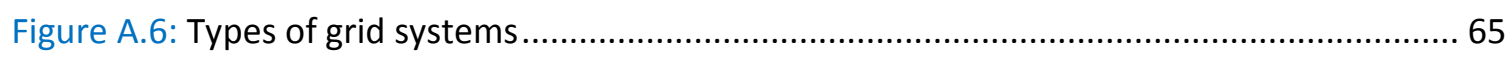

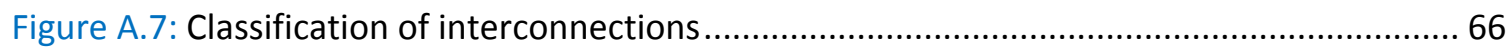

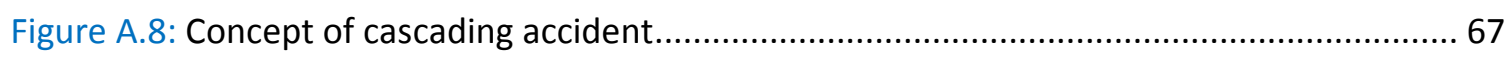

Figure A.9: Influence of PV penetration on demand-supply balance ......................................... 68

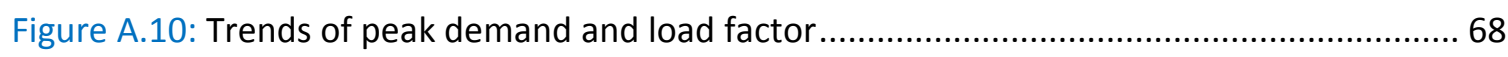

Figure A.11: Typical annual trend of residential peak demand for Southern California Edison ... 69

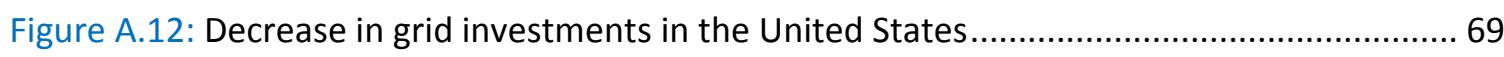

Figure A.13: Comparison of national electric power supplies in 2007 ....................................... 70

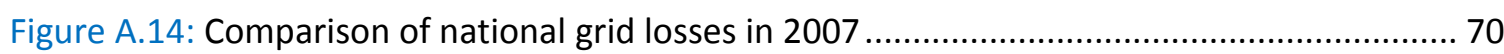

\section{List of tables}

Table 1: Comparison between existing grid and the future smart grid ....................................... 11

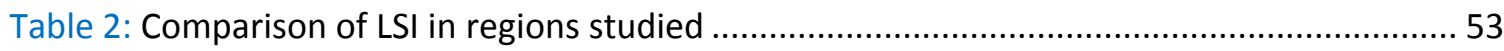

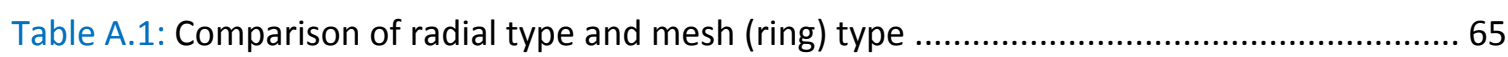





\section{Summary of key points}

This working paper focuses on the potential role of electric vehicles (EVs) as a dispatchable, distributed energy storage resource to provide load shifting in a smart grid environment. EVs represent both a new demand for electricity and a possible storage medium that could supply power to utilities. The "vehicle-to-grid" (V2G) concept could help cut electricity demand during peak periods and prove especially helpful in smoothing variations in power generation introduced to the grid by variable renewable resources such as wind and solar power. This paper proposes a method for simulating the potential benefits of using EVs in load shifting and V2G applications for four different regions - the United States, Western Europe, China and Japan - that are expected to have large numbers of EVs by 2050.

The starting point is the Energy Technology Perspectives 2008 (ETP 2008) BLUE Map scenario for power supply and transport systems (IEA, 2008). According to the scenario, increased use of renewable energy technologies and the widespread introduction of EVs can play an important role in reducing $\mathrm{CO}_{2}$ emissions in the power supply and transportation sectors. To maintain power quality, especially frequency, energy storage systems will be needed to mitigate power fluctuations caused by variable renewable generators. Large capacities of energy storage are an integral part of the power system in the BLUE Map scenario. Rather than specific numerical values, it is the relative amounts of storage against net variability that is important.

The smart grid is a generic concept of modernising power grids, including activation of demand based on instantaneous, two-way, interactive information and communication technologies. Features of a smart grid include grid monitoring and management, advanced maintenance, advanced metering infrastructure, demand response, renewables integration, EV integration, and V2G. As electric infrastructures age worldwide, there is increasing interest in smart grid technologies that:

- self-heal $^{1}$

- motivate and include the consumer in energy decisions

- resists attack

- provide power quality (PQ) for $21^{\text {st }}$ century needs

- accommodate all generation and storage options

- enable markets

- optimise assets and operate efficiently.

In this working paper, a simplified algorithm was developed to estimate the benefits of load shifting in a smart grid environment using the results of the BLUE Map scenario as boundary conditions. Features of the numerical simulation method developed include:

- Calculation of daily balances of the demand and supply, utilising V2G as power storage resource in each country or region.

- Consideration of the influence of wind power fluctuation, based on a Monte Carlo method.

- Consideration of the smoothing effect of wind power, based on the fact that as the amount of wind power increases in a given geographical region, the net variability of wind power decreases, based on a law of large numbers.

Simulation results indicate that load shifting and V2G can reduce the energy storage capacity required to maintain power quality. Without load shifting, the worldwide requirement for

\footnotetext{
${ }^{1}$ Self-healing refers to an engineering design that enables the problematic elements of a system to be isolated and, ideally, restored to normal operations with little or no human intervention. The modern, self-healing grid will perform continuous, online self-assessments and initiate corrective responses.
} 
energy storage capacity ranges from $189 \mathrm{GW}$ to $305 \mathrm{GW}$ by 2050, corresponding to variations due to wind power of $15 \%$ to $30 \%$. With load shifting, the range of required energy storage capacities decreases to $122 \mathrm{GW}$ to $260 \mathrm{GW}$.

The modelling methods and conclusions detailed in this report confirm that load shifting and V2G offer potential benefits in some regions and situations. However, load shifting and V2G also Page $\mid 8$ have many technical hurdles to overcome including:

- accurate forecasting of renewable energy supply and demand

- guaranteeing the availability and controllability of EV and V2G capacity

- creating optimal incentives for EV owners and system operators to adopt load shifting and V2G

- ensuring the best mix of EV lithium-ion (Li-ion) battery storage and large-scale energy storage options (such as pumped hydro)

- preventing decreased lifetime of EV Li-ion batteries due to frequent charge-discharge cycles

- establishing a viable transparent business model

- obtaining statistical data on the driving patterns and availability of EVs. 


\section{Introduction}

The Energy Technology Perspectives (ETP 2008) BLUE Map scenario aims to cut energy related $\mathrm{CO}_{2}$ emissions by half between 2005 and 2050. Based on the BLUE Map targets, renewable energy resources account for $21 \%$ of the total global $\mathrm{CO}_{2}$ emission mitigation in 2050 (Figure 1). This contribution comes on top of significant renewable growth in the Baseline scenario. ${ }^{2}$ The share of renewables in power generation will rise to $46 \%$ in 2050 , compared to around $19 \%$ today.

The bulk of the growth of renewables will be based on variable renewable supply options: wind, solar and hydroelectric power will each grow to around 5000 TWh. A power supply based on variable renewables will always be subject to weather variations. Given the high share of variable renewables in the total global power supply in the BLUE Map scenario, power system planners face an emerging challenge that will require engineering solutions to "keep the lights on".

Figure 1: $\mathrm{CO}_{2}$ emissions reduction during 2005-50 based on the BLUE Map scenario

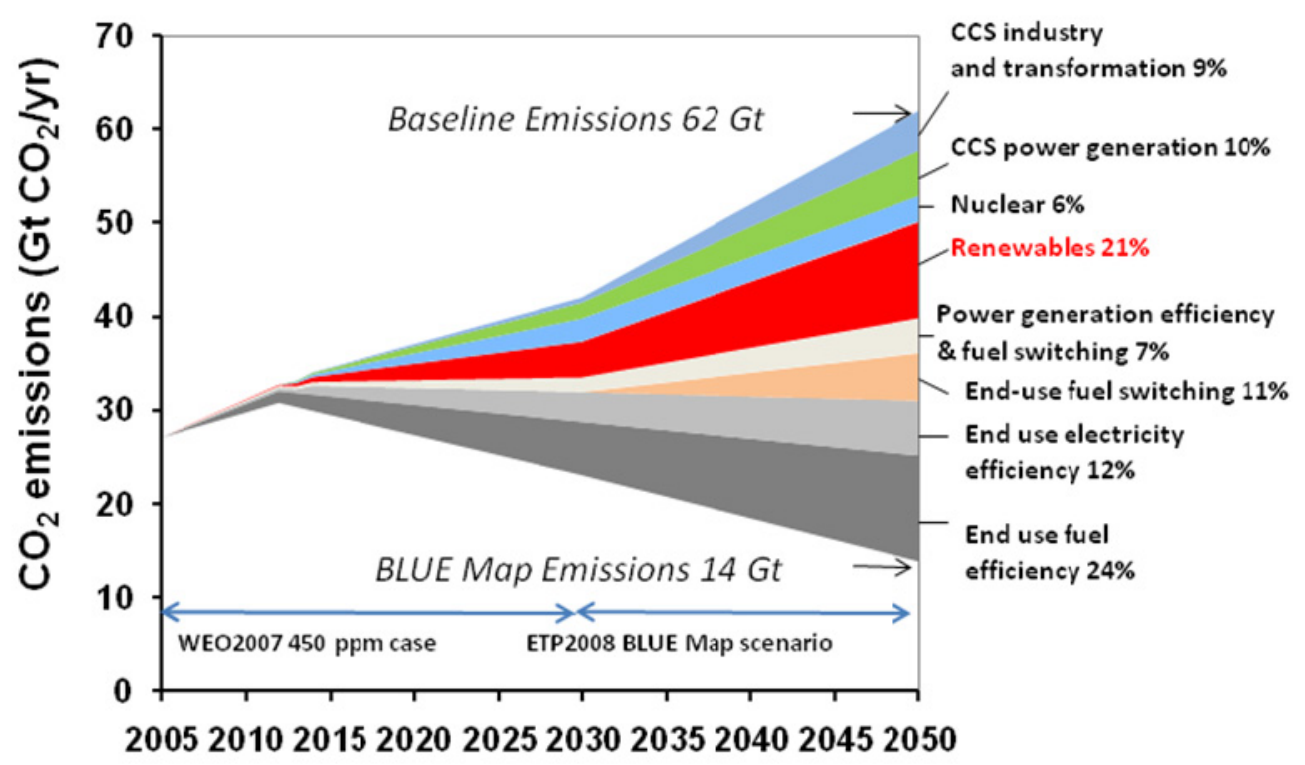

Middle-load electricity supply, usually provided by natural-gas combined-cycle plants, can play an important role in balancing supply and demand. It can also serve as backup capacity in the event of a renewable power supply shortfall. Under a high renewable share scenario (with large contributions from wind and photovoltaic [PV] power), the ability of the middle load to adjust supply will run short. Therefore, mitigating supply fluctuations due to renewables will require energy storage systems as a countermeasure. However, there is no consensus on the worldwide requirement for energy storage capacity.

\section{Grids and smart grids}

The most fundamental principle for the power grid is that power supply and demand must be completely balanced at all times. Otherwise, power system frequency is never stabilised.

\footnotetext{
${ }^{2}$ The ETP 2008 Baseline scenario reflects developments that will occur with the energy and climate policies that have been implemented to date and is commonly referred to as the business as usual case.
} 
Frequency falls when demand exceeds supply; conversely, frequency rises when supply exceeds demand. With the increasing usage of renewable technologies and electric vehicles (EVs), balancing supply and demand becomes a much more important issue. A detailed discussion of the power grid, including grid configurations, the impact of renewables, load curves and efficiency, is provided in Annex 2.

Page | 10 In ordinary electric grids without two-way communication technologies, the supply from power generation plants is measured and operated to balance demand by a centralised electric power company via a bi-directional control system, or by an independent system operator (ISO) using uni-directional information technologies. In contrast, smart grids are automatically and multidirectionally controlled by interactive information technologies. The fundamental concept of a smart grid is shown in Figure 2.

Figure 2: Smart grid concept

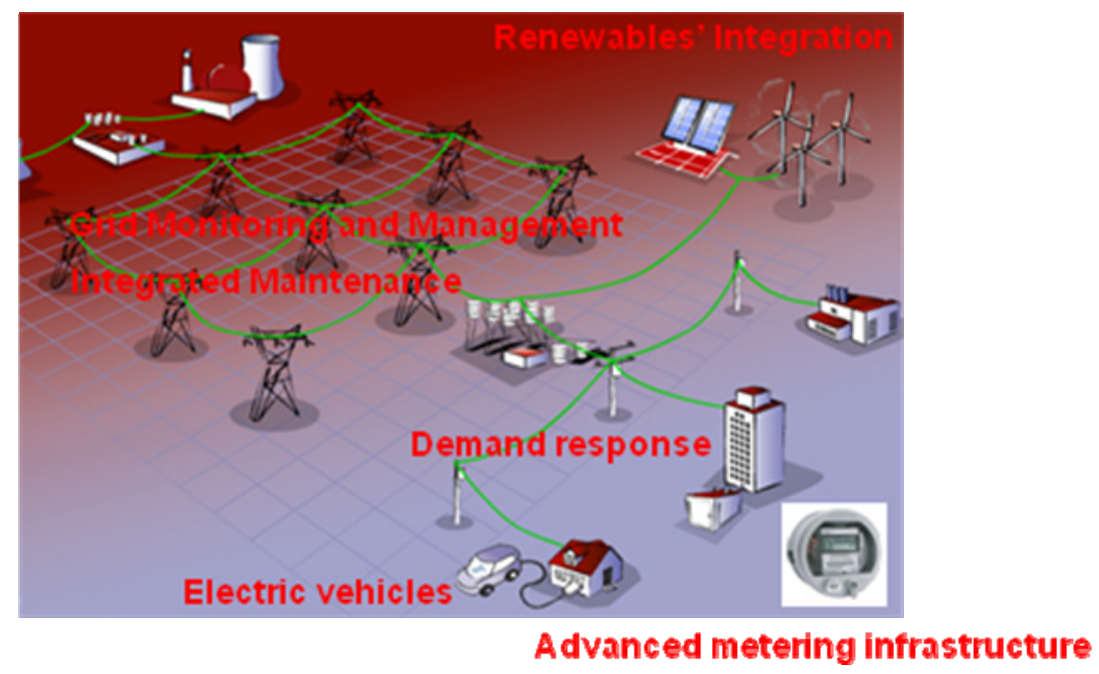

Source: DOE (2009), The SMART GRID: An Introduction (diagram courtesy of the US Department of Energy).

The main features of a smart grid include:

- grid monitoring and management

- integrated maintenance

- advanced metering infrastructures

- demand response

- renewables integration

- electric vehicles

- energy storage.

The qualitative benefits of smart grids include:

- power reliability and power quality (PQ)

- safety and cyber-security

- energy efficiency

- environmental and conservation benefits

- direct financial benefits. 
Table 1: Comparison between existing grid and the future smart grid

\begin{tabular}{|c|c|c|}
\hline Principal characteristic & Existing grid & Future smart grid \\
\hline Self-heals & $\begin{array}{l}\text { Responds to prevent further } \\
\text { damage. Focus is on protecting } \\
\text { assets following system faults. }\end{array}$ & $\begin{array}{l}\text { Automatically detects and } \\
\text { responds to actual and emerging } \\
\text { transmission and distribution } \\
\text { problems. Focus is on prevention. } \\
\text { Minimises consumer impact. }\end{array}$ \\
\hline $\begin{array}{l}\text { Motivates and includes } \\
\text { the consumer }\end{array}$ & $\begin{array}{l}\text { Consumers are uninformed and } \\
\text { non-participative with the power } \\
\text { system. }\end{array}$ & $\begin{array}{l}\text { Informed, involved and active } \\
\text { consumers. Broad penetration of } \\
\text { demand response. }\end{array}$ \\
\hline Resists attack & $\begin{array}{l}\text { Vulnerable to malicious acts of } \\
\text { terrorism and natural disasters. }\end{array}$ & $\begin{array}{l}\text { Resilient to attack and natural } \\
\text { disasters with rapid restoration } \\
\text { capabilities. }\end{array}$ \\
\hline $\begin{array}{l}\text { Provides power quality } \\
\text { for } 21^{\text {st }} \text { century needs }\end{array}$ & $\begin{array}{l}\text { Focused on outages rather than } \\
\text { power quality problems. Slow } \\
\text { response in resolving power } \\
\text { quality (PQ) issues. }\end{array}$ & $\begin{array}{l}\text { Quality of power meets industry } \\
\text { standards and consumer needs. PQ } \\
\text { issues identified and resolved prior } \\
\text { to manifestation. Various levels of } \\
\text { PQ at various prices. }\end{array}$ \\
\hline $\begin{array}{l}\text { Accommodates all } \\
\text { generation and storage } \\
\text { options }\end{array}$ & $\begin{array}{l}\text { Relatively small number of large } \\
\text { generating plants. Numerous } \\
\text { obstacles exist for } \\
\text { interconnecting distributed } \\
\text { energy resources. }\end{array}$ & $\begin{array}{l}\text { Very large numbers of diverse } \\
\text { distributed generation and storage } \\
\text { devices deployed to complement } \\
\text { the large generating plants. "Plug- } \\
\text { and-play" convenience. } \\
\text { Significantly more focus on and } \\
\text { access to renewables. }\end{array}$ \\
\hline Enables markets & $\begin{array}{l}\text { Limited wholesale markets still } \\
\text { working to find the best } \\
\text { operating models. Not well } \\
\text { integrated with each other. } \\
\text { Transmission congestion } \\
\text { separates buyers and sellers. }\end{array}$ & $\begin{array}{l}\text { Mature wholesale market } \\
\text { operations in place; well integrated } \\
\text { nationwide and integrated with } \\
\text { reliability co-ordinators. Retail } \\
\text { markets flourishing where } \\
\text { appropriate. Minimal transmission } \\
\text { congestion and constraints. }\end{array}$ \\
\hline $\begin{array}{l}\text { Optimises assets and } \\
\text { operates efficiently }\end{array}$ & $\begin{array}{l}\text { Minimal integration of limited } \\
\text { operational data with asset } \\
\text { management processes and } \\
\text { technologies. Siloed business } \\
\text { processes. Time-based } \\
\text { maintenance. }\end{array}$ & $\begin{array}{l}\text { Greatly expanded sensing and } \\
\text { measurement of grid conditions. } \\
\text { Grid technologies deeply } \\
\text { integrated with asset management } \\
\text { processes to most effectively } \\
\text { manage assets and costs. } \\
\text { Condition-based maintenance. }\end{array}$ \\
\hline
\end{tabular}

Source: http://www.netl.doe.gov/moderngrid/docs/AVisionforthe SmartGrid_Final_v1_0.pdf

Currently, the share of renewables and plug-in EVs on the grid is low. However, according to the BLUE Map scenario, high shares of renewables contributing to the total electricity supply and EVs contributing to total electricity demand will be required to reduce $\mathrm{CO}_{2}$ emissions. For example, under the BLUE Map scenario, EVs could account for approximately $10 \%$ of annual demand in 2050.

With interactive communication, control of both supply and demand will be feasible. Through demand response, power grids should experience higher reliability and quality. Conversely, the output of renewable energy supplies varies with weather, time, season and other intermittent 
effects. Given a high share of renewables, demand response will play an important role in mitigating such power variations.

\section{Load shifting}

Page | 12 Load shifting is the practice of managing electricity supply and demand so that peak energy use is shifted to off-peak periods. Properly done, load shifting helps meet the goals of improving energy efficiency and reducing emissions by smoothing the daily peaks and valleys of energy use and optimising existing generation assets.

Load shifting may be accomplished in several ways. Demand response programmes shift load by controlling the function of air conditioners, refrigerators, water heaters, heat pumps, and similar electric loads at maximum demand times. In the United States, Florida Light \& Power reportedly reduced its overall residential demand of $16 \mathrm{GW}$ by $1 \mathrm{GW}$ with an on-call programme that controlled water heaters and air conditioners in customers' homes.

Energy storage is an important component of load shifting. For example, pumped hydro facilities use off-peak electricity to pump water from a low reservoir into a higher one, then reverse the flow during peak periods to generate hydroelectric power. Some thermal storage applications use off-peak power at night to freeze water into ice, which then provides lowpower air conditioning during daytime peak periods. Off-peak electricity may also be stored in conventional or advanced batteries, including lead-acid, lithium-ion, sodium-sulphur or electrolytic flow batteries, some of which are available on megawatt scales. Energy storage is especially critical for managing the output of intermittent renewable resources such as solar and wind power, ensuring that their generation capacity is available when needed most and maximising their value.

\section{Future energy storage needs}

A numerical approach has been established to estimate the energy storage capacity needed to support future power grids that include a high share of renewables (IEA Working Paper Prospects for Large-Scale Energy Storage in Decarbonised Power Grids, 2009, OECD/IEA, Paris).

Features of the numerical simulation method include calculation of daily demand and supply balances in individual countries with wind power variations based on the Monte Carlo method, and consideration of the smoothing effect of wind power. Even though the magnitude of variations due to an individual renewable energy generator can be large, a wide geographical dispersion of such generators mitigates the net variation, making the magnitude of the net variation less than that of each individual variation. In this simulation, this smoothing effect was treated as a parameter, and only the short-term variation of wind power was focused on in order to discuss frequency change, with average output assumed to be a constant. The consideration of long-term variations of wind power and solar photovoltaic (PV) will be addressed in future assessments. The fundamental algorithms are described in Annex 1.

In this study, the energy storage needed to mitigate power fluctuation was largely determined by net variation of the wind power supply. Simulations of wind power net variation levels between $15 \%$ and $30 \%$ resulted in estimates of needed storage capacity ranging from $189 \mathrm{GW}$ to $305 \mathrm{GW}$ (Figure 3). 
Figure 3: Growth of necessary energy storage capacity worldwide during 2010-50

a) Variation ratio: $15 \%$

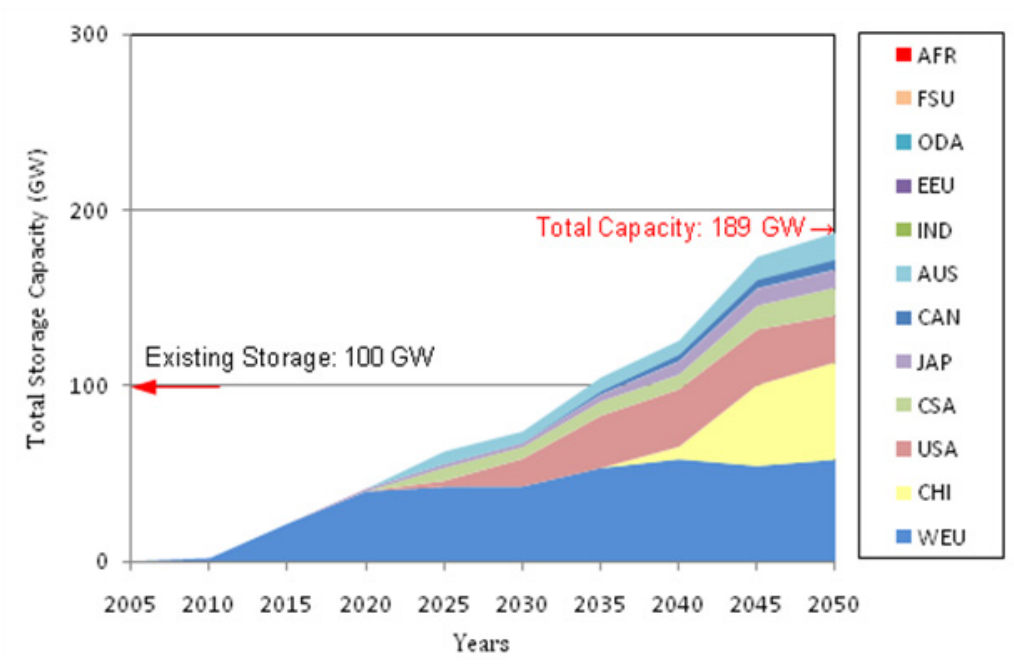

b) Variation ratio: $30 \%$

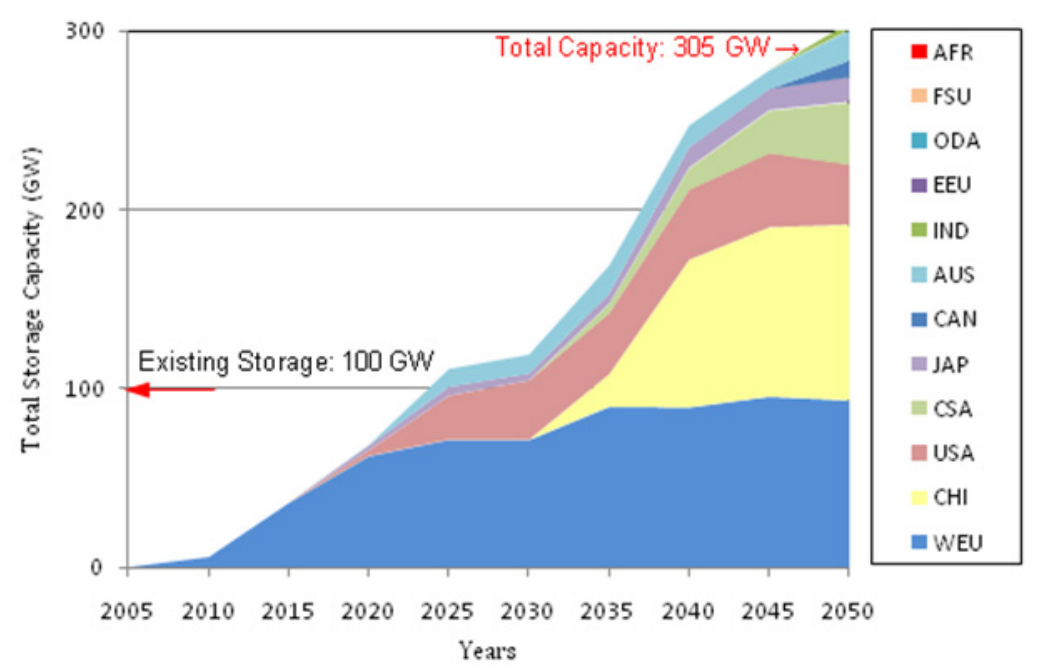

WEU: Western Europe; CHI: China; CSA: Central South America; JAP: Japan; AUS: Australia; IND: India; EEU: Eastern Europe; FSU: Former Soviet Union; AFR: Africa

A key element of this simulation method is that the capacity of energy storage is highly dependent on the share of renewables in individual countries. The number of storage system options should be increased worldwide. Since the needed energy storage capacity also depends on the variation of wind power, monitoring and forecasting of the wind power variation is another key component. Strategies may need to be developed to minimise variation and storage investment requirements. In particular, the smoothing effect plays an important role in reducing the variation of the wind power supply.

\section{Electric vehicles (EVs)}

EVs are an important part of efforts to reduce $\mathrm{CO}_{2}$ emissions in transportation systems. According to the BLUE Map scenario, the worldwide need for electricity to charge EVs will reach 2500 TWh in 2050, representing entirely new demand (Figure 4). 
Figure 4: Potential growth of plug-in EVs in key markets through 2050

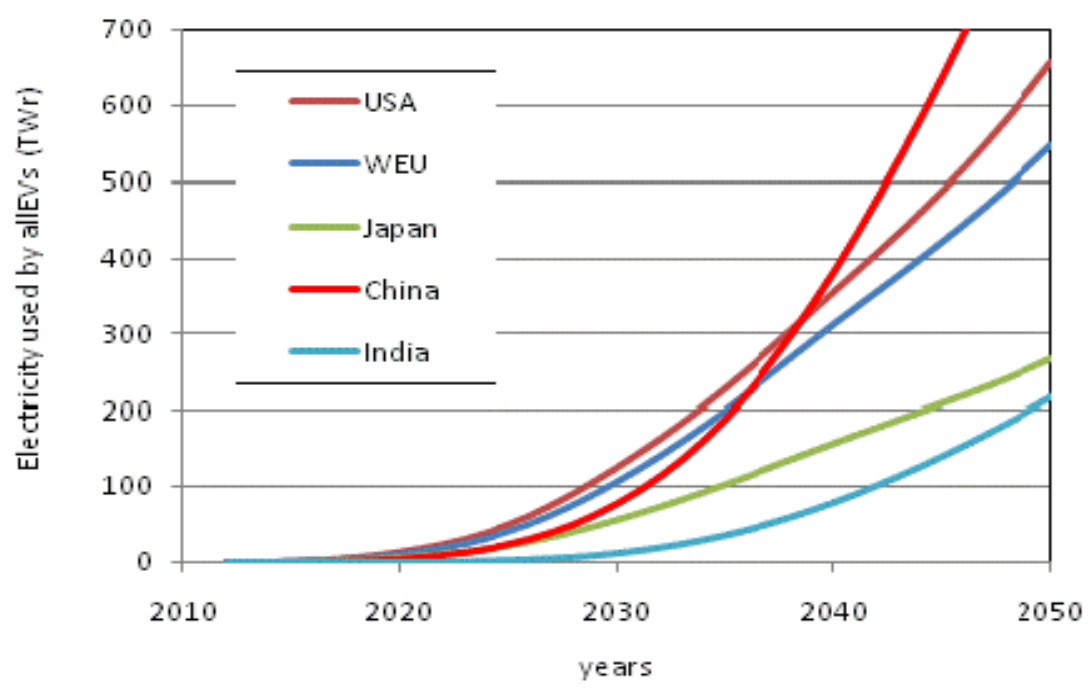

WEU $=$ Western Europe.

However, EVs also have large-capacity batteries, making them a form of distributed energy storage. They have the potential to supply electricity to the power grid at peak demand, taking the place of middle-load resources (like thermal power plants) and large-scale energy storage systems (such as pumped hydro plants). Plug-in EVs, which can be charged in the home, offer great potential as a target of demand response, especially in load shifting. Therefore, EVs should be integrated into the electricity supply through advanced smart grid networks with two-way communication technologies. This concept is called "vehicle-to-grid" (V2G).

The BLUE Map estimation of growth of plug-in EVs includes the following key assumptions:

- During the 2010-15 period, new EV and PHEV models will be introduced at low production volumes as manufacturers gain experience and learn. Early adopter consumers play a key role in sales, and sales per model are fairly low as most consumers wait to see how things develop. After 2015 , sales per model and the number of models increase fairly dramatically to 2020 as companies move towards full commercialisation.

- The underlying assumption is that a steady number of new models will be introduced over the next 10 years, with eventual targeted sales for each model of 100000 units per year. However, it is also expected that this will take time to occur, especially in the early years production levels will be much lower as manufacturers test new designs with limited production runs.

- EVs are assumed, on average, to have a range of $150 \mathrm{~km}$ (about 90 miles) and PHEVs' allelectric ranges (AER) to start at $40 \mathrm{~km}$ ( 25 miles), rising on average over time as battery technologies improve and costs decline. Overall energy efficiency is assumed to be $80 \%$, rising to $95 \%$ when regenerative braking is in use. Both types of EV are assumed to have an average in-use fuel efficiency of about $0.2 \mathrm{kWh} / \mathrm{km}(0.3 \mathrm{kWh} / \mathrm{mile})$. If vehicles can be made more efficient, the range will be higher for a given battery capacity or the battery capacity requirements will decrease.

\section{Vehicle-to-grid (V2G)}

The primary purpose of EVs is transportation. Therefore, V2G should be implemented while maintaining routine EV operation. Usually, peak late-afternoon traffic occurs during the peak 
electricity demand period (from 3 p.m. to 6 p.m.). According to US statistics, even in that period $92 \%$ of vehicles are parked and potentially available to the grid (Kempton et al., 2001). Therefore, it might be possible to supply electricity in small amounts to power grids from many EVs.

As an incentive for EV owners, EVs could serve the peak power market by charging during offpeak hours, when the price of electricity is low, and selling under contract payments during high-peak hours. If this payment cost is lower than the costs of centralised power generated, electric power company companies will also realise profits.

Three elements are required for V2G to function as intended (Letendre and Kempton, 2002):

- Power connection for electrical energy flow from vehicle-to-grid.

- Control or logical connection, needed for the grid operator to determine available capacity, request ancillary services or power from the vehicle and to meter the result.

- Precision certified metering on board the vehicle. For fuelled vehicles (fuel cell and hybrid), a fourth element - a connection for gaseous fuel (natural gas or hydrogen) - could be added so that on-board fuel is not depleted.

One conceptual barrier to V2G is the belief that the power available from the EVs would be unpredictable or unavailable because they would be on the road. Although an individual vehicle's availability for demand response is unpredictable, the statistical availability of all vehicles is highly predictable and can be estimated from traffic and road-use data. Figure 5 indicates a typical daily travelling pattern of gasoline-driven cars in Japan. It shows that $50 \%$ of gasoline-fuelled cars travel less than $30 \mathrm{~km}$ per day, and that $30 \%$ of gasoline-fuelled cars travel less than $15 \mathrm{~km}$ per day.

Figure 5: Typical daily travelling patterns of gasoline-fuelled cars in Japan

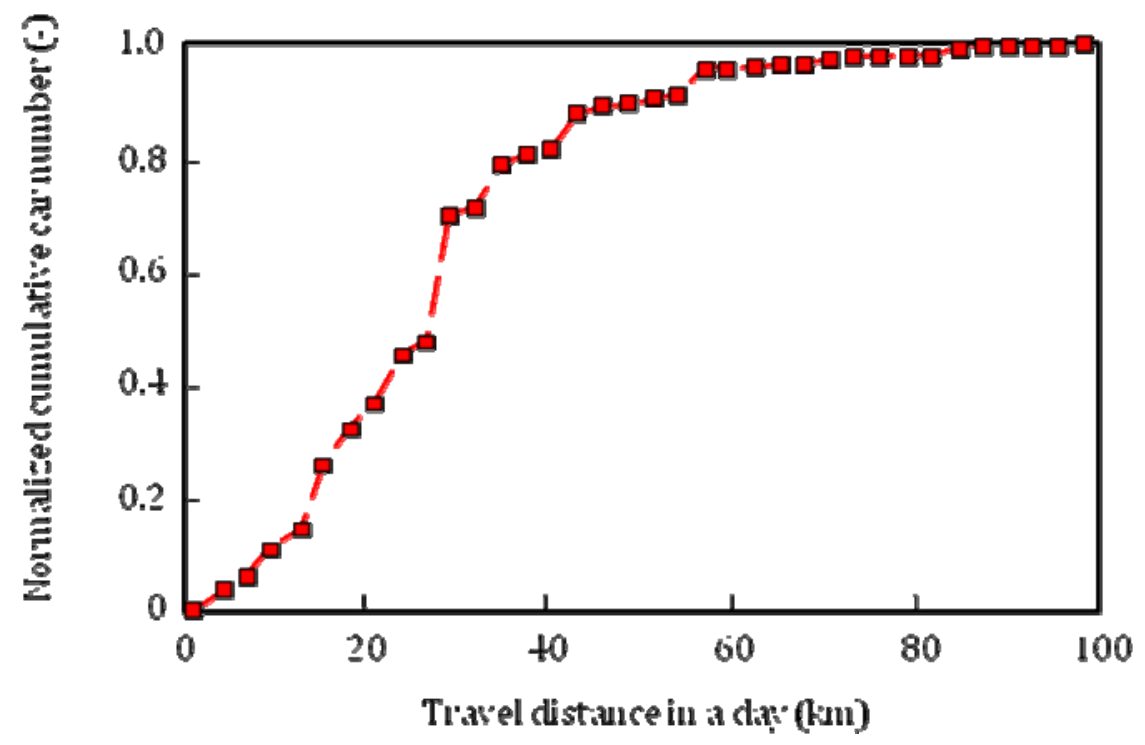

Source: Sagawa and Skaguchi, 2000.

The time of day during which a car is used is also an important element for optimising the energy system. To evaluate the feasibility of V2G, statistical travelling patterns should also be evaluated. Since these travelling patterns will be quite different in each region, monitoring and analysis of such patterns is a key point when discussing the feasibility of V2G. 



\section{Developing a V2G simulation}

\section{Objectives}

Page | 17

To estimate the full advantages of V2G use in smart grid, a comprehensive evaluation, which includes the main characteristics of smart grids previously identified, must be made. In this working paper, a high share of renewables and load shifting available through V2G were specifically focused on as important parameters.

There are three main objectives when simulating the V2G load-shifting prospects of smart grids:

- Establishing a methodology to estimate the influence of load shifting (assuming V2G as a typical demand response) under high-share renewable generation.

- Estimating the extent of benefits of load shifting and V2G under high-share renewables.

- Identifying relevant regional differences.

The starting point of this effort was the power generation mix used in the ETP 2008 BLUE Map scenario. This generation mix was calculated using the ETP MARKAL model, which considers natural-gas combined-cycle (NGCC) for middle-load generation as backup capacity when variable renewables generate less power. Demand can be met by either the backup capacity or energy storage.

\section{Simulation conditions}

Generally, power demand varies considerably with time of day and season. The annual total demand is defined as an integrated value of daily demand throughout a year. The power generation mix consists of fossil fuel and nuclear-power-based base load, thermal-power-based middle load, plus wind power and PV. The base load is operated under a constant output, while variable renewable resources such as wind and PV power are associated with weather-related power output variations. To ensure electricity quality, especially electricity frequency, maintaining balance between demand and supply is essential. The middle load plays a role in adjusting the supply - which includes constant-output-based base load and variable-powerbased renewable energies such as wind and PV - to the demand. This time-sensitive demand and generation mix depends on individual areas. Therefore, to estimate the benefit of load shifting in individual areas, boundary conditions of daily and monthly demand curve as well as the generation mix should be required.

The boundary conditions chosen for this simulation depend on the ETP 2008 BLUE Map scenario of power supply (IEA, 2008). Conditions vary with actual individual policies, but the BLUE Map scenario provides a good initial approximation for the purposes of this working paper. For example, according to the scenario, approximately $20 \%$ of power generated in the United States by 2050 will be from renewable energy (Figure 6).

The simulation also considers forecasts of annual total demand (Figure 7, again for the United States). In this case, annual total demand is expected to increase rapidly after 2030, including new demand for EVs. Electricity demand for EVs alone will reach about $700 \mathrm{TWh}$ in the United States in 2050, representing as much as half of all new demand. 
Figure 6: Trend of generation mix in the United States

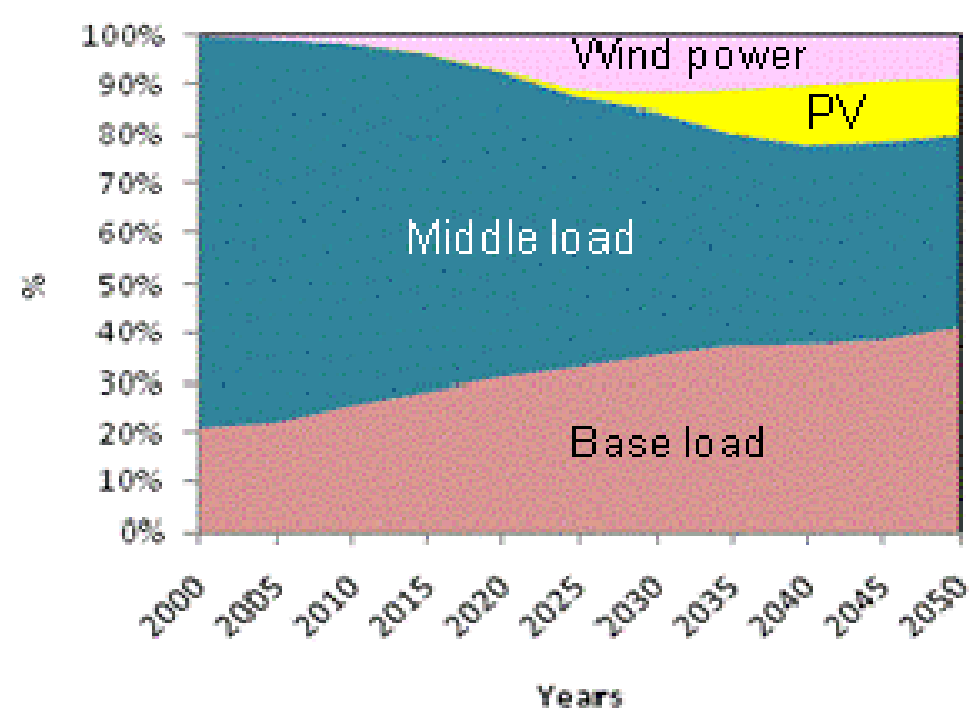

Figure 7: Forecast of annual total demand in the United States

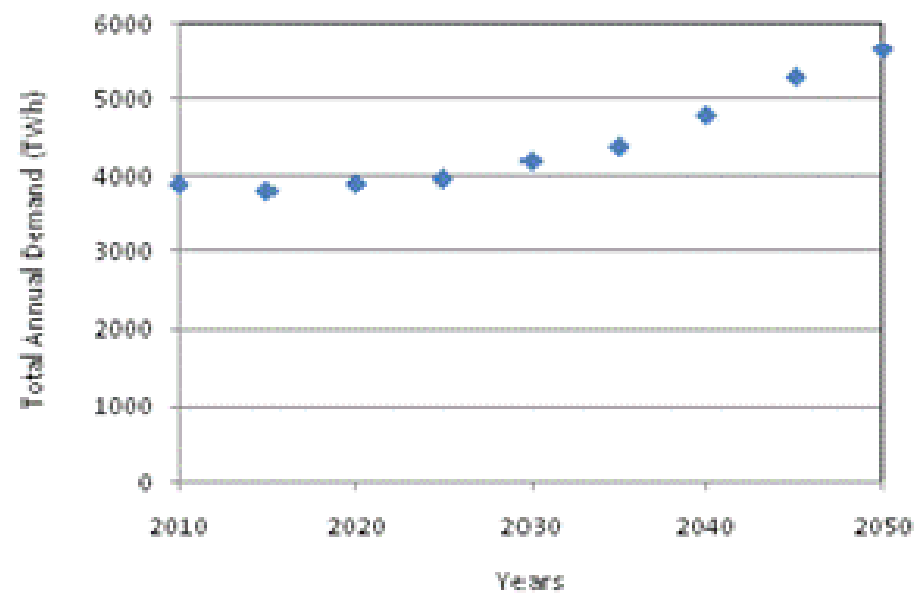

The simulation also requires the annual and daily demand curves, which were estimated by actual data (Figures 8 and 9). In the United States, summer and winter seasons represent maximum demand for air conditioning and space heating, respectively.

Figure 8: Daily load curve in the United States

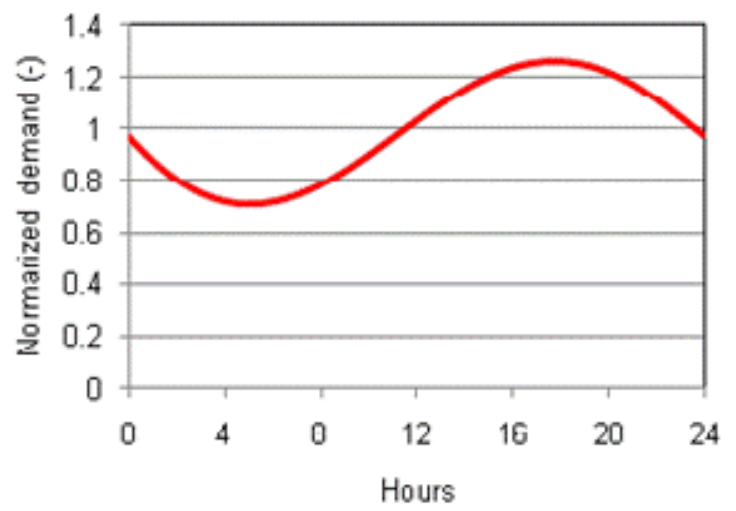


Figure 9: Annual load curve in the United States

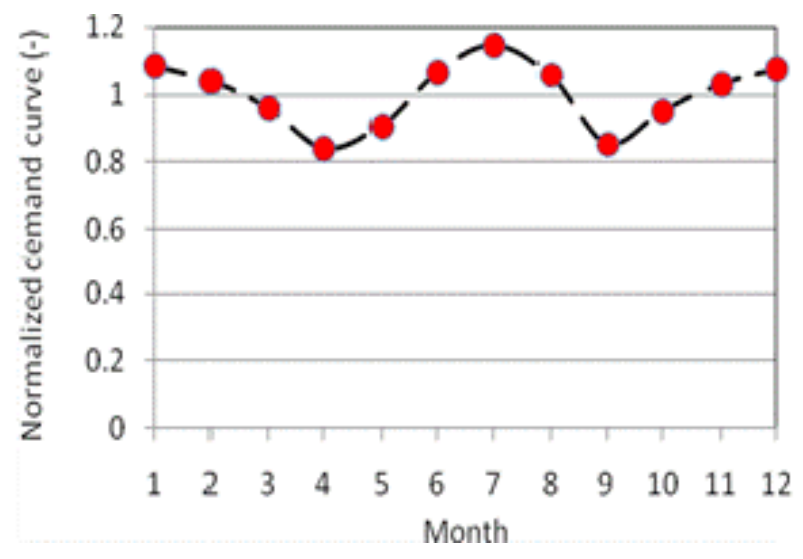

Page | 19

\section{Modelling approach}

As mentioned, demand should balance the total electricity supply based on base load, middle load, and wind and PV power. Therefore, to estimate the balance between demand and supply, applicable operational models of base load, middle load, wind and PV generators will be required. In this section, the fundamental concept of each operation is described.

\section{Operational model of base load}

Base load includes power supplies from nuclear reactors, coal-fired plants and diversion hydropower systems. In the simulation, the base-load operation was modelled as constant (Figure 10).

Figure 10: Base-load operation curve

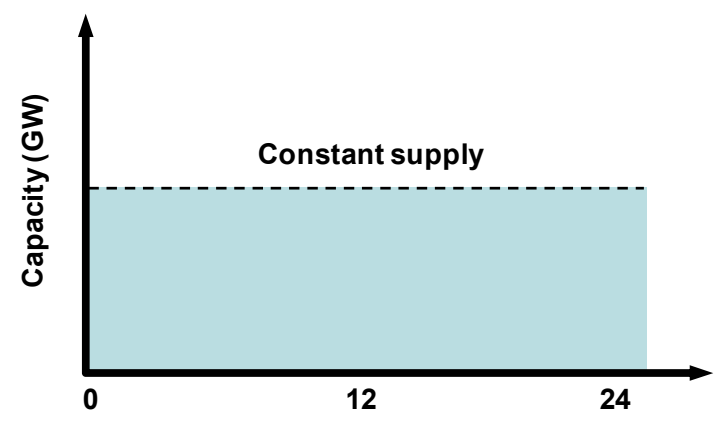

\section{Operational model of PV power}

Figure 11 shows the normalised operation curves of PV power. The PV option supplies power from 06:00 to 18:00 during the day, with output power dependent on the weather. 
Figure 11: PV normalised operation curve: $f_{P V}$

Page | 20

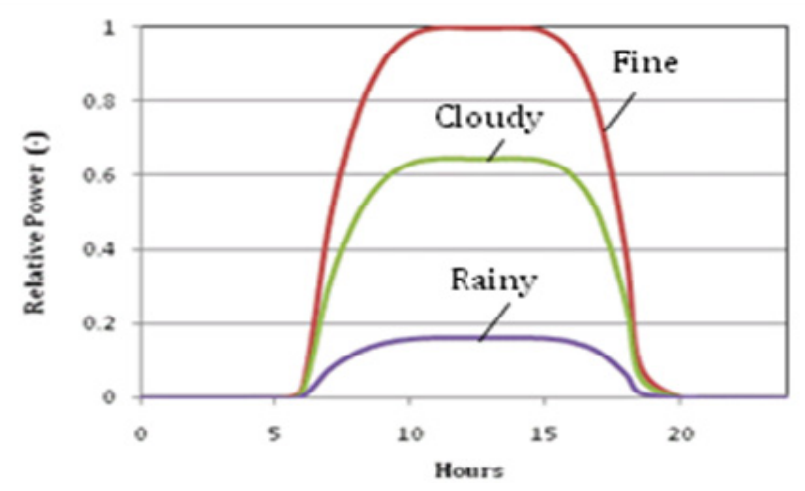

Three weather patterns were considered. The weather patterns of each day were estimated by a uniform random number $X$ based on weather probability data for fine, cloudy and rainy days $\left(P_{f}, P_{c l}\right.$ and $P_{r}$, respectively):

Fine weather: $X>1-P_{f}$

Cloudy weather: $1-P_{f}>X>1-P_{f}-P_{c l}$

Rainy weather: $1-P_{f}-P_{c l}>X$

$P_{f}, P_{c l}$ and $P_{r}$ were assumed to be $0.80(80 \%), 0.17(17 \%)$ and $0.03(3 \%)$, respectively. With this operational curve, the power supply from $\mathrm{PV}$ was given by:

$$
P_{P V}=C_{P V} \cdot f_{P V} \cdot \Delta T
$$

where $C_{P V}$ is a constant set to satisfy the $P V$ share, $f_{P V}$ is a normalised operation curve (Figure 11), and $\Delta T$ is time mesh. Details of $f_{P v}$ are described in Annex 1. In this calculation, only the time variation of overall output of PV was considered. In future work, variation of PV output should also be considered. Therefore, only the effect of the weather influenced the estimate of the overall PV power capacities.

\section{Operational model of wind power}

For the purposes of the simulation, wind speed was simulated by a random number based on a Weibull distribution rather than an actual wind speed distribution (Figure 12), as is commonly done. This approach assumes that wind speeds can vary significantly over short time periods, and the impact of this variation needed to be assessed in greater detail. In this simulation, $0.1 \mathrm{~h}$ or 6 minutes was assumed as a representative time scale of short-term variation of wind power, yielding an average wind speed of $8 \mathrm{~m} / \mathrm{s}$ (Figure 13) and a simulated wind speed distribution (Figure 14) for which the curve shape was quite similar to that produced by a Weibull distribution, confirming the use of random numbers. 
Figure 12: Actual wind speed distribution, New Mexico, United States

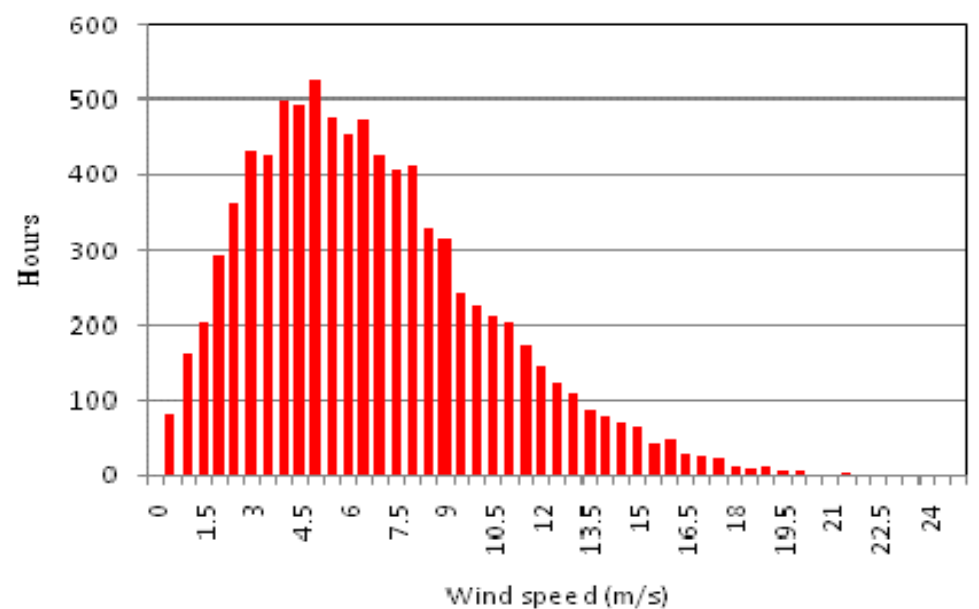

Source: Lee Ranch, Sandia National Laboratories, 2003.

Figure 13: Simulated wind speed (average: $8 \mathrm{~m} / \mathrm{s}$ )

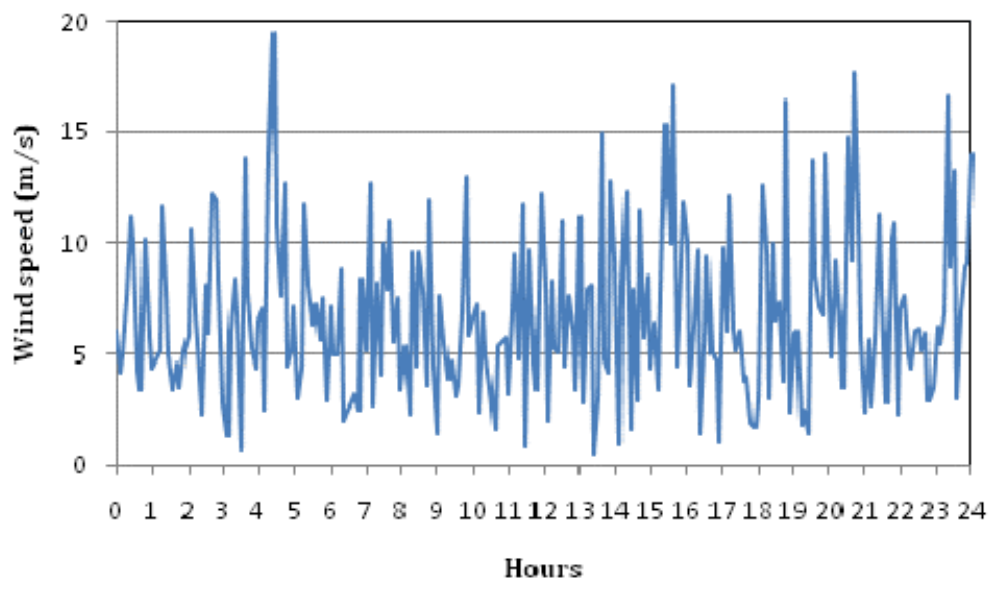

Figure 14: Distribution of simulated wind speed

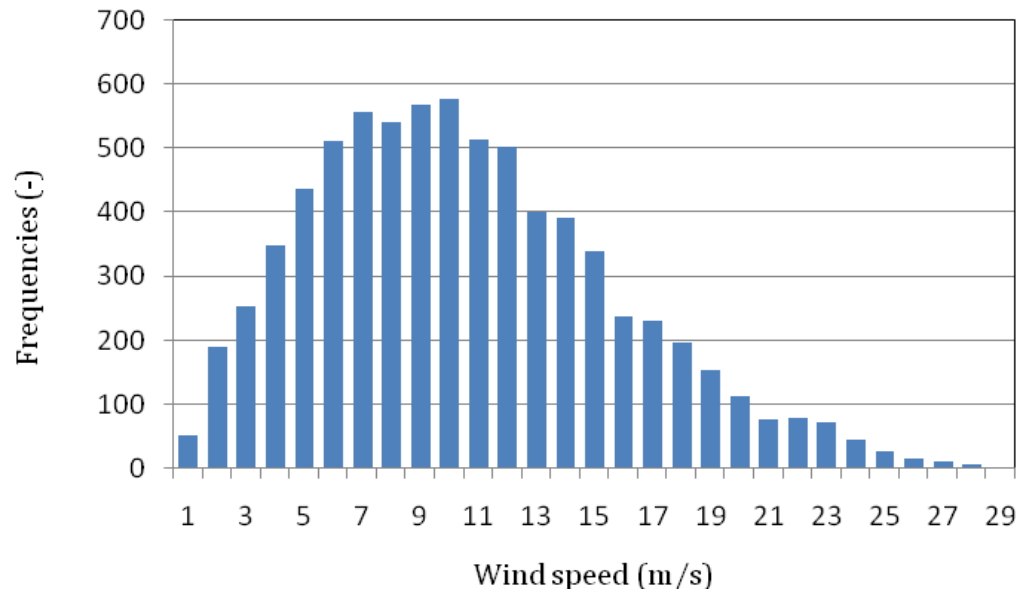


Figure 15 shows the operational curve of a wind turbine that was modelled in the simulation. The cut-in and cut-out wind speeds were assumed to be $3 \mathrm{~m} / \mathrm{s}$ and $26 \mathrm{~m} / \mathrm{s}$, respectively. When the wind speed exceeds the cut-out speed, the wind power supply immediately drops to zero.

Figure 15: Normalised operational curve for wind power model

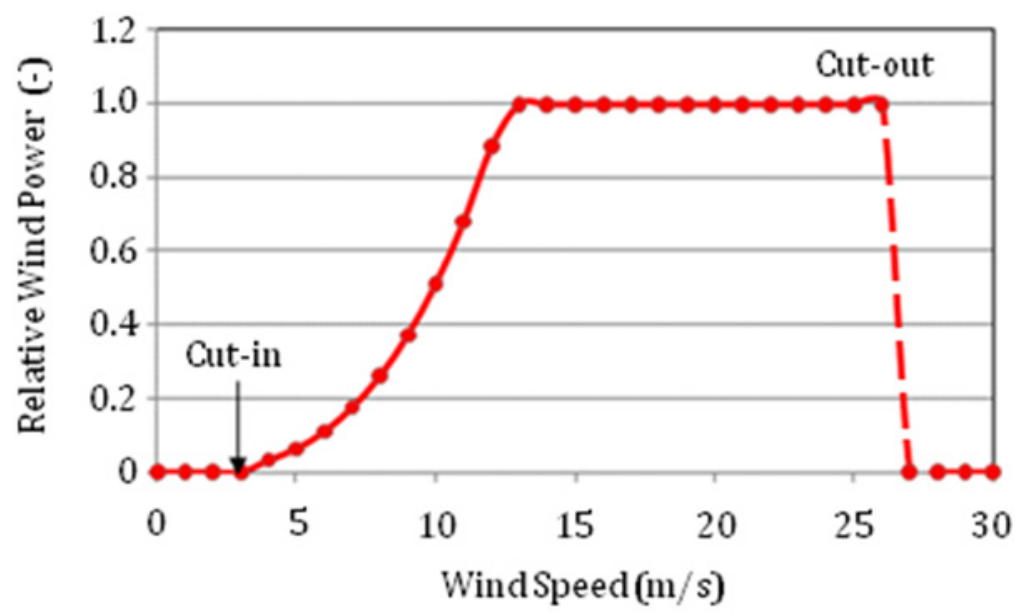

According to the operational curve, the power generation capacity was assumed to be constant at speeds from $13 \mathrm{~m} / \mathrm{s}$ to $26 \mathrm{~m} / \mathrm{s}$, proportional to the curve of the wind speed. At wind speeds from $3 \mathrm{~m} / \mathrm{s}$ to $13 \mathrm{~m} / \mathrm{s}$, with this operational curve, the power supplied was expressed as:

$$
P_{W}=C_{W} \cdot f_{W} \cdot \Delta T
$$

where $C_{w}$ is a constant, $f_{w}$ is a normalised operation curve of wind power (Figure 15), and $\Delta T$ is time mesh. Details of $f_{w}$ are described in Annex $1 . C_{w}$ was set to satisfy the share of wind power estimated in the BLUE Map scenario. The operational curve provides the fluctuated wind power supply using the random wind speed.

Wind turbines will be distributed geographically throughout individual regions and countries. Consequently, power variations from different turbines in different areas should be slightly correlated, while the cumulative generation of all the turbines should have less net variation than an individual turbine or groups of turbines in a given area. This is the wind farm smoothing effect, which can be observed on many scales.

Such a smoothing effect would be noticeable when combining wind power produced at different points located in non-correlated areas (Figure 16). In this simulation, the smoothing effect was simulated by summing the output of several wind turbines as:

$$
P_{W(S . E)}=\frac{\sum P_{W(i)}}{m}
$$

where $P_{W(S . E)}$ is the overall wind power with the smoothing effect, $\mathrm{PW}_{(i)}$ is the $\mathrm{i}$-th wind turbine power output, and $\mathrm{m}$ is the numbers of samples. As the number of wind turbines increases, the variation of $\mathrm{P}_{\mathrm{w}(\text { (S.E) }}$ would be expected to decrease. 
Figure 16: Wind farm smoothing effect on power fluctuation

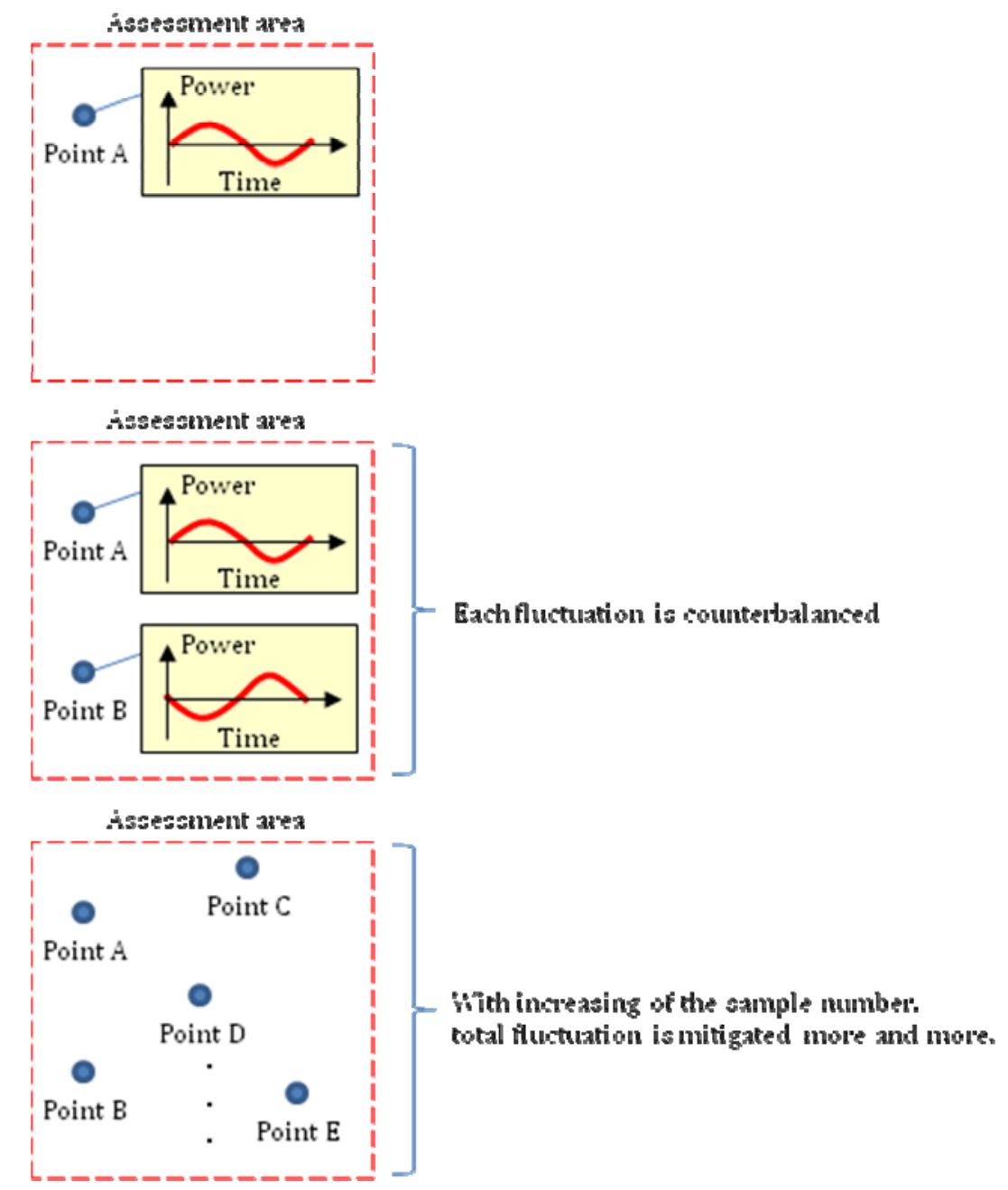

To examine the effects of wind smoothing, the simulation calculated the trend of wind power supplies with 35 and 10 samples based on Equation 4 (Figure 17 left and right, respectively). In both cases, the time-averaged supply was assumed to be $130 \mathrm{GW}$. As is evident, 35 samples exhibit less variation than 10 samples. In fact, the variation ratio for 35 samples is $15 \%$, compared to $30 \%$ for 10 samples. This shows the importance of the smoothing effect on net power variation with geographically distributed wind power generators.

The relationship between the number of samples and the variability of cumulative wind power for several sample number follows a discernable pattern (Figure 18). Net variation decreases with increasing numbers of samples. Statistically, if a set of random numbers are independent of each other, the variation of the average value generally decreases with the inverse square root of the sample number (as indicated by the fitted blue curve in the figure). The simulated results indicate that the smoothing effect depends on this generalisation of the law of large numbers. Net variation is dependent on the number of wind turbines and their correlation. If wind speeds in an area are quite independent each other, the net variation will decrease as area increases. For the purposes of this working paper, the boundary conditions of the net variation of wind power output were assumed to be $15 \%$ and $30 \%$, as they were in the previous paper on large-scale energy storage (IEA, 2009). 
Figure 17: Comparison of simulated wind power with different sample numbers, for 35 samples (left) and 10 samples (right)
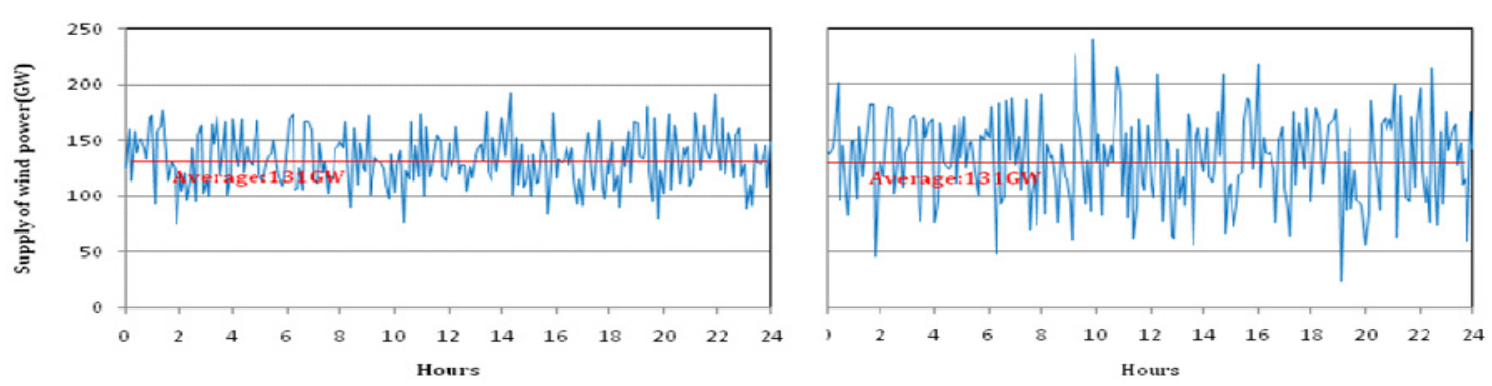

Figure 18: The relationship between number of samples and net variation

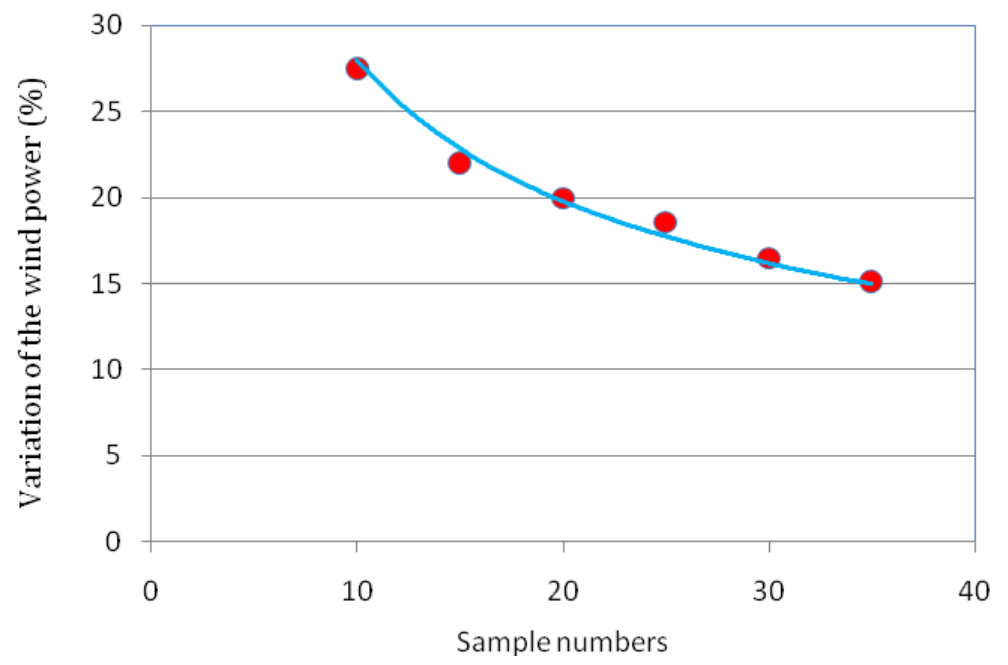

\section{Operational model of middle load}

Middle load is served by NGCC, simple gas turbines and stored hydropower systems. The supply of the middle load was estimated based on the balance of demand and supply as follows:

Supply of the middle load $=$ Demand $-($ Base load + PV power + Wind power $)$

If the term (Base load + PV power + Wind power) exceeded demand, the excess supply was omitted from the supply of the wind power (shut down/braking of wind turbines).

\section{Concept of simulation}

Figure 19 shows the fundamental concept of the simulation method. In the simulation method, the balance between demand and supply was calculated for every $0.1 \mathrm{~h}$ (6 minutes). Since this simulation was based on a Monte Carlo method, 30 daily calculations were made and averaged to get the smoothing daily balance between the demand and the supply (Figure 19). The weather was assumed to be fine. 
Figure 19: Fundamental concept of the simulation method
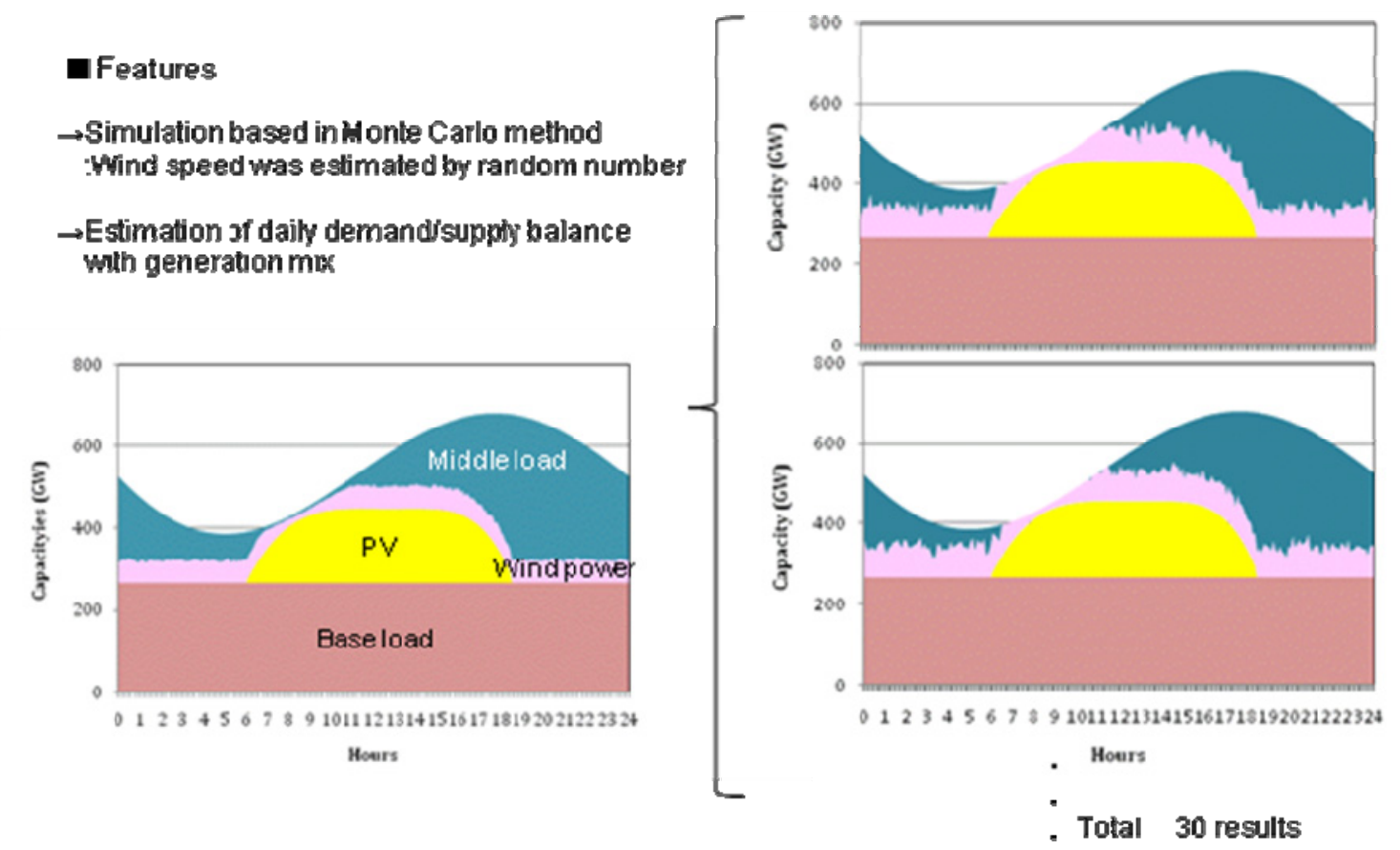

The conceptual operational steps involved in using V2G to support load shifting are:

- Prediction of demand curve without EVs charge for the next day.

- Estimation of the period of the minimum middle load.

- Allocation of EVs charge to the period of the minimum middle load.

- V2G process initiated.

To model load shifting and support the simulation of smart grids, "wind power output", "uncontrollable demand in the next few days", and "base- and middle-load generation capacities" are forecast or scheduled for a certain period. Other information such as "daily change of the middle-load supply" and "optimal charge time for EVs" is estimated and entered. In this estimate, an important purpose of load shifting is to keep the generation of the middleload capacity as constant as possible. As a result of load shifting, stand-by thermal plant capacity can be expected to shift to stand-by.

If the middle-load power changes, the charge period of the EVs is optimised to make the load uniform (Figure 20). To reduce the supply of the middle load at maximum demand, power is discharged to the grid from available EVs. To evaluate the effect of V2G, the percentage of the car battery capacity allowed to be used to service the system is an important parameter. Also in this simulation, the percentage of EVs available for V2G was assumed to range from $0 \%$ to $30 \%$, much less than the $92 \%$ maximum potential described earlier. In addition, the availability of EVs was assumed to be without limitation. The balance between demand and supply in each country was calculated based on all the operational models of base load, middle load, and PV and wind power, as described in the modelling approach. 
Figure 20: Concept of load shifting

Page | 26

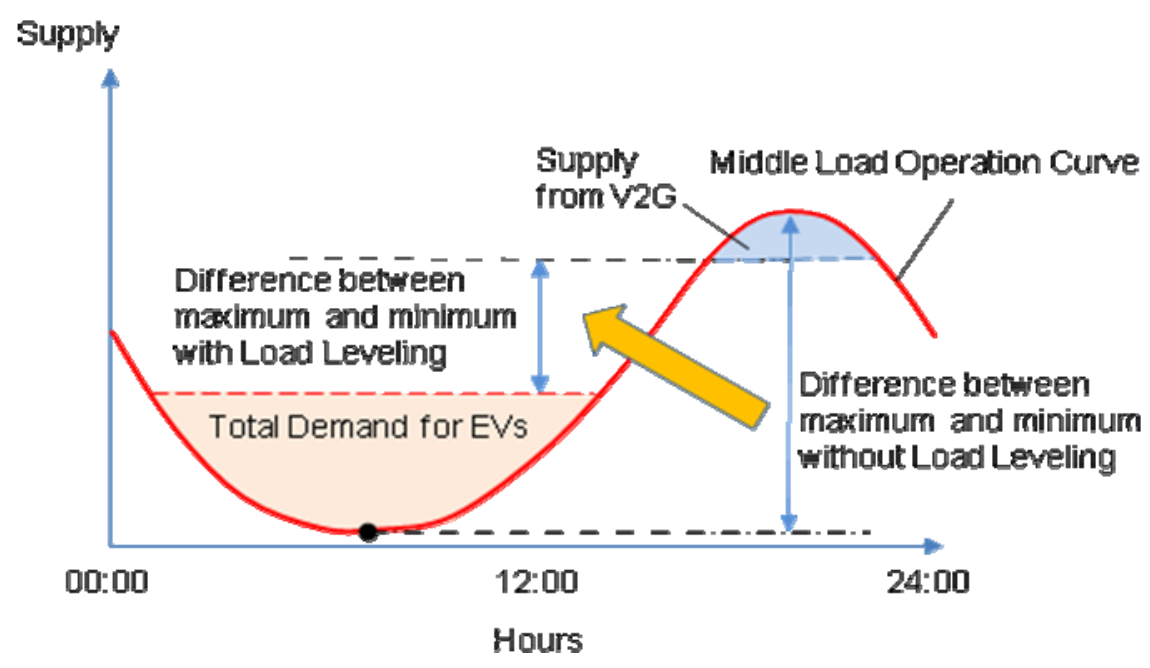

As boundary conditions, the average wind speed was assumed to be $8 \mathrm{~m} / \mathrm{s}$, the variation of wind power was assumed to be $15 \%$, and the V2G ratio, defined as the ratio between overall charged power of EVs and discharged power from EVs, was assumed to range from $10 \%$ to $30 \%$.

\section{Effects of load shifting}

Given a high share of renewables worldwide, energy storage systems will be essential as a counter measures to maintain electricity quality, especially electrical frequency. The required capacity of energy storage was estimated in the present simulation. Furthermore, the influence of load shifting accomplished via energy storage was estimated as levelling.

Middle-load capacity plays an important role in balancing supply and demand under the variations of demand and renewable energy generation. In this simulation, middle-load capacity was provided by natural gas combined-cycle (NGCC) plants. On a time scale of hours, the supply of the middle load was assumed to be controlled by the starting and stopping of each constituent NGCC unit. However, on the time scale of minutes, mitigating short-term power fluctuations actually depends on the adjustable speed and operational load point of each NGCC plant (Figure 21). An NGCC is assumed to operate in the range between $60 \%$ to full load of its rated capacity, with individual plants having an adjustable speed of approximately $8 \% / \mathrm{min}$ (Figure 22).

To absorb power fluctuations due to wind power, the following conditions should be satisfied:

$$
\Delta P_{T}>\Delta P_{R},
$$

Adjustable speed of $N G C C>$ Fluctuation rate of the wind power

Where in this example $\Delta P_{T}$ is (full load $-60 \%$ load), and $\Delta P_{R}$ is (maximum fluctuation - minimum fluctuation) of the wind power. If the conditions of Equations 6 and 7 are satisfied in the demand and supply balance simulation, it can be concluded that the middle-load capacity can successfully cope with the variability. If this condition is not satisfied, some countermeasures are required to prevent power system frequency fluctuation, difficulty in dispatching generation, and curtailment of renewable energy generation. In the present simulation, the condition of Equation 7 was satisfied automatically because the NGCC will be able to have up to $48 \%$ adjustability in $0.1 \mathrm{~h}(6 \mathrm{~min} \times 8 \% / \mathrm{min})$. The adjustability is larger than (full load $-60 \%$ load). 
Figure 21: Combining variable renewable with NGCC

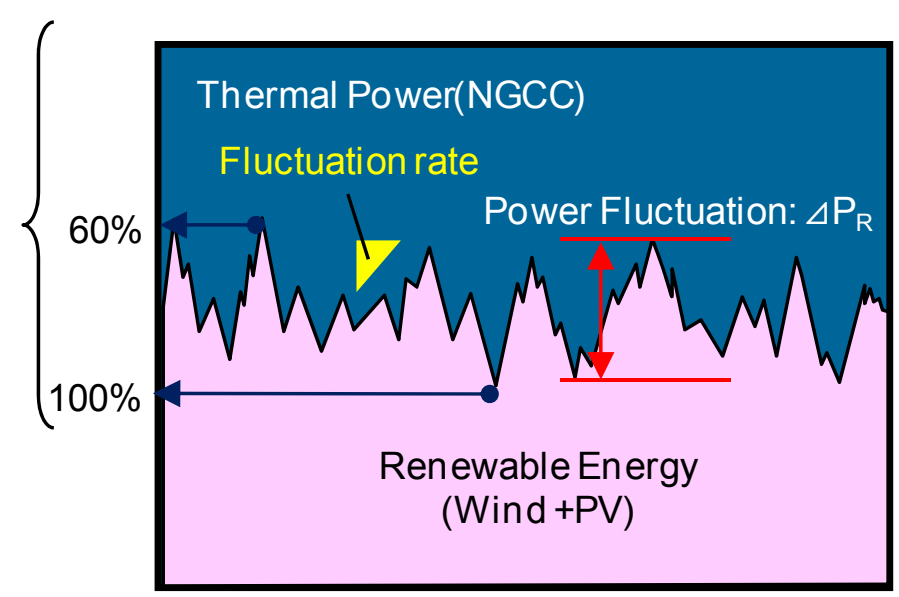

Figure 22: Adjustable speed rate and operational load range of NGCC

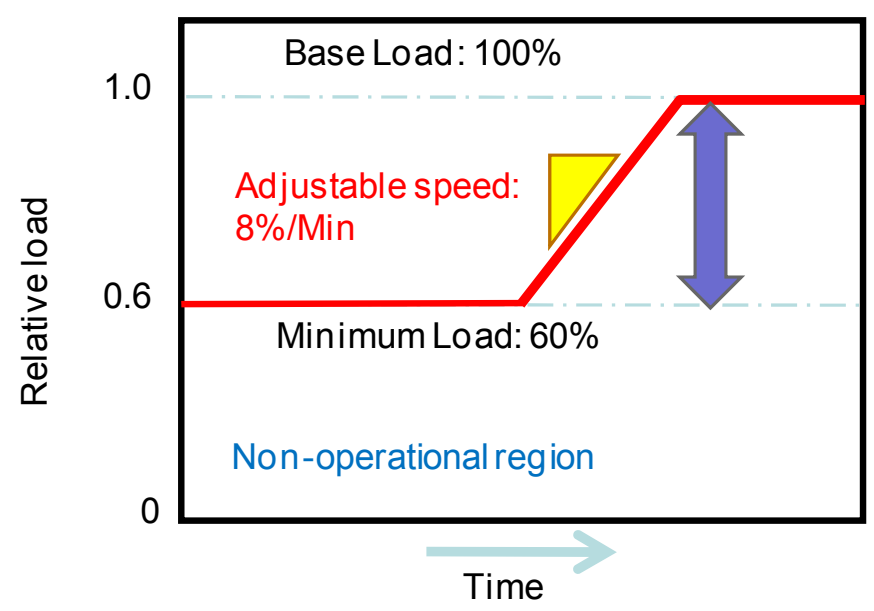

Figure 23: Daily balance of demand and supply on two typical days in 2050 (variation ratio: 15\%)

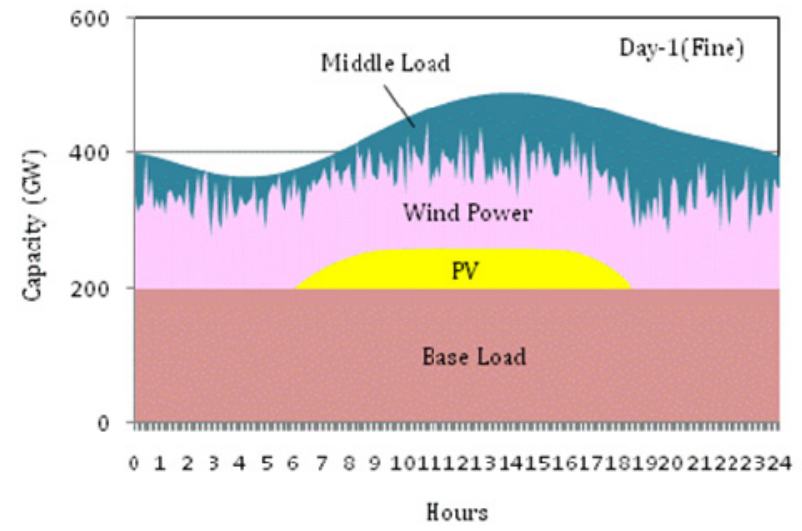

a) Fine weather case

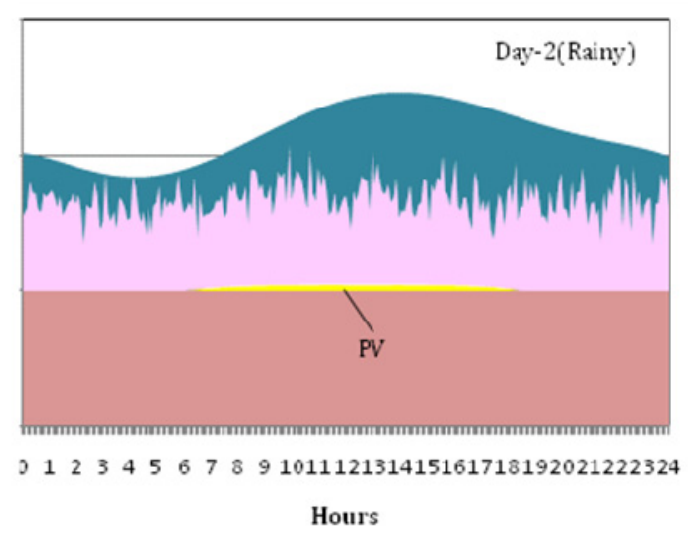

b) Rainy weather case 
Figure 23 plots the daily balances of demand and supply for two typical days - one with fine weather and one rainy - in June 2050, a month with minimum demand. In this simulation, sample sizes of 10 and 35 were used, and the variation ratio of the wind power was $15 \%$. Since the net variation of wind power is important, individual countries or regions should establish methods to measure and analyse it in the future.

Page | 28 Figure 24 shows the trends of the middle-load supply during a typical day with and without load shifting. The middle-load supply varies every $0.1 \mathrm{~h}$, in accordance with the fluctuation of the wind power supply (in blue). The average middle-load supply (solid red line) represents an $80 \%$ load factor. The full-load and 60\%-load lines show the frequent occurrences of large upper and lower wind power variations beyond the margins of middle-load capacity operation. In the case with load shifting (top), the average middle load is more uniformly flat than in the case without load shifting (bottom). In particular, the minimum middle-load supply in the case with load shifting is much larger than it is in the case without load shifting.

Figure 24: Comparison of daily trend of middle load in a typical day under minimum load (variation rate: $15 \%)$
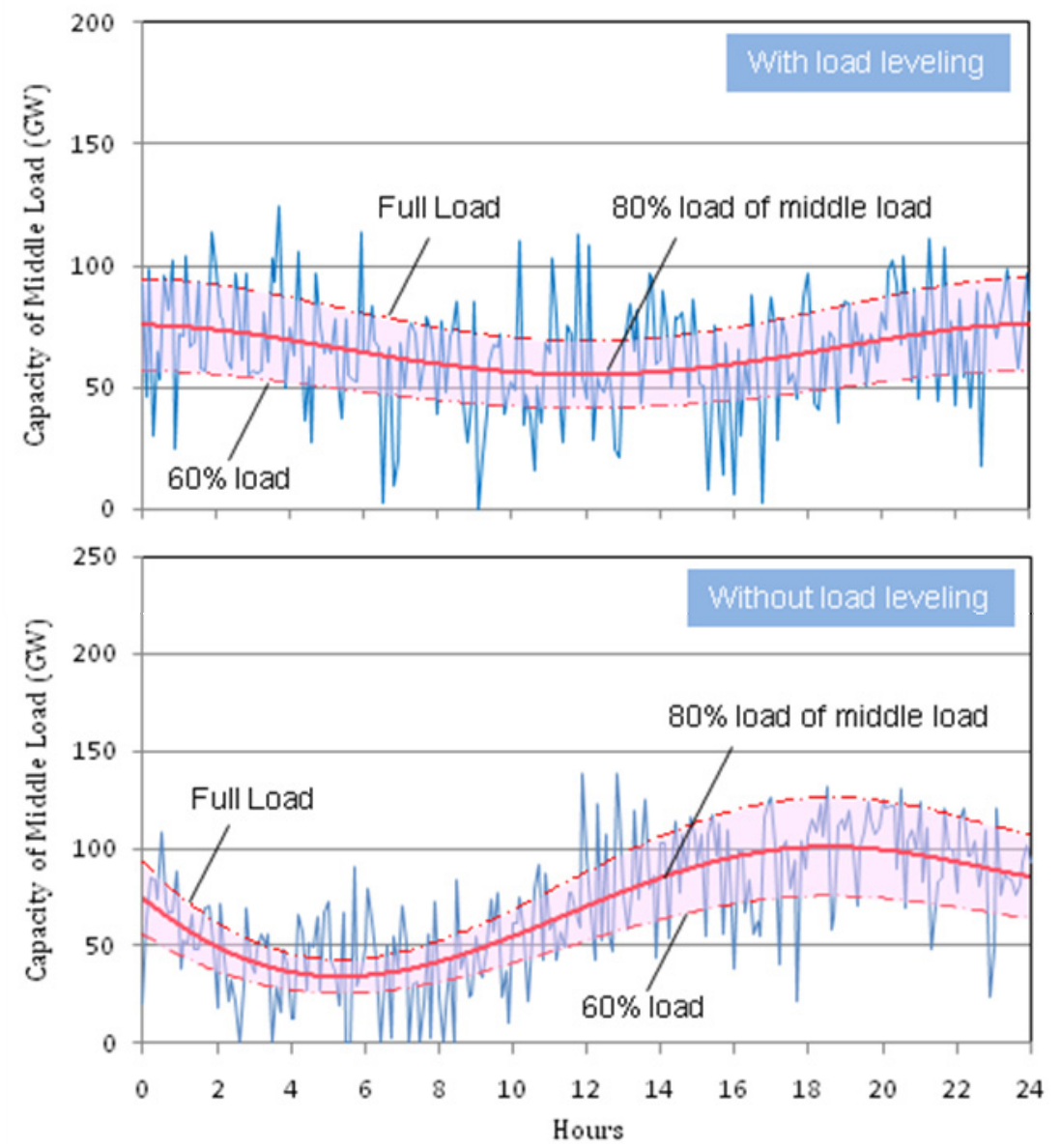

Figure 25 shows the high (red) and low (blue) excursions from the 60\%-load to full-load range that must be compensated for in Figure 24. The maximum magnitudes of the fluctuation are $47 \mathrm{GW}$ with load shifting and $53 \mathrm{GW}$ without load shifting. This indicates that load shifting effectively decreases the energy storage required to absorb the excess power generated. 
Figure 25: Excess capacities in a typical day (variation rate: 15\%)
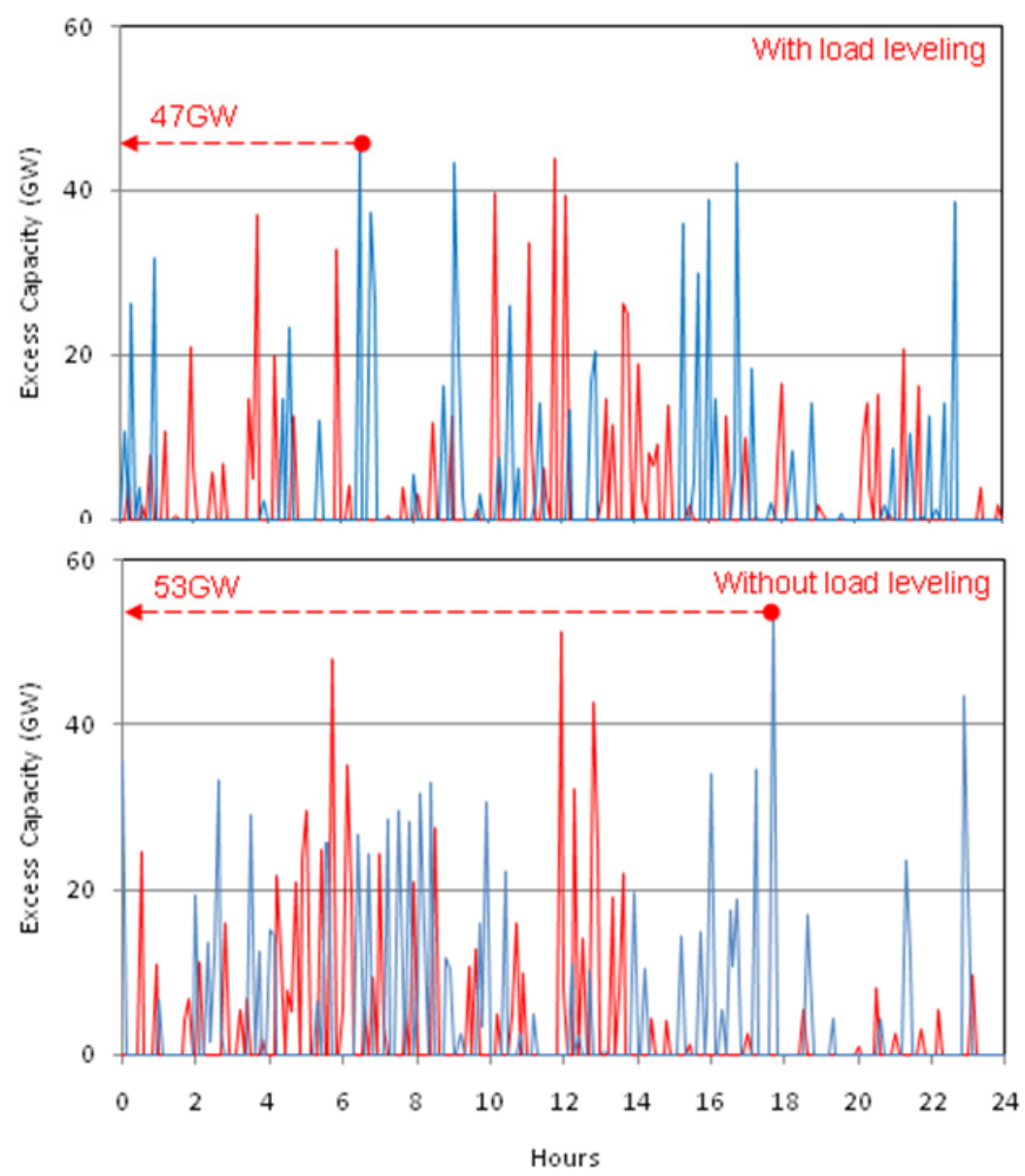

Figure 26 estimates the degree to which load shifting could reduce the amount of energy storage capacity required worldwide. Earlier studies (IEA, 2009) determined that the required capacity depends heavily on the variability of wind power and ranges from $189 \mathrm{GW}$ to $305 \mathrm{GW}$ corresponding to variations of $15 \%$ to $30 \%$ without load shifting. With load shifting, those capacities are $122 \mathrm{GW}$ and $260 \mathrm{GW}$, respectively.

V2G can make a significant contribution to those capacities. However, future EVs are expected to store the bulk of their electricity in lithium-ion batteries, which are more expensive than conventional competing large-scale energy storage options such as pumped hydro and compressed air energy storage (CAES). Consequently, V2G will not offer an economically competitive option until at least 2025. Consequently, V2G may be more practical supplying power during peak demand periods rather than serving middle-load operation. 
Figure 26: Decreasing effect of the requiring energy storage capacity

Page | 30

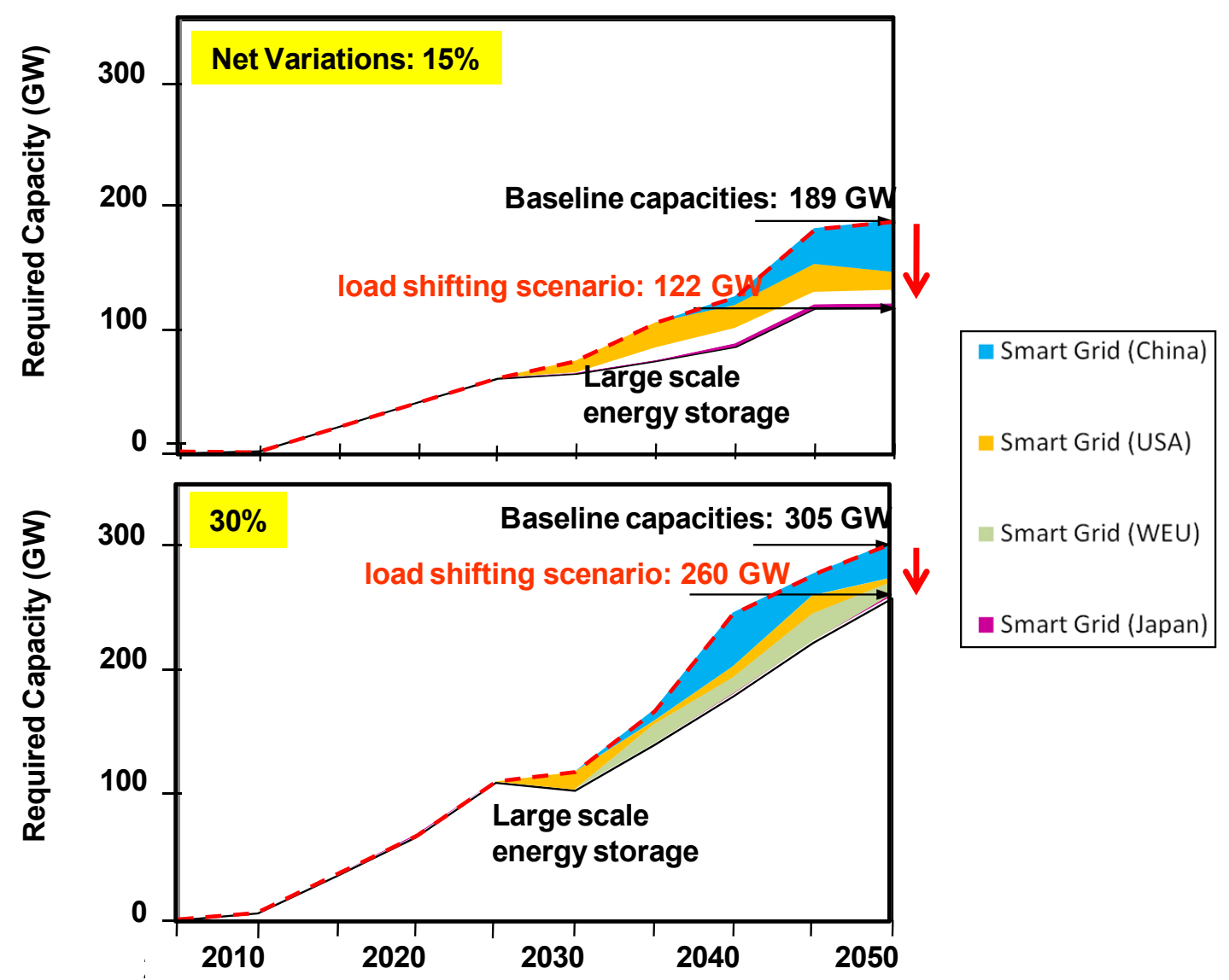




\section{Selected results of V2G simulation}

This working paper focuses on the United States, Western Europe, China, and Japan as case studies for the V2G concept. These four regions are expected to provide large markets for EVs, and have diverse demand curves and generation mixes. It will be important to estimate universal impacts of load shifting due to V2G under different boundary conditions.

\section{Simulation analysis for the United States}

In this simulation, the variation of wind power in the United States was assumed to be $15 \%$. Figures 27 and 28 show the demand/supply balances with and without load shifting, and the trends of charge and discharge. Figure 27 shows the results in April and September, which are the minimum demand months in the United States.

In 2025, when the amount of power supplied by V2G is small, the load-shifted demand curve is slightly different than the original demand curve (red dashed curve). In 2040 and 2045, without load shifting wind power is predicted to be curtailed from 08:00 to 10:00, since the sum of the base load, PV, and wind power exceeds the minimum demands of the day. From the perspective of trying to maximise the use of renewable energy, such curtailments should be avoided. Further, in these months, the operation of the middle load varies greatly during the day. In the case without load shifting, the required capacity of the middle load should be estimated based on the maximum generation in the day.

After 2035, as the total supply of base load, PV and wind power approaches or exceeds the demand at 08:00, the middle-load supply reaches its minimum. To mitigate this minimum supply, the maximum charging of EVs occurs at 08:00.

With well-managed load shifting and V2G, renewables are used to their fullest without curtailments. In addition, the difference between maximum and minimum generation of the middle load is less than it would be without load shifting and V2G. This means that load shifting and V2G substantially reduce the standby middle load and daily start and stop (DSS) capacity.

Figure 28 shows the results for the United States in August and December, which are the maximum demand months. In this case, since the overall demand is larger than the minimum, there is no curtailment of wind power. Also, as was the case during minimum demand periods, load shifting decreases the difference between the middle and maximum power of the middle load. Since the amount of power supplied by EVs does not change with the season, the benefit of load shifting is greater during times of minimum demand than it is during maximum demand. 
Figure 27: US demand-supply balance in minimum demand months (April, September)

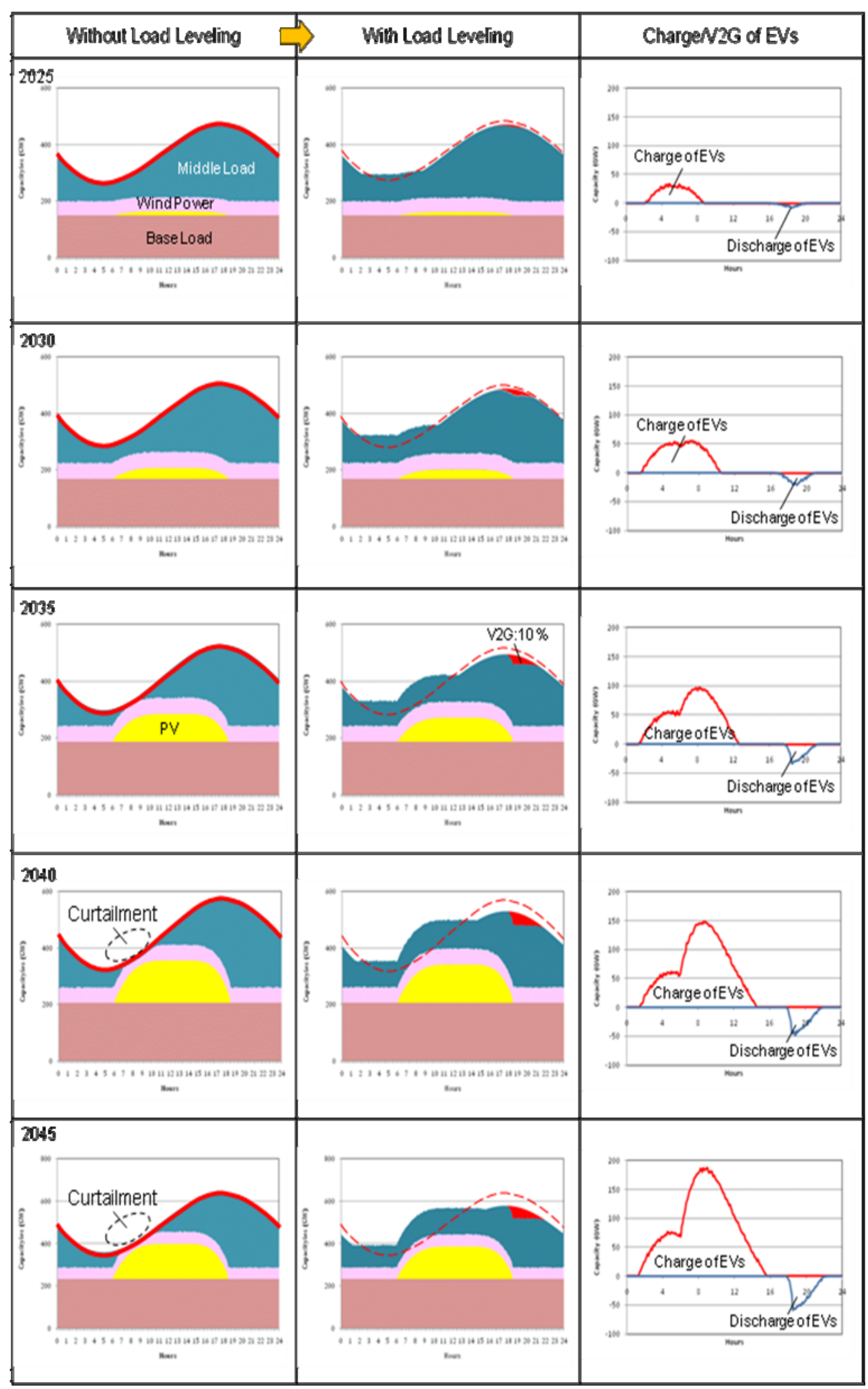


Figure 28: US demand-supply balance in maximum demand months (August, December)

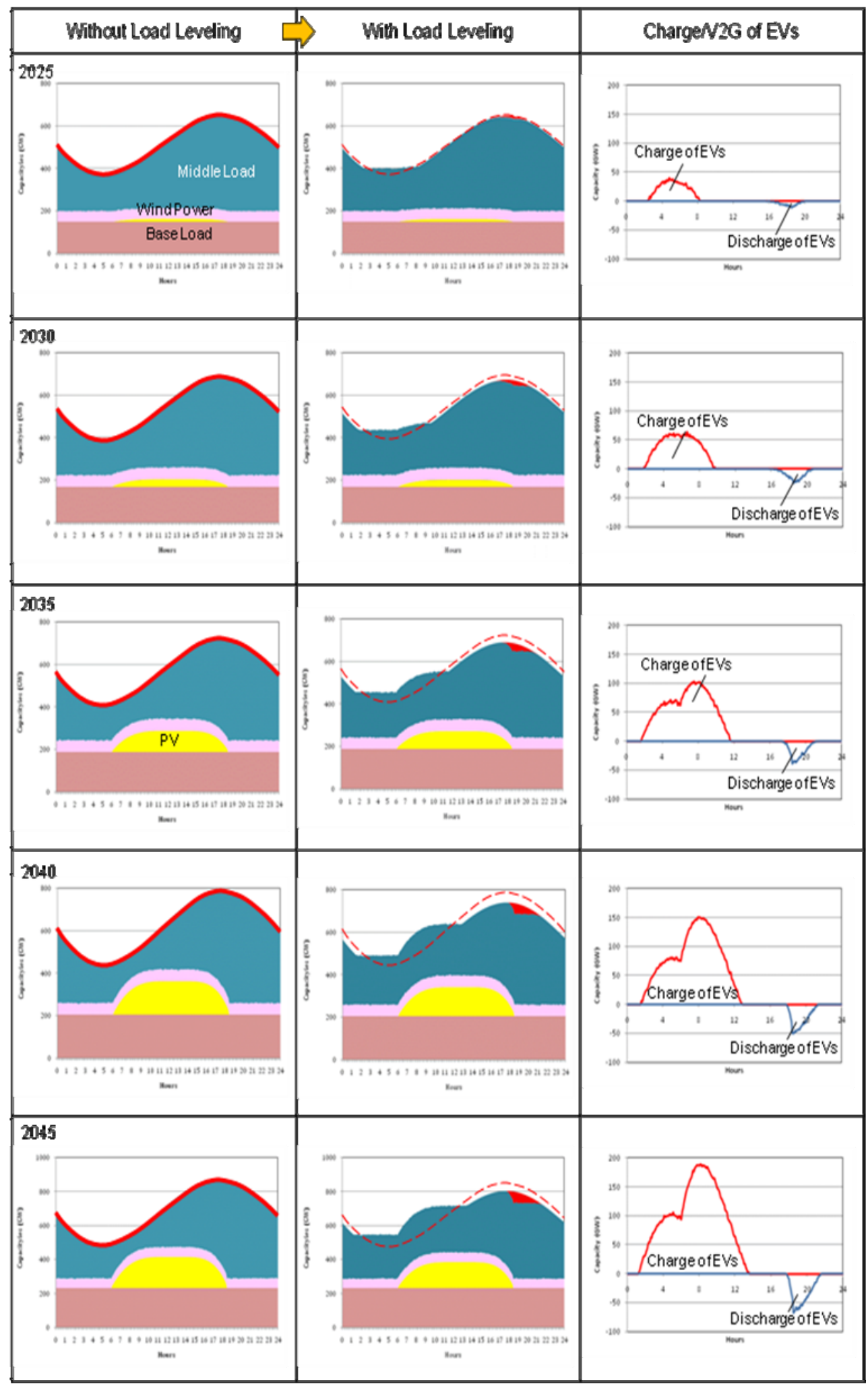

Page | 33

Figure 29 shows how the demand-supply balances during maximum demand in 2045 change with the percentage of V2G resources available. As the V2G percentage increases, the maximum generation of the middle-load capacity is remarkably reduced. 
Figure 29: US demand-supply balances during maximum demand with various V2G ratios in 2045
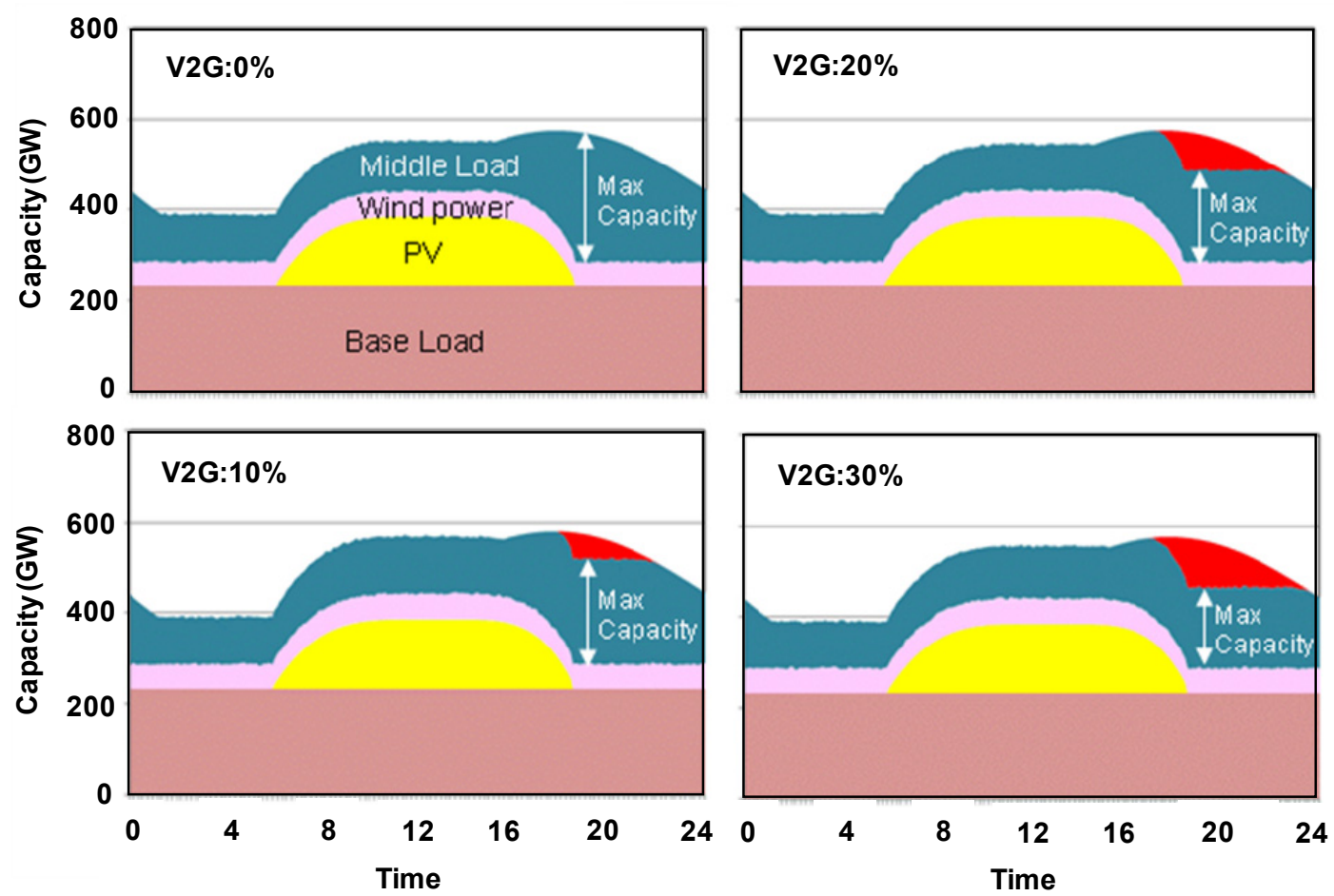

Figure 30: Daily trend of middle-load generation in the maximum demand months in the United States with different $\mathrm{V} 2 \mathrm{G}$ ratios

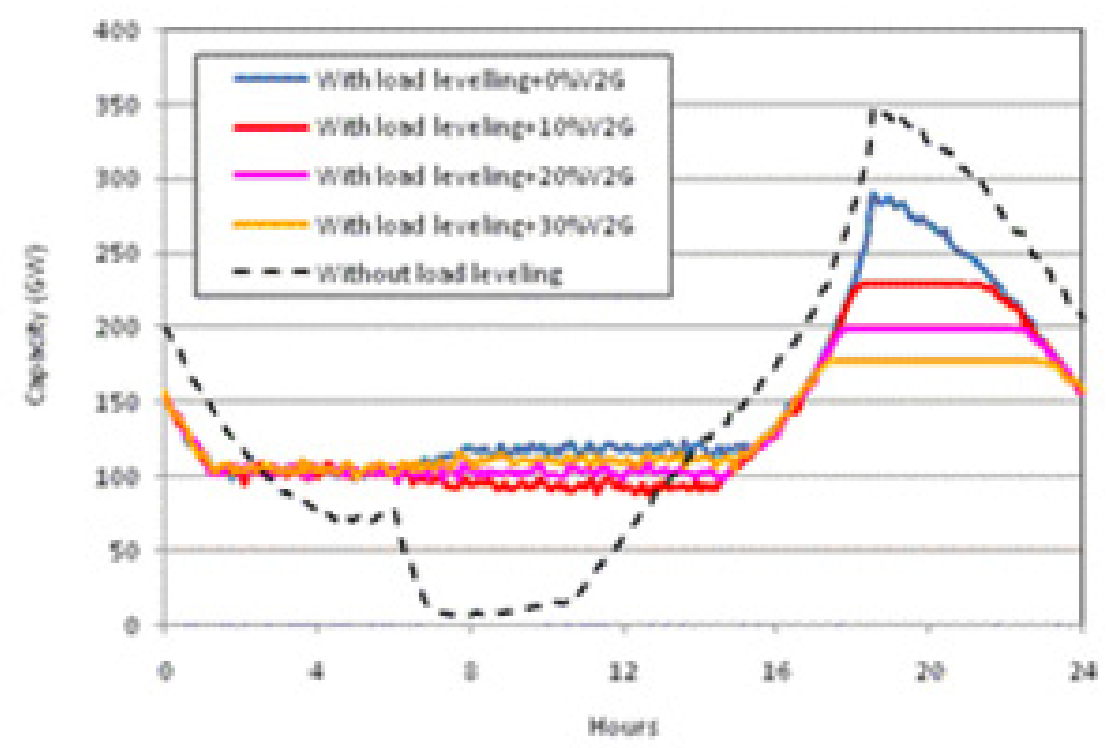

Figure 30 compares the daily trend of the middle-load generation with various V2G percentages. In the case without load-levelling, the difference between the maximum and minimum supply of the middle power is remarkable. However, as the V2G ratio increases, the discrepancy decreases. 
Figure 31 shows the relationship between the maximum capacity of the middle-load generation and V2G percentages. A feasible V2G percentage should be determined after monitoring and analysing EV driving patterns.

Figure 31: Relationship between V2G ratio and the maximum middle-load capacity in the United States

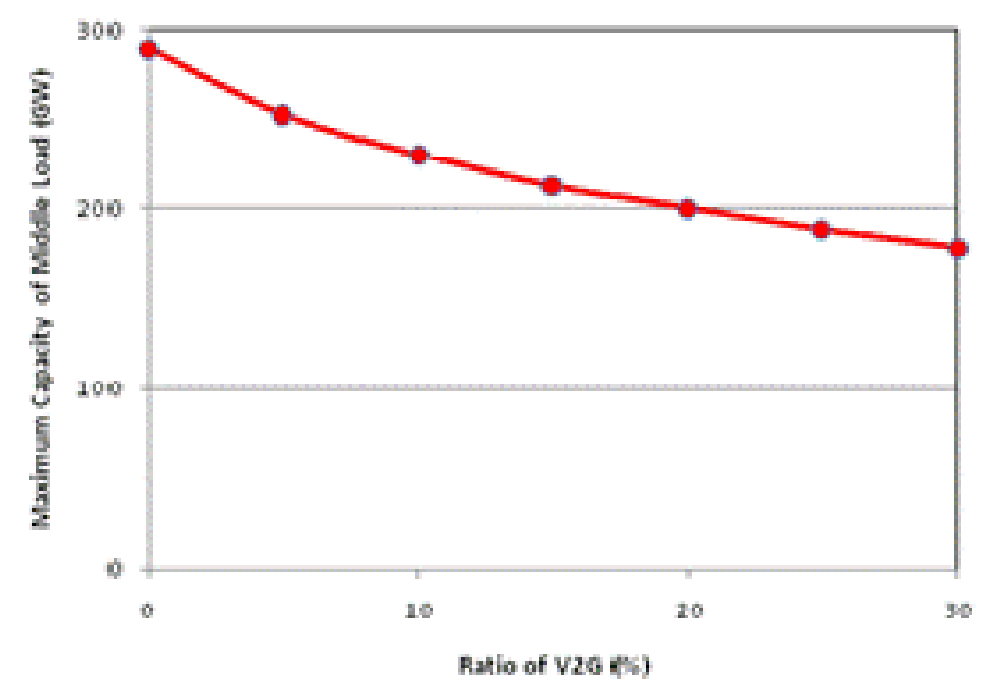

\section{Simulation analysis for Western Europe}

In this simulation, the variation of wind power in Western Europe was assumed to be $15 \%$. Figure 32 shows the generation production mix based on the BLUE Map scenario for 2000-50 in the region. As wind and PV power increase, the generation share of the middle-load capacity decreases gradually. After 2020, the ratio of the middle load is forecast to stabilise at around $30 \%$.

By 2050, the annual power demand increases from 3000 TWh to 4600 TWh (Figure 33). The estimated power demand of EVs in 2050 is expected to be about $550 \mathrm{TWh}$, accounting for approximately one-third of new demand between 2010 and 2050.

Figure 32: Trend of generation production mix in Western Europe

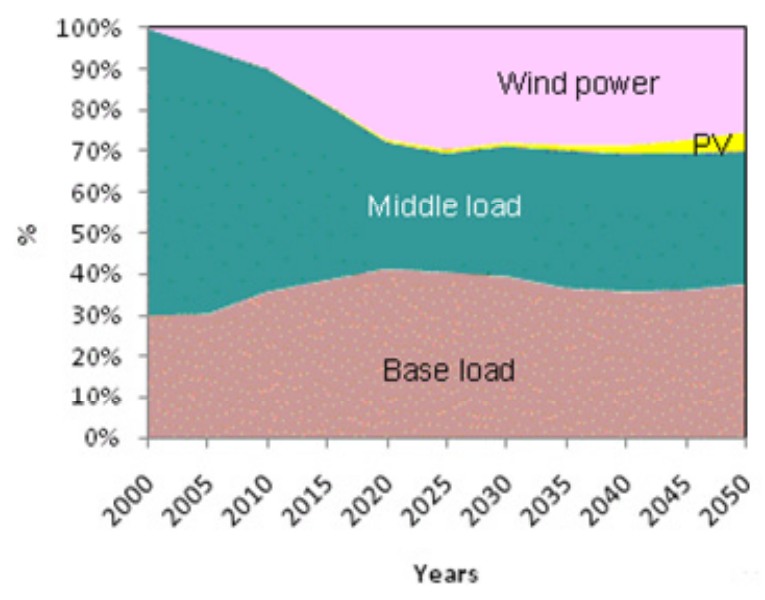


Figure 33: Growth of annual energy demand in Western Europe

Page | 36

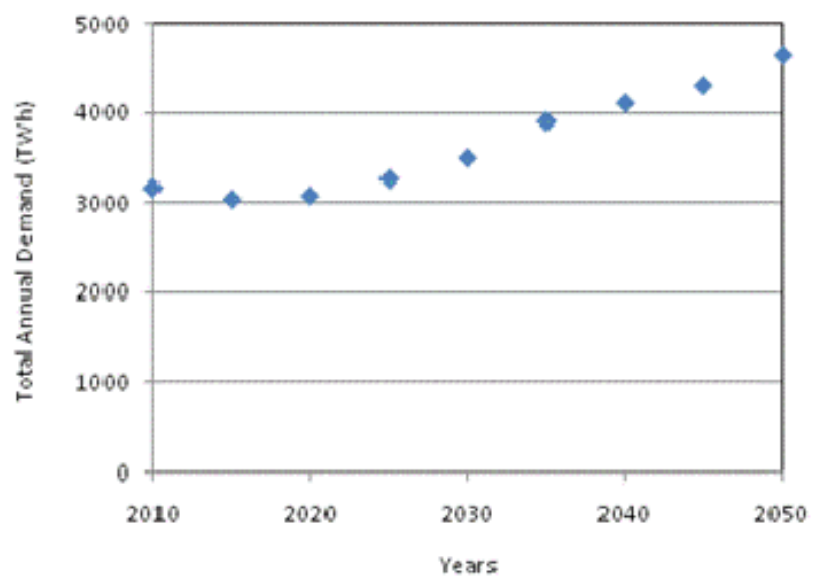

Figure 34: Daily demand curve in Western Europe

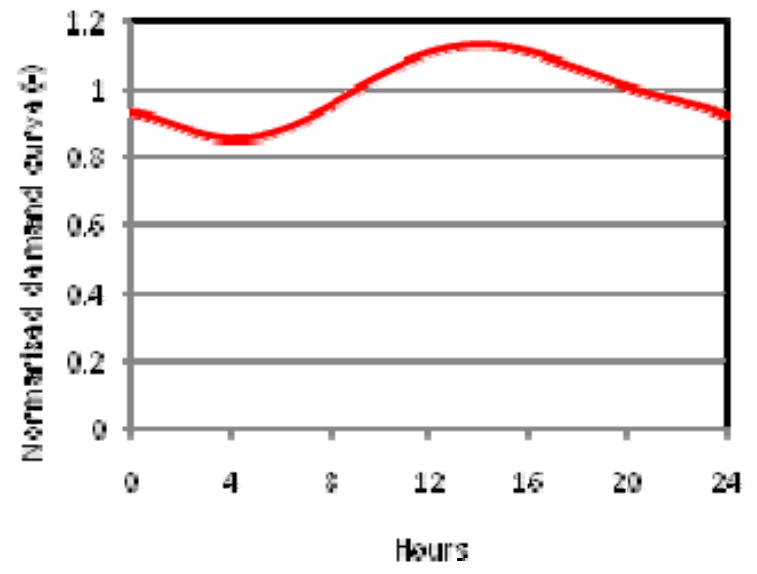

Figure 35: Annual demand curve in Western Europe

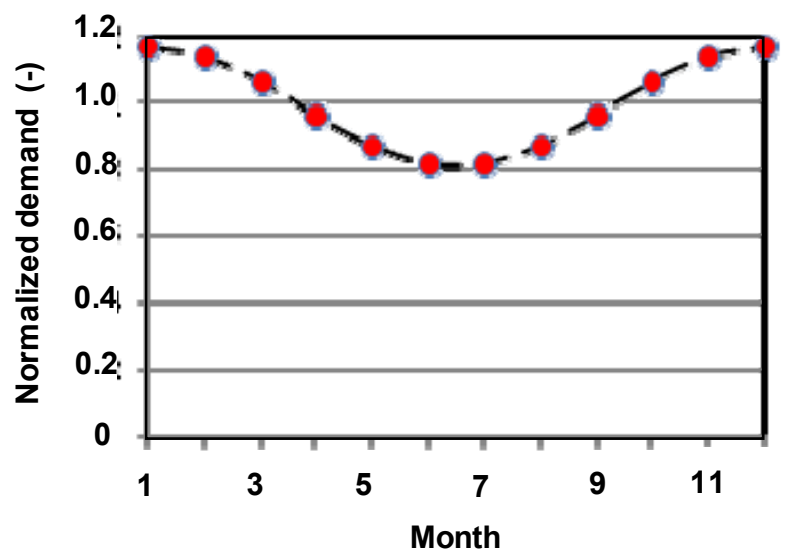


Figures 34 and 35 indicate the daily and annual demand curves for Western Europe. In the daily demand curve, the relative difference between maximum and minimum demand is less than it is in the United States. In Western Europe, June and July are the minimum demand months due to low demand for air conditioning; January and December are the maximum demand months due to space heating needs.

Figures 36 and 37 show the supply and demand balance with and without load shifting for the minimum and maximum demand months in Western Europe from 2025 to 2045. Note that the share of wind power in Western Europe is higher than it is in the United States, while the share of $P V$ is lower. As a result, wind power curtailment never occurs, even in periods of minimum demand without load shifting. However, with load shifting and 5\% V2G supplying power from EVs, the output becomes more uniform.

In 2025 , when the amount of power supplied by EVs is insufficient, the load-shifted demand curve is close to the original demand curve (dashed red curve). In Western Europe, the introduction of EVs is expected to be high enough to provide load shifting of the middle load in 2045. This condition seems to be satisfied even without V2G. In 2045, the charging and discharging (V2G) of EVs are expected to overlap. This situation is known as "vehicle to vehicle" (V2V), and implies that EVs provide enough electric power to charge other EVs but not enough to supply the power grid. In addition, the difference between maximum and minimum capacities of the middle load decreases. This means that reducing the standby middle load and DSS operation of the middle load will be feasible.

In Western Europe's maximum demand months of December and January, the magnitude of load shifting is determined by the maximum demand case (Figure 37). The uniform middle-load supply based on load shifting is confirmed. As before, the difference between the minimum and maximum power of the middle load decreases due to load shifting. The impact and implications of the $\mathrm{V} 2 \mathrm{~V}$ operation described above and illustrated in the figure are significant.

As mentioned, the share of renewables is higher in Western Europe than in the United States, while the share of the middle load is smaller. Therefore, in Western Europe the overall power supplied by EVs is enough to perform load shifting without V2G (Figure 38 summarises data for 2045). In the figure, the red regions indicate the contribution of V2G. Even in the case of $5 \%$ V2G, the period using V2G is distributed uniformly, which means that load levelling is achieved without V2G. In fact, the maximum capacities of the middle load, which are indicated by white arrows in each case, are all very similar.

Figure 39 compares the daily trend of the middle load during the minimum demand season. Even without V2G, the generation of the middle-load capacity is flat compared to that of the United States. Figure 40 shows the relationship between V2G percentage and the maximum middle-load generation. Reduced demand of the middle load due to V2G is never prominent. 
Figure 36: Western Europe demand-supply balance in minimum demand months (June, July)

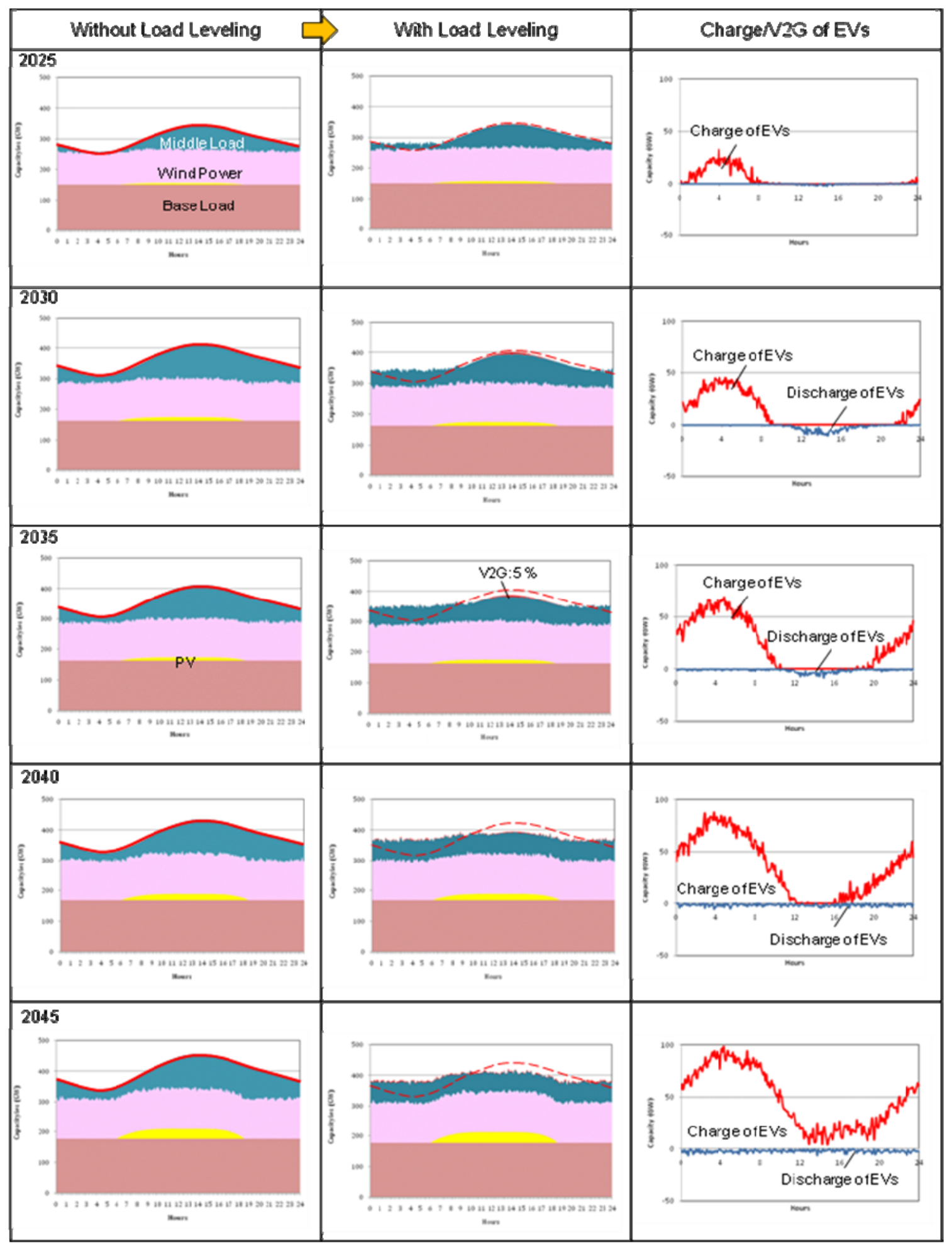


Figure 37: Western Europe demand-supply balance in maximum demand months (January, December)

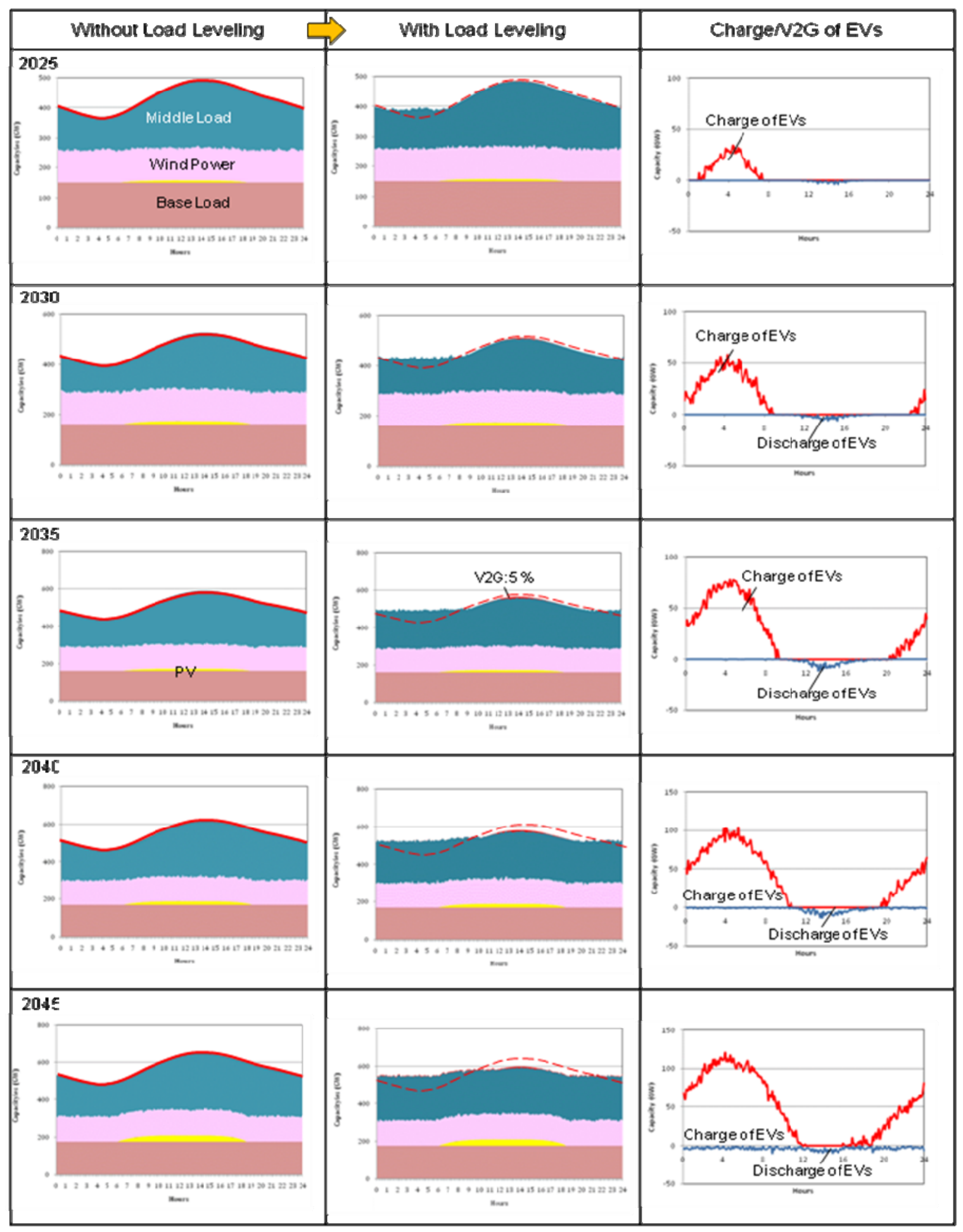


Figure 38: Comparison of effect of V2G in 2045 in Western Europe

Page $\mid 40$
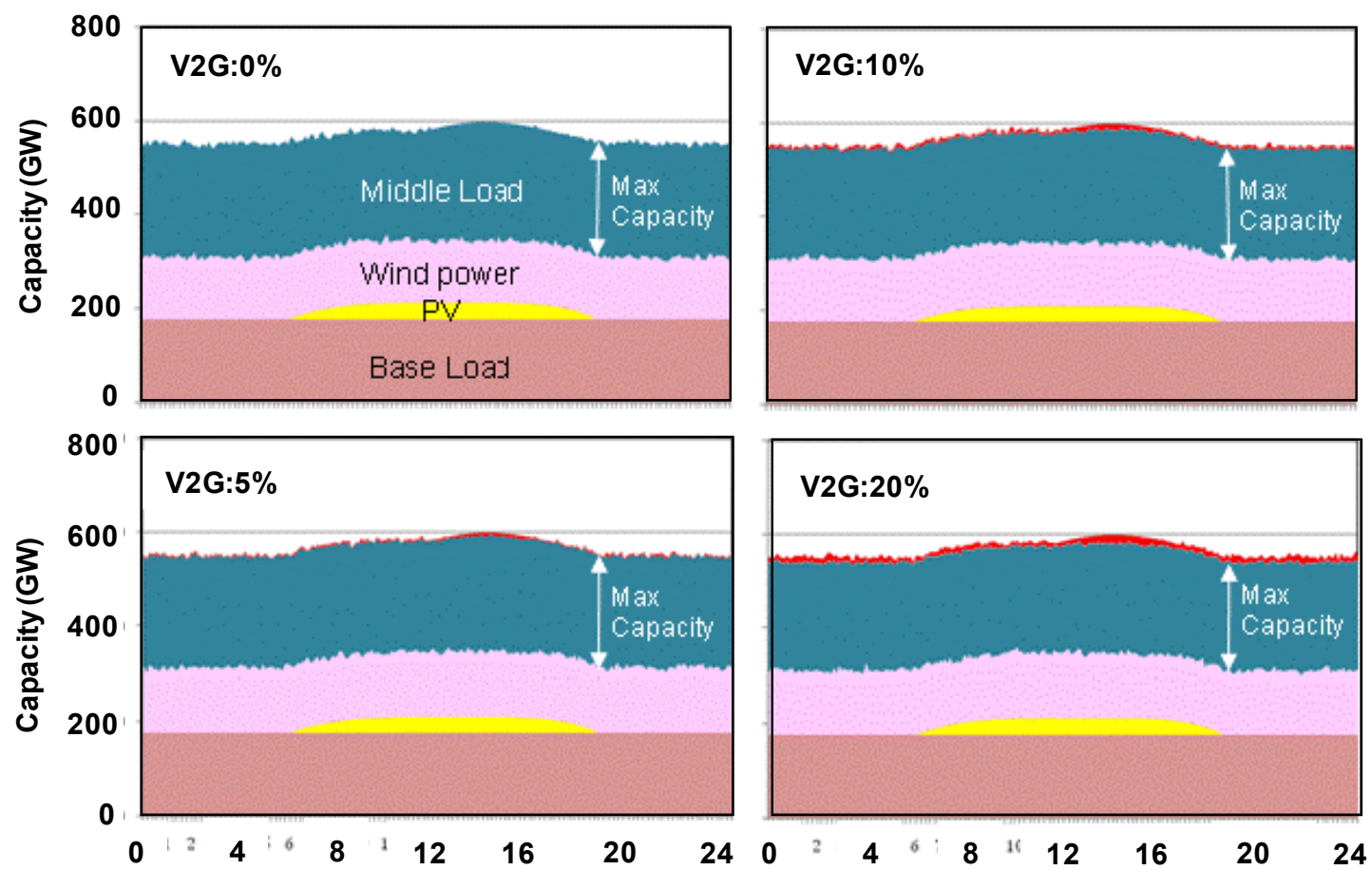

Figure 39: Daily trend of middle-load generation during maximum demand months in Western Europe with different $\mathrm{V} 2 \mathrm{G}$ ratios

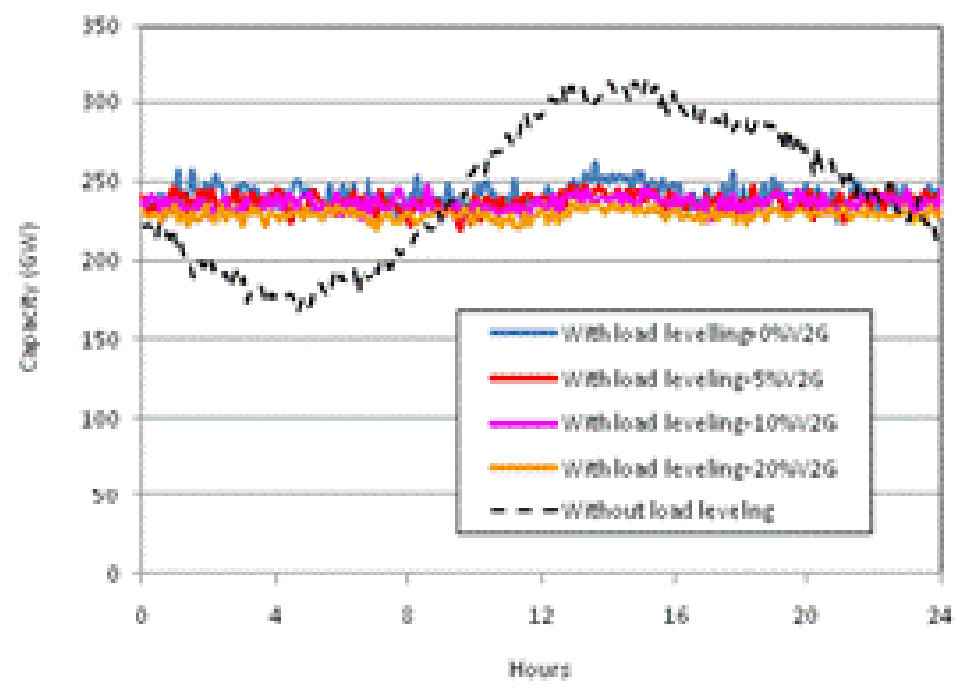


Figure 40: Relationship between V2G ratio and the maximum middle-load capacity in Western Europe

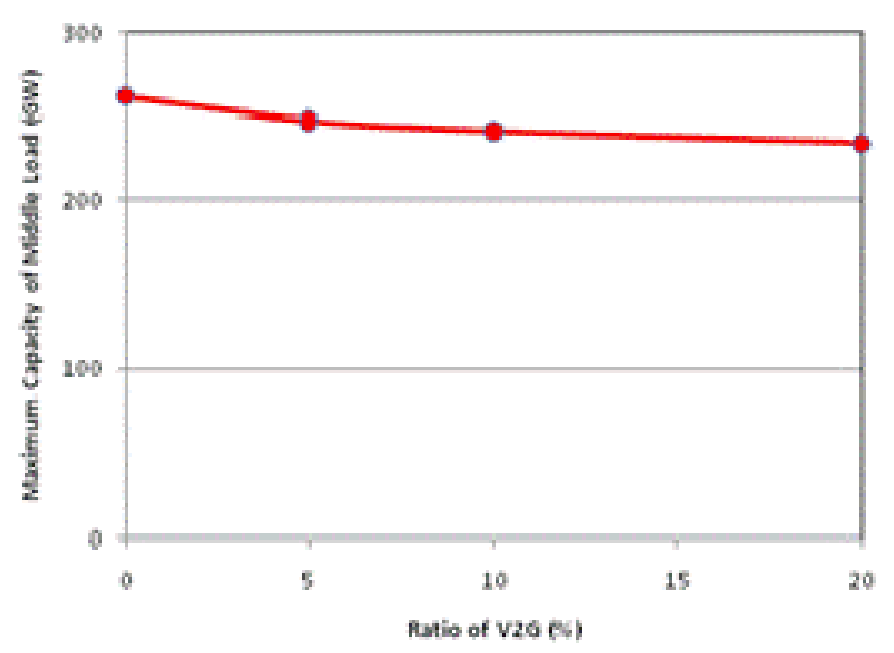

\section{Simulation analysis for China}

In this simulation, the variation of wind power in China was assumed to $15 \%$. Figure 41 shows the generation mix in China through 2050 based on the BLUE Map scenario. The current share of the middle load in China is relatively higher than in other countries. While the share of the middle load decreases rather slowly, it will be smaller in 2050 as shares of the base load and wind power increase. Since China has the potential to generate $1000 \mathrm{GW}$ of wind power, the effective utilisation of wind energy will be a key point in the power scenario.

Figure 41: Trend of generation mix in China

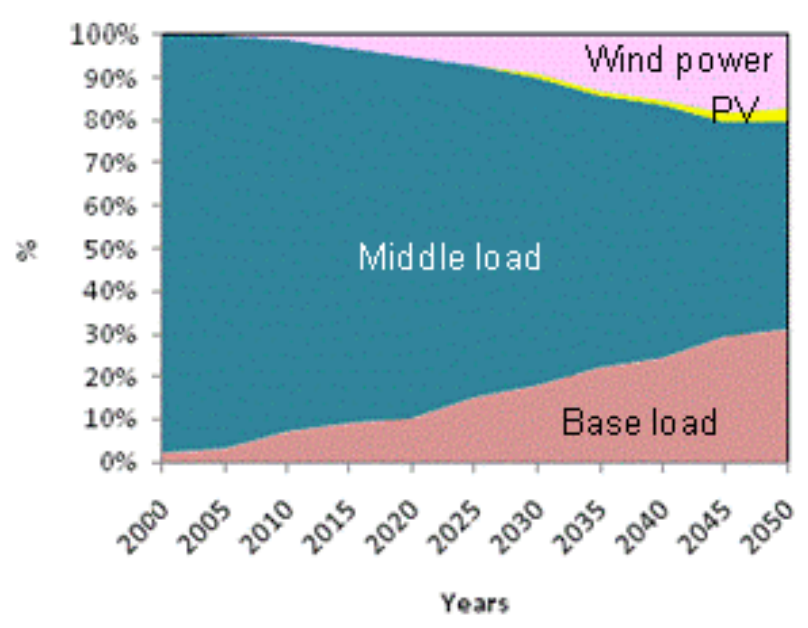

Figure 42 shows the growth of annual demand from 2010 to 2050. Demand will increase steadily to approach $10000 \mathrm{TWh}$, which will be the largest demand worldwide in 2050. The required demand from plug-in EVs will be approximately $1000 \mathrm{TWh}$, which represents about one-sixth of the increase in demand from 2010 to 2050.

In the daily demand curve (Figure 43), the magnitude of the difference between maximum and minimum demands is not large, similar to that observed in Western Europe. In China, February is the minimum demand month due to the lunar New Year holidays, which see a drop in industrial power consumption. August and December are the maximum demand months. However, there is no pronounced difference in the demand throughout the year except in February (Figure 44). 
Figure 42: Growth of annual demand in China

Page | 42

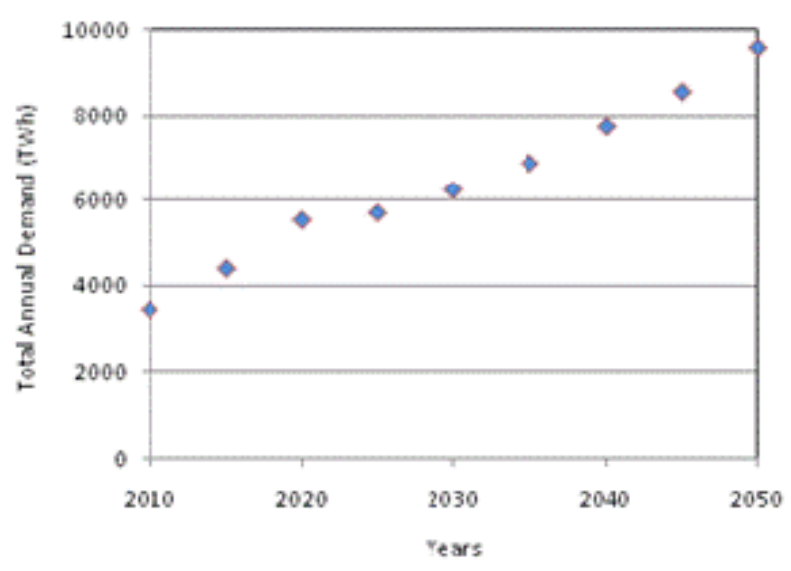

Figure 43: Daily demand curve in China

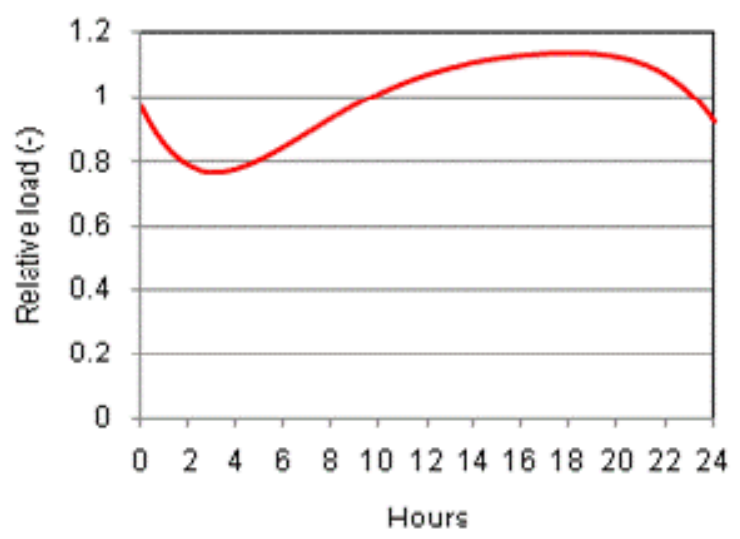

Figure 44: Annual demand curve in China

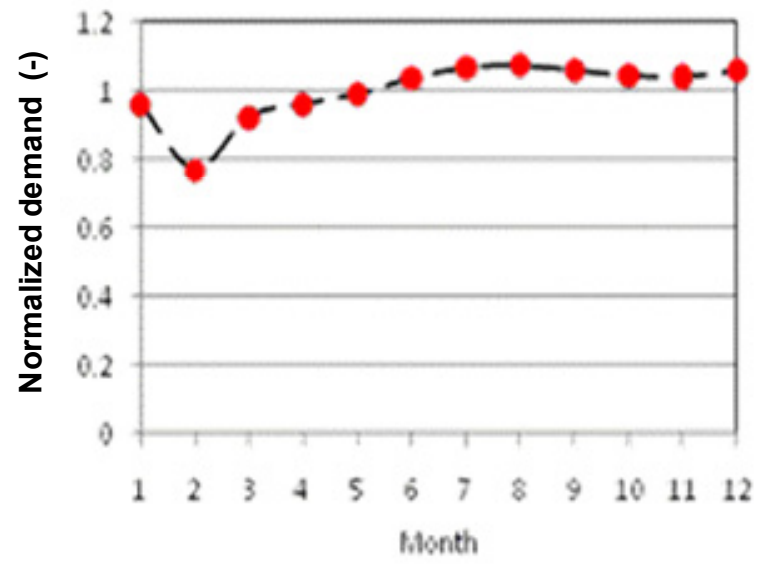

Figures 45 and 46 show the demand-supply balance for China in the minimum and maximum demand months of 2025 to 2045, assuming 5\% V2G. As mentioned above, the share of the middle load is relatively higher in China than in the United States and Western Europe. Therefore, even in the minimum-demand period (Figure 45), the overall capacity of EVs is never enough to make the middle-load output uniform, even though the overall generation capacity of EVs is projected to be the largest worldwide. Even for $5 \%$ V2G, the period of V2G is localised; in other words, the EV charge and discharge (V2G) periods never overlap, as they do in Western Europe. This clearly defines the separate roles for load shifting and V2G. 
Figure 45: China demand-supply balance in minimum demand month (February)

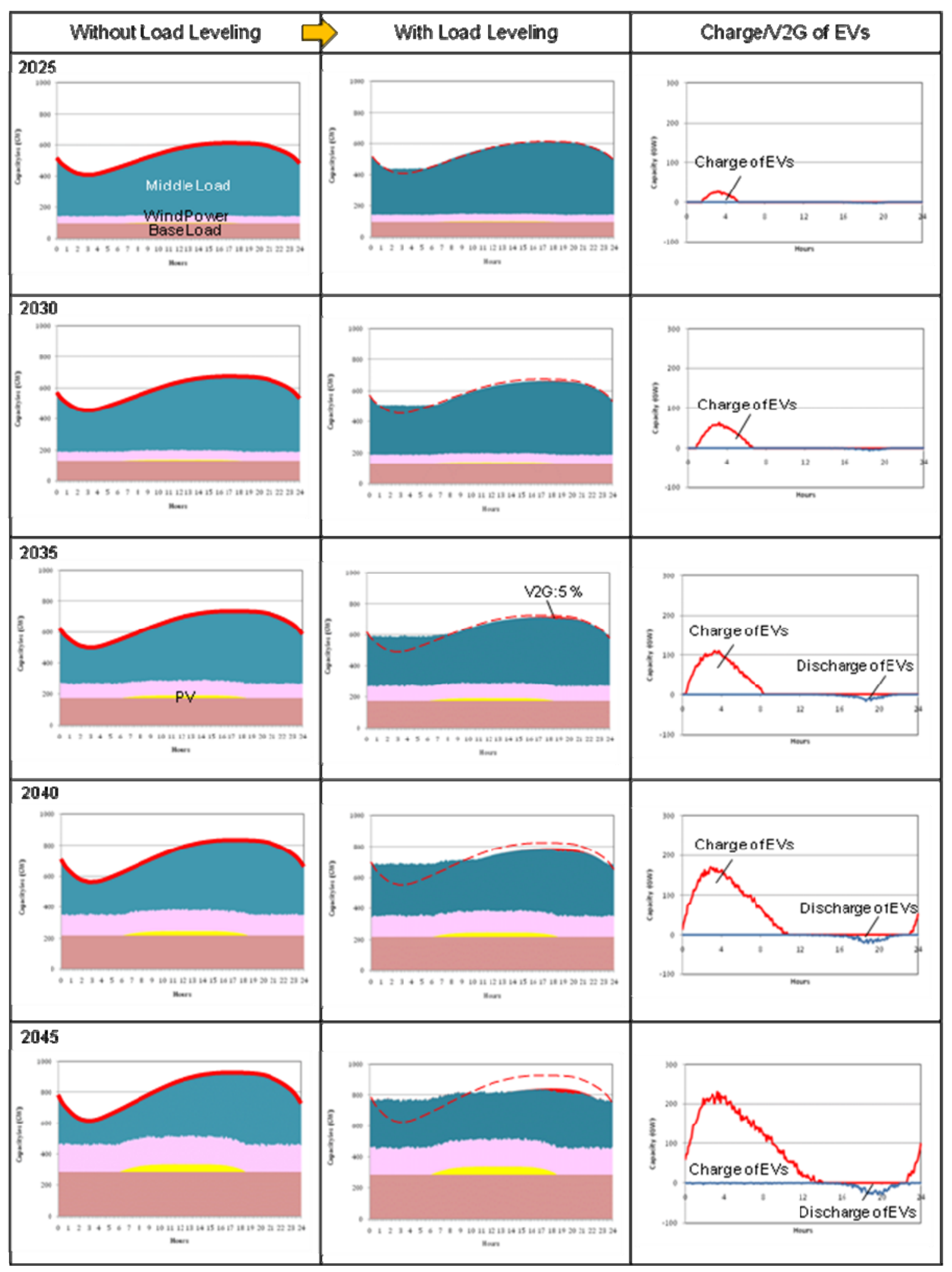


Figure 46: China demand-supply balance in maximum demand month (August)

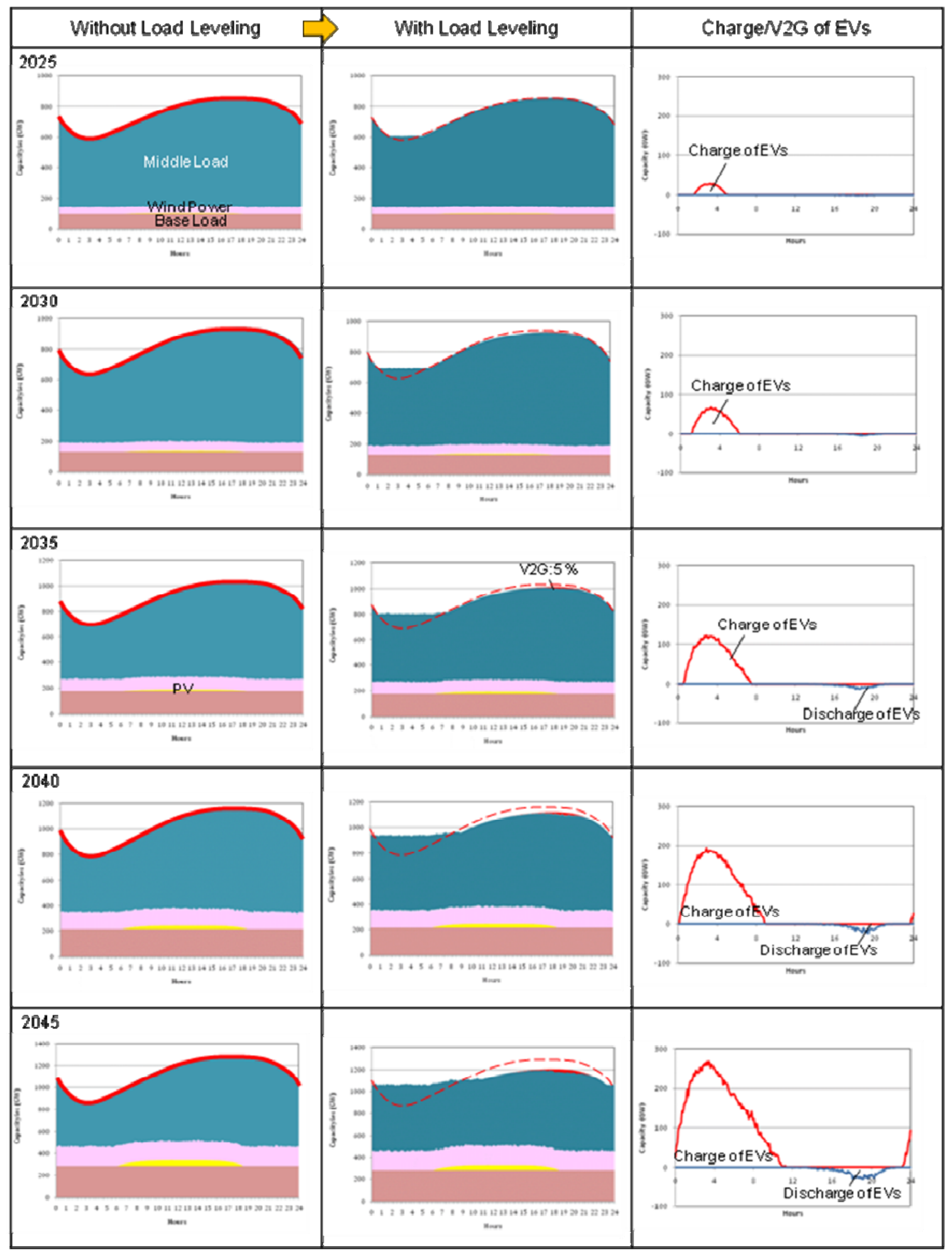

As mentioned above, in China the share of the middle load is higher than it is in the United States and Western Europe. Therefore, the effect of V2G load shifting is relatively small. With increasing percentages of V2G (indicated by the red areas in Figure 47), the maximum capacities of the middle load (white arrows) decrease. In China, the concept of V2G will effectively achieve load shifting of the middle load. 
Figure 47: Comparison of effect of V2G in China in 2045
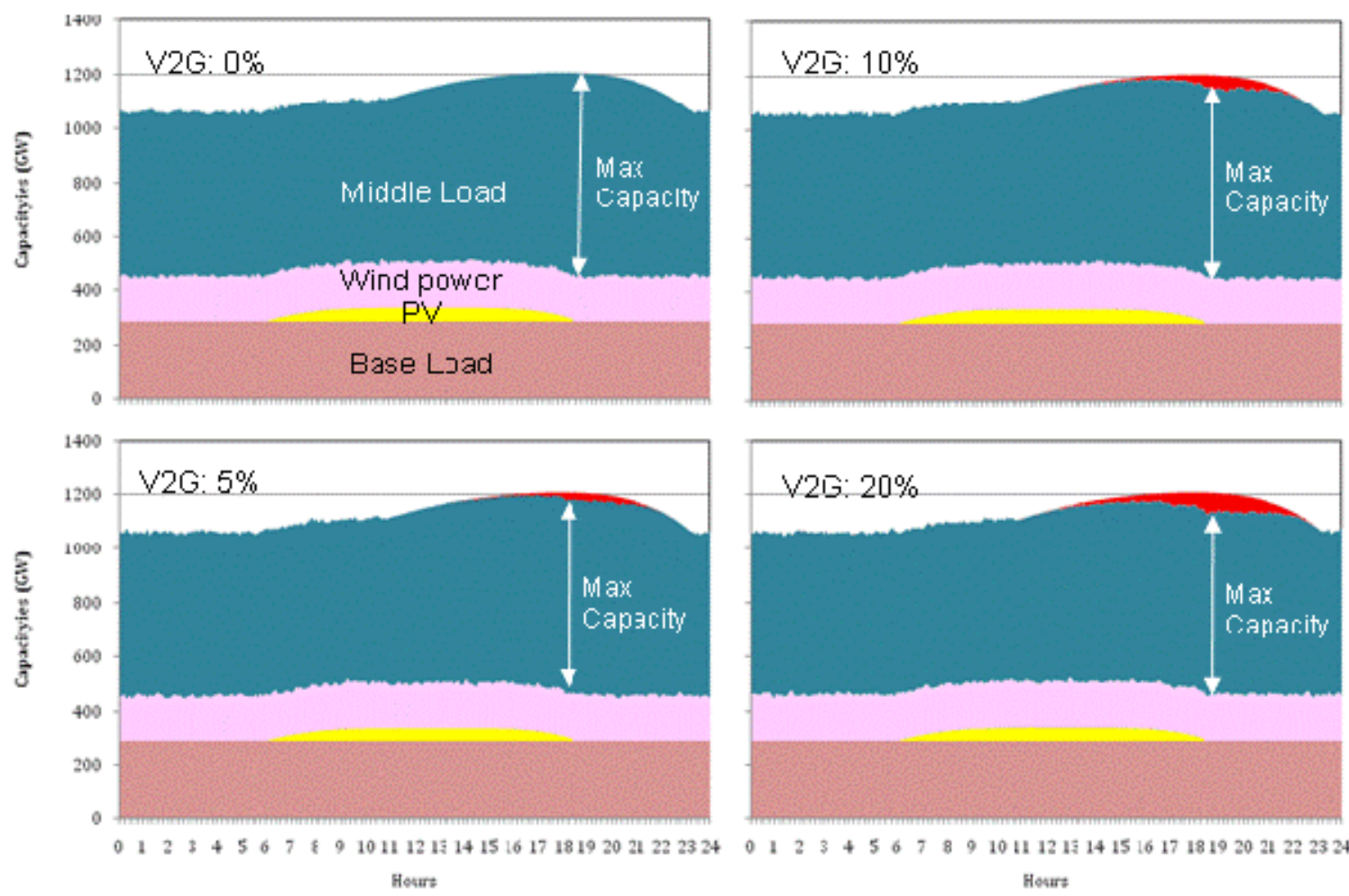

Page $\mid 45$

Figure 48 compares the daily change of the middle-load supply in the minimum demand season. From 00:00 to 12:00, the middle-load output is quite uniform. It then peaks between 12:00 and 24:00.

Figure 48: Comparison of daily trend of middle load in the maximum demand season in China

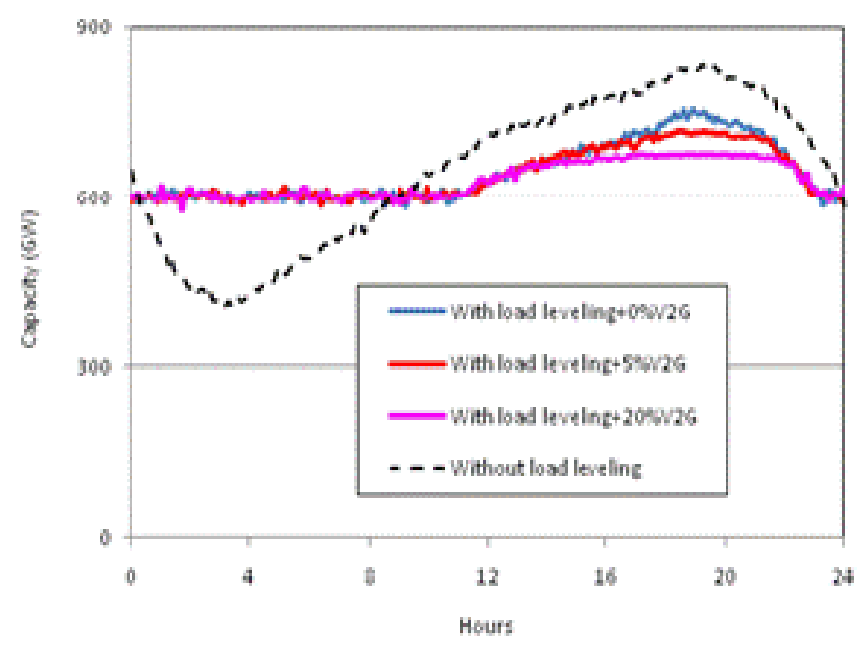

Figure 49 shows the relationship between the percentage of V2G available and the maximum middle-load capacity. The reduction effect of the middle load due to V2G is never prominent, as EV generation capacity will never keep pace with the increase of the total demand. 
Figure 49: Relationship between V2G ratio and the maximum middle-load capacity

Page | 46

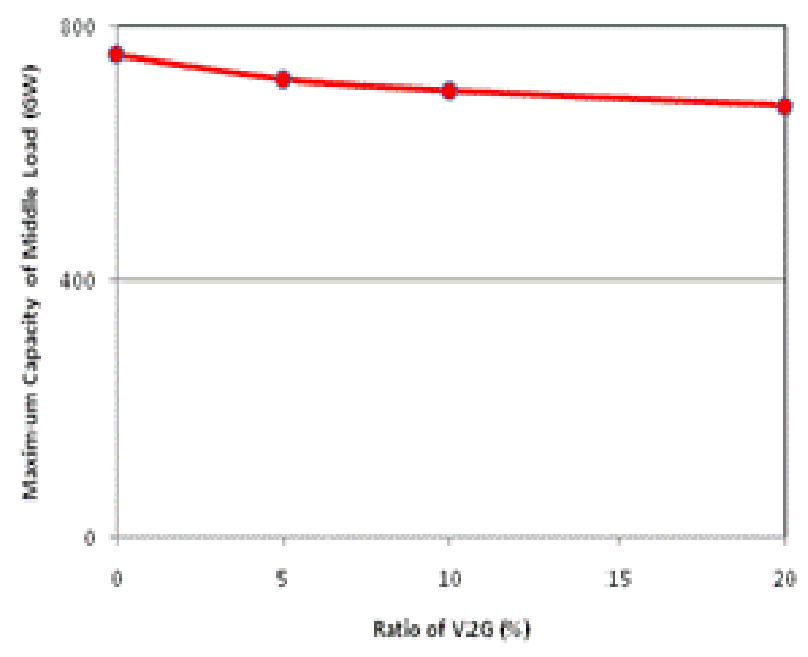

\section{Simulation analysis for Japan}

In this simulation, the variation of wind power was assumed to be $15 \%$. Figure 50 shows the anticipated generation mix from 2000 to 2050 in Japan. Nuclear power will contribute approximately $50 \%$ of overall demand. As the proportion of wind and PV power increases, the middle-load capacity will decrease.

Figure 50: Trend of generation mix in Japan

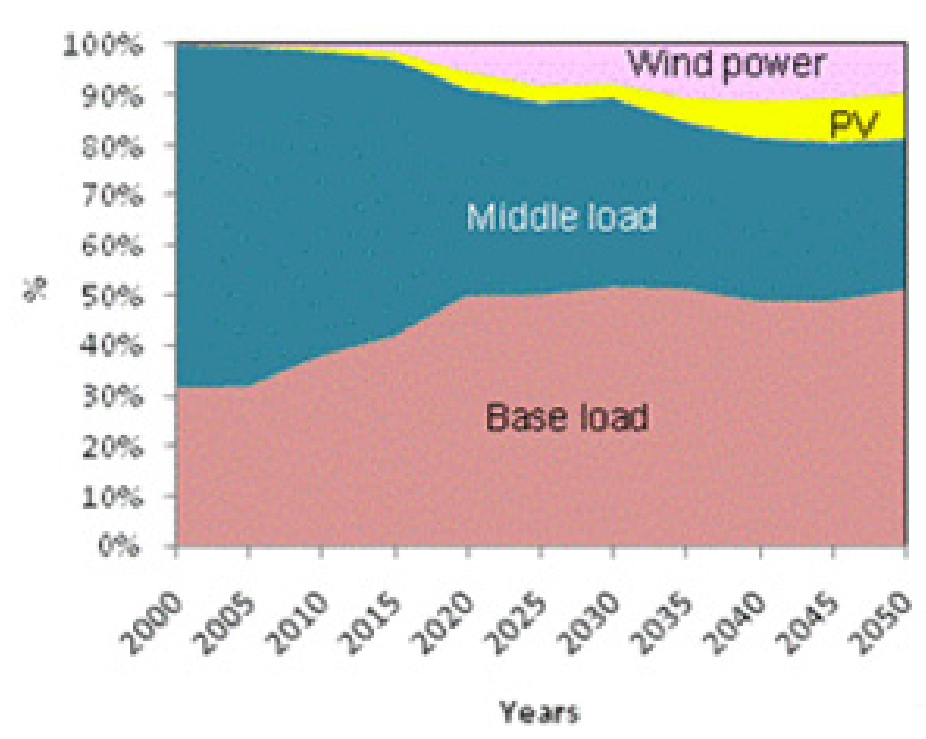

Annual total demand in Japan is expected to increase rapidly after 2030, and exceed $1500 \mathrm{TWh}$ in 2050 (Figure 51). This result includes the demand for charging EVs, which will reach about 250 TWh in 2050. Therefore, half of Japan's increased demand by 2050 will be due to EVs. 
Figure 51: Growth of annual demand in Japan

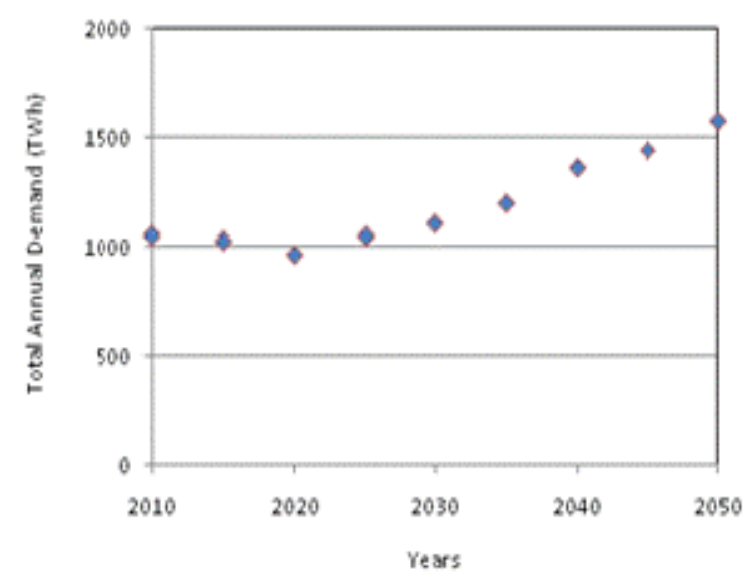

Page | 47

In the daily demand curve for Japan (Figure 52), the maximum demand is twice the minimum. In the annual demand curve (Figure 53), May and October are the minimum demand months while August is the maximum demand month. As in the United States, Japan experiences maximum demand in the summer and winter as electricity is used for air conditioning and space heating, respectively.

Figure 52: Daily demand curve Japan

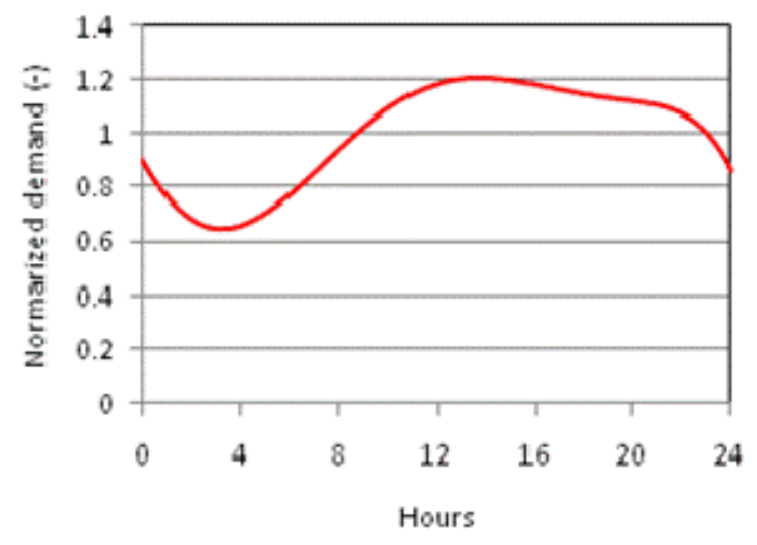

Figure 53: Annual demand curve in Japan

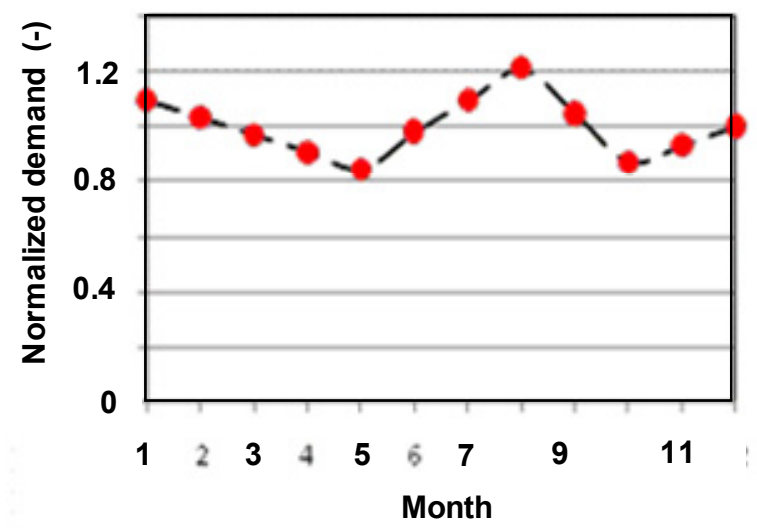


Figures 54 and 55 show the balance between demand and supply with and without load shifting for the minimum and maximum demand months in Japan for the years 2025 to 2045, with 5\% V2G. Without load shifting, wind power must be curtailed at the minimum demand period since the sum of the base load, PV and wind power generation exceeds the minimum demand in a day. As the magnitude of the curtailment is less than $10 \mathrm{GW}$, the dumped wind power might be absorbed by the existing $25 \mathrm{GW}$ capacity of pumped hydro storage system. However, from the viewpoint of an effective utilisation of renewable energy, such curtailment should be avoided.

May and October are the minimum demand months (Figure 54). With load shifting and a V2G ratio of $5 \%$, more effective usage of renewables is achieved without curtailment. As the contribution of stored electricity from EVs increases, the output of the middle load becomes more uniform. Because the ratio of nuclear plus renewables is high in Japan, the introduction of EVs is sufficient to perform load shifting of the middle load in 2035 even without implementation of V2G. In 2045, periods of EV charge and discharge (V2G) overlap, as they are expected to in Western Europe. Even during periods of maximum demand (Figure 55), the effect of load shifting is significant in 2040 and 2045. 
Figure 54: Japan demand-supply balance in minimum demand months (May and October)

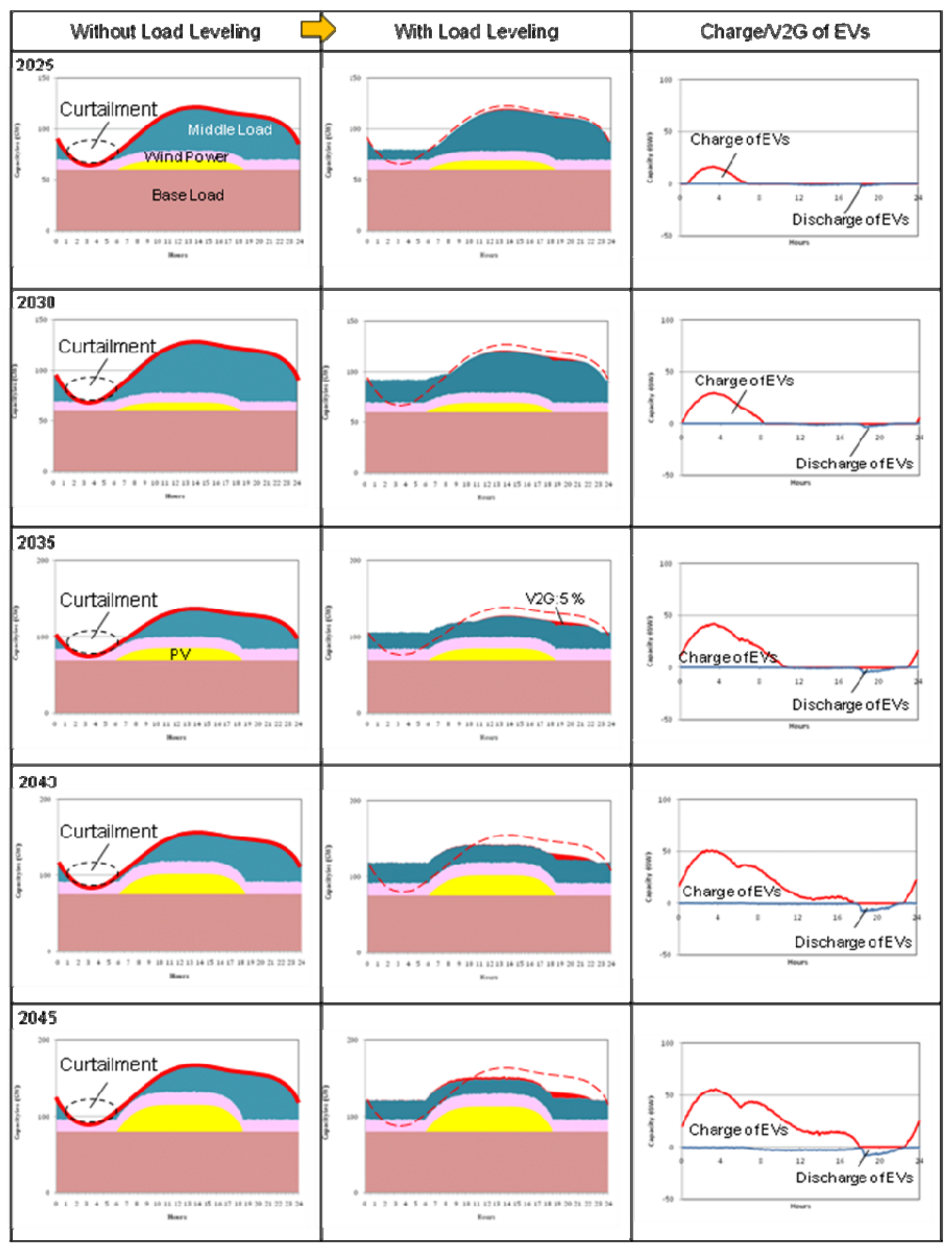


Figure 55: Japan demand-supply balance in maximum demand month (August)

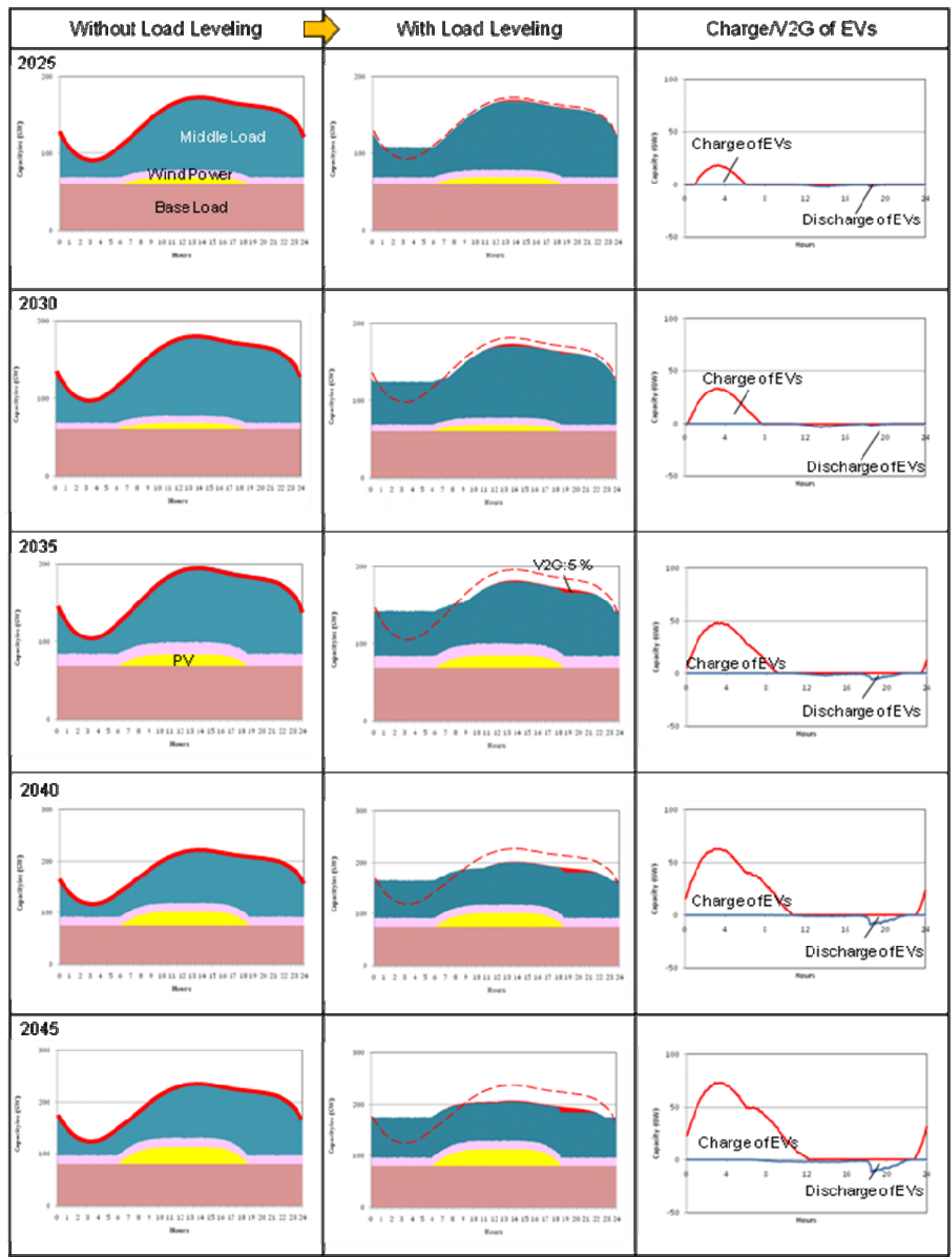

Figure 56 compares the effect of different V2G percentage ratios in 2045. In the case of $20 \%$ V2G, the period of V2G is distributed uniformly. As mentioned above, in Japan the share of nuclear plus renewables is higher than in the United States, Western Europe and China. The middle-load capacity is also comparatively lower. Even without V2G, load shifting is performed 
to some extent. As the V2G percentage ratio increases, the maximum capacities of the middle load (white arrows) decrease slightly.

Figure 56: Comparison of effect of V2G in Japan in 2045
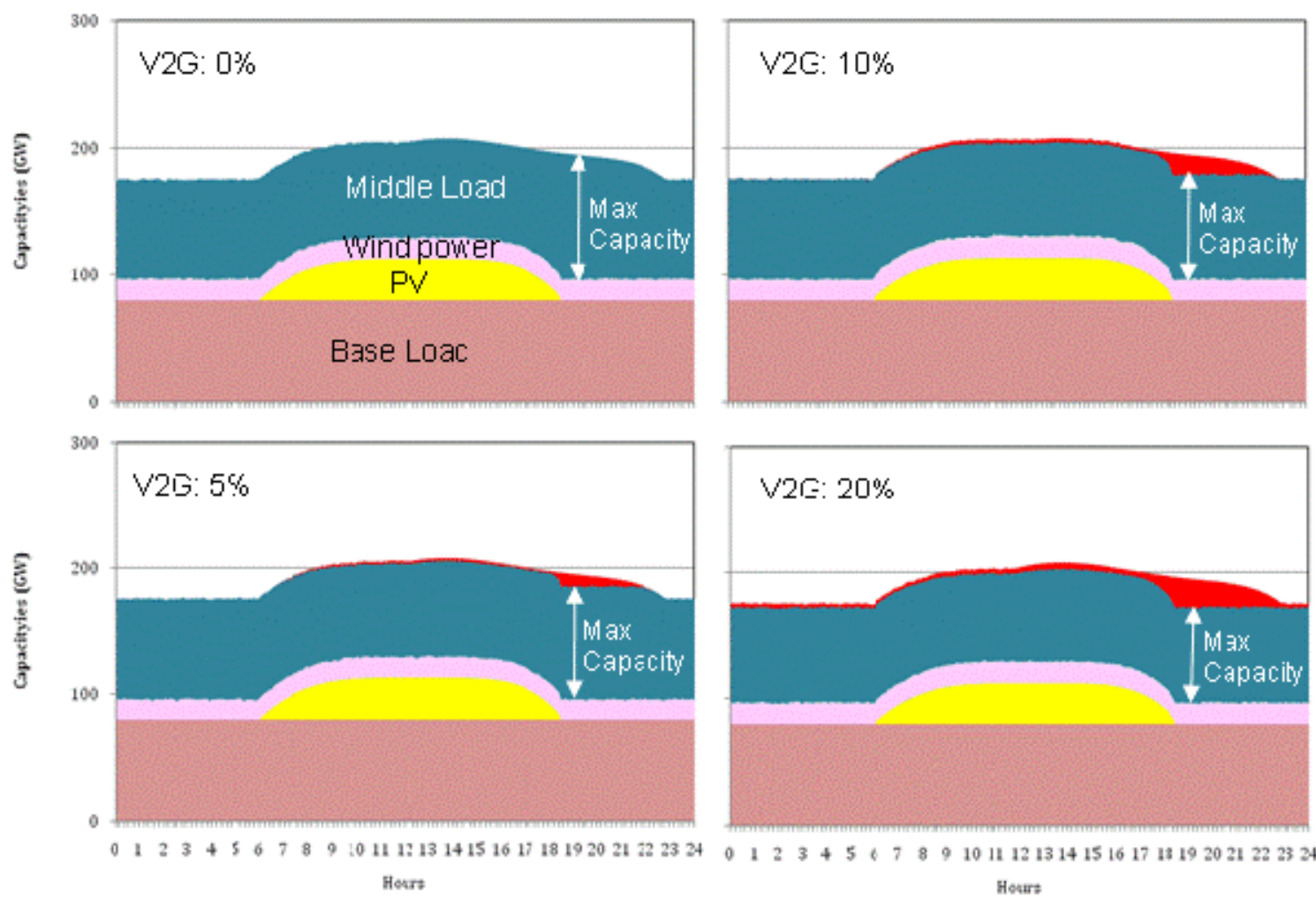

Page | 51

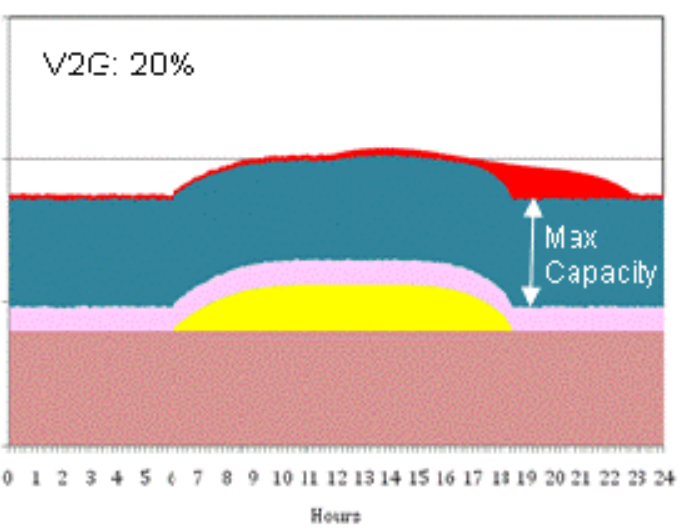

Similarly, without V2G, the capacity of the middle load is relatively flat (Figure 57). Examination of the relationship between V2G percentage ratio and maximum middle-load capacity shows that the reduction effect of the middle load due to V2G is never prominent (Figure 58).

Figure 57: Comparison of daily trend of middle load in the maximum demand season in Japan

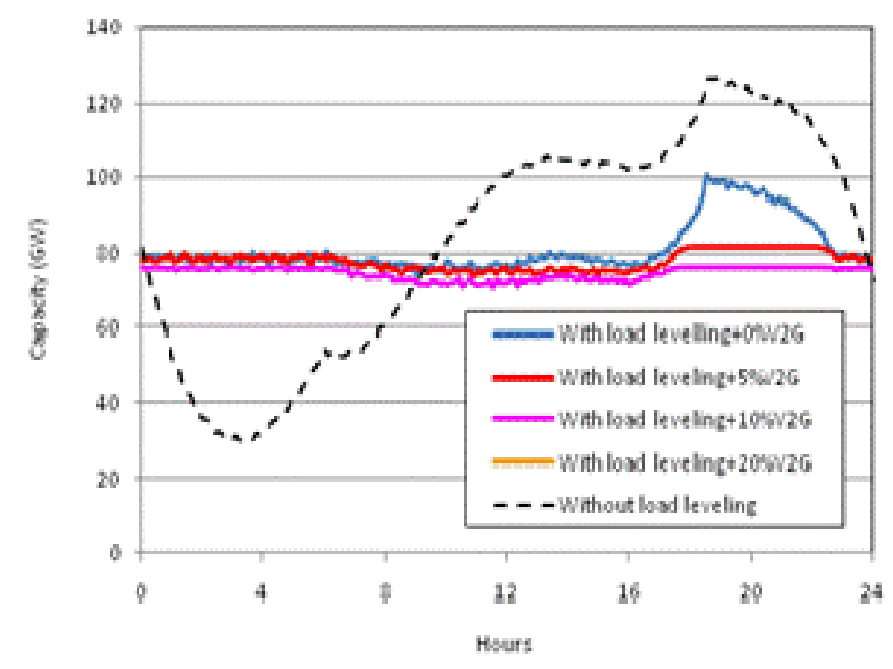


Figure 58: Relationship between V2G ratio and the maximum middle-load capacity in Japan

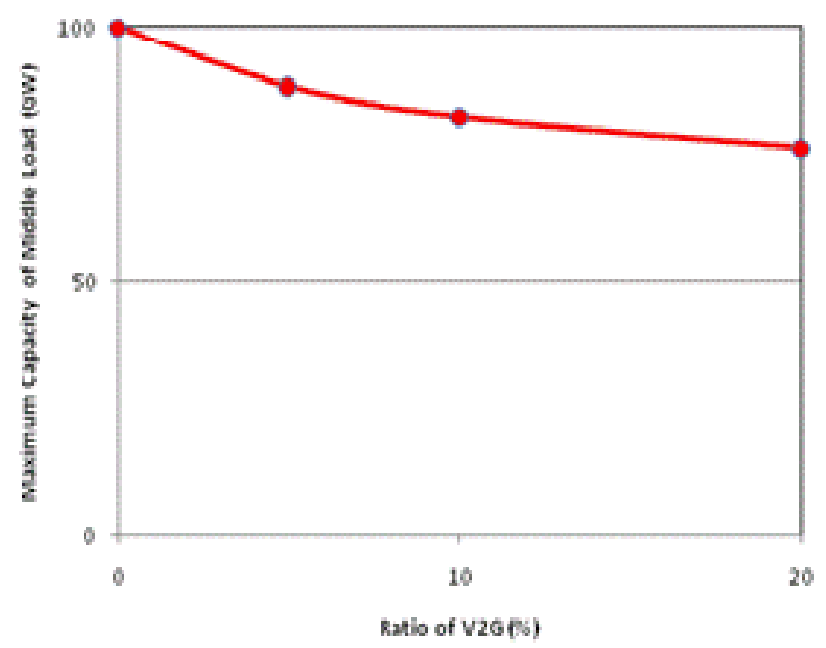

\section{Suggested index to evaluate load shifting}

The main purpose of load shifting is to make the supply of the middle load uniform. In Figure 59 left, the capacity of EVs available for V2G service is insufficient, and there is a discrepancy between the maximum and the minimum supplies of the middle load. In Figure 59 right, the load shifting is achieved and supply of the middle load is uniform, although the capacity of the EVs is superfluous.

Figure 59: Load shifting situations with a shortage (left) and excess (right) of EV generation capacity
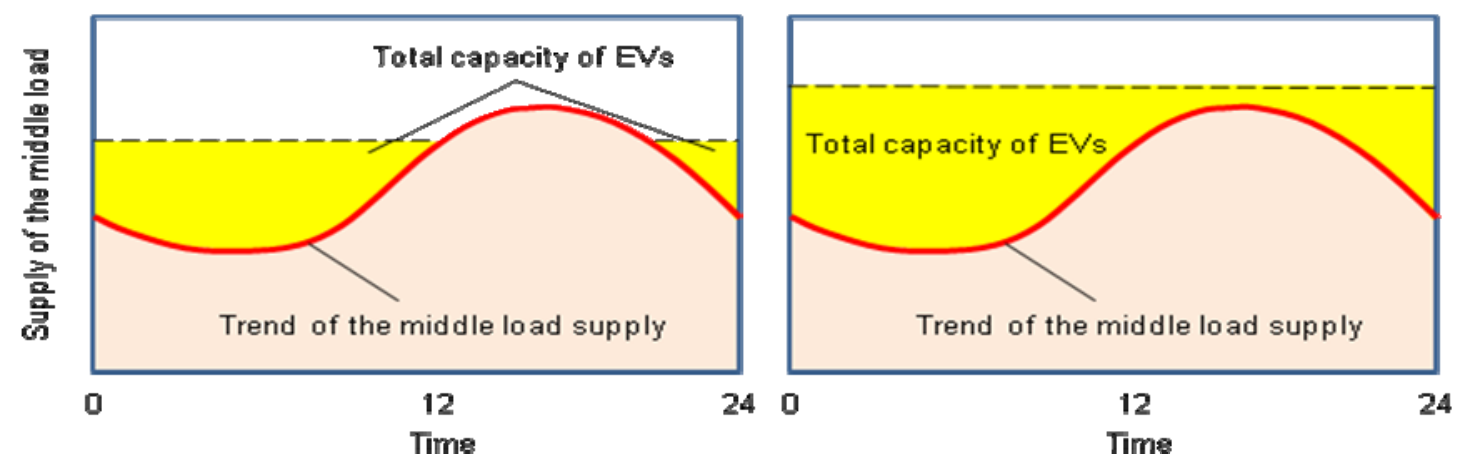

It would be useful to develop an index to estimate the minimum EV capacity needed to perform load shifting and achieve a uniform middle-load supply (Figure 60).

To achieve the ideal situation, the following condition must be satisfied:

$$
P_{T_{\max }} T-\int p_{\text {thermal }} d t<P_{E V S} T
$$

where $P_{T(\max )}$ is the maximum supply of thermal power without load shifting, $t$ is time of day, $T$ is 24 hours, $p_{\text {thermal }}$ is the supply of thermal power, and $\mathrm{P}_{\mathrm{EVs}}$ is the EV demand. Therefore, the load shifting index (LSI) may be expressed as:

$$
\therefore L . S . I=\frac{P_{T_{\max }} T-\int p_{\text {thermal }} d t}{P_{E V S} T}<1
$$


This index is a non-dimensional number expressing the magnitude of load shifting. Therefore, if the LSI is less than unity, the demand due to EVs will be enough to make the supply of the middle load uniform.

Applying Equation 9 to the four regions studied for the years 2025 and 2050 yields an LSI higher than unity in all cases. However, in 2050 the LSI is close to unity in Western Europe and Japan, which means the demand of EVs is barely adequate to make the supply of the middle load uniform. The LSI allows a more quantitative discussion of such issues. When applying the LSI to actual cases, careful estimation of each term in Equation 9 is critical.

Figure 60: Proposed index to estimate load shifting

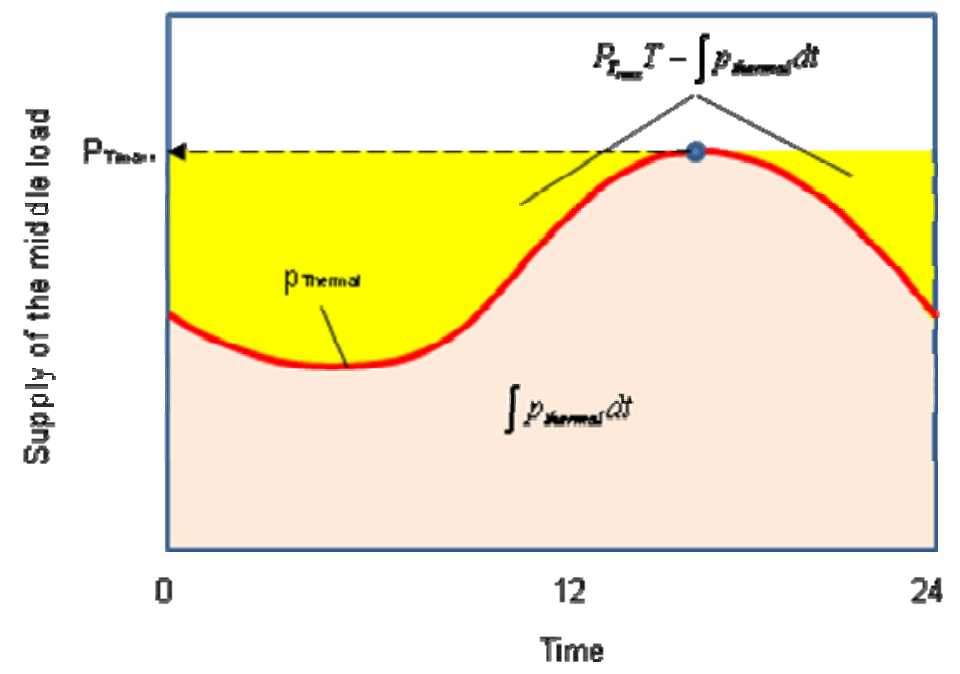

Table 2: Comparison of LSI in regions studied

\begin{tabular}{|l|c|c|}
\hline Region & LSI in 2025 & LSI in 2045 \\
\hline United States & 21.83 & 3.73 \\
\hline Western Europe & 13.13 & 1.40 \\
\hline China & 38.89 & 3.77 \\
\hline Japan & 8.93 & 1.81 \\
\hline
\end{tabular}





\section{Conclusions and recommendations}

This working paper describes the results of a simulation study related to load shifting using EVs in a V2G energy storage application based on the BLUE Map scenario. A new algorithm was developed to evaluate large-scale power systems and to optimise the grid stabilisation needed when using variable renewables and plug-in EVs. The following results were obtained:

- The primary benefit of load shifting via V2G is reducing the energy storage capacity needed to maintain power quality on electric grid systems with large proportions of intermittent renewable generators such as wind and PV. Simulations previously undertaken suggested that without load shifting, a worldwide energy storage capacity ranging from $189 \mathrm{GW}$ to $305 \mathrm{GW}$ would be necessary. With load shifting, the range of needed energy storage capacity was reduced to $122 \mathrm{GW}$ to $260 \mathrm{GW}$. This means that EV-based load shifting is beneficial and can reduce the required energy storage capacity. Rather than specific numerical values, it is the ability of EVs to reduce the amount of energy storage required that is most important.

- The simulation confirmed that using EVs to shift load would produce good results in Western Europe and Japan, which are characterised by a low share of middle load, by 2050. In contrast, V2G load shifting will provide limited benefits in the United States and China, which have greater shares of middle load. However, V2G did produce remarkable $\mathrm{CO}_{2}$ emissions reduction even in those regions.

- A new index to measure the extent of load shifting was suggested. More quantitative discussions will be possible using this index.

In the future, domestic-size batteries, heat-pump water heaters and other resources will be expected to play an important role as residential energy storage to perform load shifting. This working paper focused on plug-in EVs as an example of residential energy storage. The following recommendations address security standards:

- To achieve V2G, the ability to control EV capacity is essential. Statistical data of vehicle usage vary greatly among individual countries; analysis of such data is a key to discuss the feasibility of V2G.

- Since the travelling patterns of plug-in EVs will be quite different in each region, monitoring and analysis of the patterns is also vital.

- Incentives for EV owners to participate in the V2G concept should be established. One incentive might be that: EVs will serve the peak power market by charging their batteries during off-peak hours when the price of electricity is low and could then sell their stored power to the revenue stream based on contract payments for time available rather than for power generated.

\section{Technical issues}

The large-scale introduction of plug-in EVs is necessary to dramatically reduce $\mathrm{CO}_{2}$ emissions from vehicles. Then, a stable balance of supply and demand is required, based on both the cost incentive of charging the EV with less expensive power at night as well as well-controlled demand from a large number of EVs. Especially with a high share of renewables and the subsequent large-scale introduction of energy storage devices, new systems that completely control EV charging will be required, instead of individual charging systems controlled by each owner. The technologies and techniques to implement V2G load shifting will take advantage of 
the advanced communications technologies of smart grids. However, there remain a number of other technical issues to solve before load shifting and V2G concepts are fully realised.

\section{Load shifting}

Page | 56 Forecast of demand and supply of renewable energy: Under a high share of renewables, weather forecast techniques for the next day are keys to predicting with high accuracy the supply of renewables. Accurately predicting demand for the next day is also a key from the viewpoint of load shifting.

Guarantee of controllable generating capacity of EVs: To perform load shifting, stable and controllable energy storage capacity including EVs is important. For large electric power companies especially, large capacities of EV generation should be guaranteed. Note that large electric power companies tend to prefer large-scale storage systems such as pumped hydro because of their simple operation and lower cost compared to Li-ion batteries, which are the main power source of EVs. Performing load shifting with Li-ion batteries requires a high-cost measurement control system.

In addition, the difference between large city areas, in which it is relatively easy to introduce EVs, and other areas should be considered. A key to establishing business models will be determining who guarantees the stable and controllable capacities of EVs, who controls and maintains the system, and who provides relevant policies and laws.

Creating an optimal implementation incentive: In the early stage of V2G load shifting, EVs will be charged at night when electricity is inexpensive as an incentive. With more EVs on the road, new incentives for load shifting should be provided. Especially during the phase-out period from early incentives based on night-time charging to load shifting, supportive incentive policies should be developed.

\section{V2G}

The effect of V2G for load shifting heavily depends on the generation mix in each country. In Japan and Western Europe, the output of the middle load becomes uniform with simple load shifting, since EV storage capacity will be comparable to middle-load capacity. However, in the United States and China, where middle-load capacity is larger than overall EV capacity, V2G has great potential to make the middle load uniform. Related challenges include:

Guarantee of controllable V2G capacity: V2G is operated as if the cumulative energy storage capacity of all EVs comprises a virtual pumped storage power plant. Therefore, the guarantee of the stable and controllable capacity will be important, just as it is for load shifting. Techniques for measuring and analysing EV power for V2G will be essential. As with load shifting, a key to establishing business models will be determining who guarantees the stable and controllable capacities of EVs, who controls and maintains the system, and who provides relevant policies and laws.

Competitiveness with large-scale energy storage system and large-scale Li-ion batteries: From the viewpoint of $\mathrm{V} 2 \mathrm{G}$, energy storage systems for residences, buildings, and other large complexes or facilities employing large-scale Li-ion batteries will also be possible. Breakthrough technologies that reduce the cost of automotive Li-ion batteries will be essential.

Decreasing lifetime of Li-ion batteries due to frequent charge-discharge cycles: The lifetime of Li-ion batteries heavily depends on the number of charge and discharge cycles. V2G operation substantially increases the number of cycles and generally shortens battery lifetime. The main 
purpose of EVs is transportation, and reducing their batteries' lifetime through V2G will not be acceptable to EV owners. This will be the most critical issues to solve.

Transparency of business model: The fundamental concept of $V 2 G$ is discharging stored electricity from EVs to power grids. The required level of the stored energy, which relates directly to possible travel distance, depends on each owner. To perform V2G, monitoring of owner driving modes, measurement and analysis of momentary stored energy, and availability of supply for V2G will be essential. The information should be communicated to EV owners with transparency to clarify their incentive to contribute to V2G operation. Theses technologies and the business models should be standardised within each country or region.

Statistical data of EV driving modes: To realise the V2G concept, a certain number of EVs with enough stored energy should be confirmed to be available and secured. To predict EV driving modes in the future, statistical data based on the driving modes of conventional vehicles should be compiled. To that end, the optimal design related to load shifting and V2G should be discussed. Since the amount of potential $\mathrm{CO}_{2}$ reduction heavily depends on the $\mathrm{V} 2 \mathrm{G}$ percentage ratio, estimating the potential of V2G with high accuracy will be important.

\section{Recommendations for future work}

In this working paper, only the effect of short-term power variation under a constant output was estimated. Estimation of long-term power variation should be a future task. As a rational assumption, the average wind speed over a long time scale should satisfy the Weibull distribution. With double Weibull distributions for the short- and long-term periods, the effect of long-term power variation should be estimated.

In this simulation, each geographical area was treated as a point approximation. Strictly speaking, the structure and status of the power grid should be considered. In the present simulation, each area is assumed to have sufficient grid resources to transmit excess power generated by the renewable resources within it. If there is a shortage in the capacity of the power grid in particular areas, then the necessary capacity of energy storage should be increased further. Grid losses should also be considered. To account for actual grid capacities and losses, larger-scale simulation based on the grid network simulation should be applied to enable an effective analysis of grid stability.

Power variations based on PV generation were also omitted from this simulation. Including them would increase the necessary capacity of energy storage. There is currently little statistical data on PV power variations. Over large areas, it might be close to a kind of white noise, which could be effectively simulated with uniform random numbers once the magnitude of power variations was estimated. The smoothing effect observed with wind power is not as distinct or pronounced with PV power. These issues are important topics for future work.

Other demand response and load management strategies in the residential, commercial and industrial sectors not only exist today but are also very significant. In most cases, they are larger than the new emerging electric transportation load, particularly during the first 20 to 30 years.

This working paper focused on the BLUE Map scenario. However, different regions and countries have different scenarios based on their own policies. Sensitivity analysis will play an important role in comparing the results of such disparities. 



\section{References}

Brooks, A. and T. Gage (2001), "Integration of Electric Drive Vehicles with the Electric Power Grid: A New Value Stream", paper presented at the $18^{\text {th }}$ International Electric Vehicle Symposium and Exhibition, Berlin, Germany.

Cooper, D. (2001), "Phase 1 Basis for Load Management: Energy Efficiency and Load Curve Impacts of Commercial Development in Competitive Markets Development", EU/SAVE 132/2001, EFFLOCOM.

European Commission (EC) (2006), "European Smart Grid Technology Platform”, EC, Brussels.

EC (2006), "European Smart Grid Technology Platform: Vision and Strategy", EC, Brussels, p. 9.

Feisst, C., W. Frye and D. Schlesinger (2008), "Smart Grid, the Role of Electricity Infrastructure in Reducing Greenhouse Gas Emissions", Cisco Internet Business Solutions Group.

Hawkins, D. (2001), "Vehicle to Grid - A Control Area Operators Perspective", presentation at the EVAA Electric Transportation Industry Conference, Sacramento, California.

International Energy Agency (IEA) (2008), Energy Technology Perspectives 2008: Scenarios \& Strategies to 2050, OECD/IEA, Paris.

IEA (2009), "Prospects for Large-Scale Energy Storage in Decarbonised Power Grids", OECD/IEA, Paris.

Kempton, W. et al. (2001), "Vehicle-to-Grid Power: Battery, Hybrid, and Fuel Cell Vehicles as Resources for Distributed Electric Power in California", Institute of Transportation Studies, Davis, California.

Kempton, W. and S. Letendre (1997), "Electric Vehicles as a New Power Source for Electric Utilities", Transportation Research: Part D, Transport and Environment, No. 2 (3), pp. 157-175.

Kempton, W. and S. Letendre (1999), "Electric Vehicles' Value if Integrated with the Utility System", paper presented at Transportation Research Board, $78^{\text {th }}$ Annual Meeting, Washington, DC.

Kempton, W. and S. Letendre (2002), "The V2G Concept: A New Model for Power?", Public Utilities Fortnightly, No. 16, 15 February.

Kempton, W. and T. Kubo (2000), "Electric-Drive Vehicles for Peak Power in Japan", Energy Policy, No. 28, pp. 9-18.

National Energy Technology Laboratory (NETL), "A Vision for the Modern Grid", United States Department of Energy, Washington, DC, www.netl.doe.gov/moderngrid/docs/A Vision for the Smart Grid_Final_v1_0.pdf.

NETL, "The NETL Modern Grid Initiative, A Systems View of the Modern Grid", United States Department of Energy, Washington, DC, www.netl.doe.gov/moderngrid/docs/ ASystemsViewoftheModernGrid_Final_v2_0.pdf.

National Institute of Standards and Technology (NIST), "NIST Releases Report on Smart Grid Development", Washington, DC, http://www.nist.gov/public_affairs/releases/ epri_smartgrid_061809.cfm 
Power Systems Engineering Research Center (PSERC), "The Electric Power Industry and Climate Change: Power Systems Research Possibilities, Final Project Report", PSERC Publication No. 07-16PSERC, Ithaca, New York, www.oe.energy.gov/DocumentsandMedia/ER_2-9-4.pdf.

Sagawa, N. and T. Skaguchi (2000), Proceedings of the $16^{\text {th }}$ Energy System, Economics, Environment Conference (in Japanese), www.ueri.co.jp/universal/Hori07.01.NucEye.pdf.

Page | 60 Tanaka M. (2006), “Real-Time Pricing with Ramping Costs: A New Approach to Managing a Steep Change in Electricity Demand", Energy Policy No. 34, pp. 3634-3643.

Union for the Co-ordination of Transmission of Electricity (UCTE) (2006), "Final Report: System Disturbance on 4 November 2006".

United States Department of Energy (2009), The Smart Grid: an Introduction, www.oe.energy.gov/smartgrid.htm.

Western Power Distribution (South Wales) PLC (2008), "Long Term Development Statement for Western Power Distribution, Electricity Distribution System", Wales. 


\section{Annex 1: Numerical algorithms}

\section{Details of simulation models}

This annex describes details of the simulation algorithm.

\section{PV operation curve model}

PV power strongly depends on the time of day and weather conditions. In this working paper, the following empirical model was developed based on actual PV operation:

For $6<\mathrm{T}<18.5$ :

$$
\begin{aligned}
f_{P V}(T)= & \left(-0.0000323955 \mathrm{~T}^{5}+0.0012949488 \mathrm{~T}^{4}-0.0133779943 \mathrm{~T}^{3}-0.07745311 \mathrm{~T}^{2}\right. \\
& +2.0436509568 \mathrm{~T}-7.9849739044) \times \mathrm{WF}
\end{aligned}
$$

For $\mathrm{T}<6$ and $18.5<\mathrm{T}$ :

$$
P V(T)=0
$$

where $T$ is the time (e.g. 18.5 is 6:30 p.m.), and WF is the factor due to the weather, as follows:

Fine weather: $\mathrm{WF}=1.0$

Cloudy weather: $\mathrm{WF}=0.65$

Rainy weather: $\mathrm{WF}=0.16$.

The PV operation curve shown in Figure A.1 was constructed based on Equation A.1. Strictly speaking, the empirical formula should be different for different regions, but in this paper, the equation was applied to all the regions. In this simulation, the effect of the power fluctuation due to PV was omitted.

Figure A.1: PV normalised operation curve: $f_{P V}$

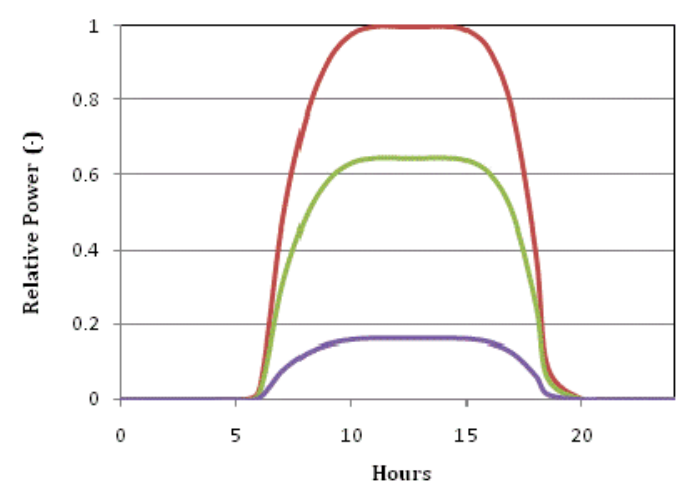

\section{Wind speed model}

Compared against actual wind speed data, the probability density distribution is well simulated with the Weibull distribution, expressed as: 


$$
f(V)=\frac{k}{c}\left(\frac{V}{c}\right)^{k-1} \exp \left(-\left(\frac{V}{c}\right)^{k}\right)
$$

where $k$ is a profile coefficient, $c$ is a scale coefficient, and $V$ is the wind speed. When $k=2$, then the distribution $f(V)$ is a Rayleigh distribution:

$$
f(V)=\frac{\pi}{2}\left(\frac{V}{\bar{V}^{2}}\right) \exp \left(-\frac{\pi}{4}\left(\frac{V}{\bar{V}}\right)^{2}\right)
$$

where $\bar{V}$ is the average wind speed. In this working paper, the Rayleigh distribution was used to represent the distribution of the wind speed. The function was expressed as an integrated equation:

$$
F(V)=\int_{0}^{V} f(V) d V=1-\exp \left(-\frac{\pi}{4}\left(\frac{V}{\bar{V}}\right)^{2}\right)
$$

Since $\bar{V}$ is changed from 0 to 1 , with a uniform random number $\mathrm{X}$, the random number $\mathrm{V}$, which obeys to the Rayleigh distribution, is given as:

$$
V=\frac{2 \bar{V}}{\sqrt{\pi}}(-\ln (1-X))^{0.5}
$$

The wind speed and its distribution (Figures A.2 and A.3) were calculated with Equation A.5.

Figure A.2: Simulated wind speed (average: $8 \mathrm{~m} / \mathrm{s}$ )

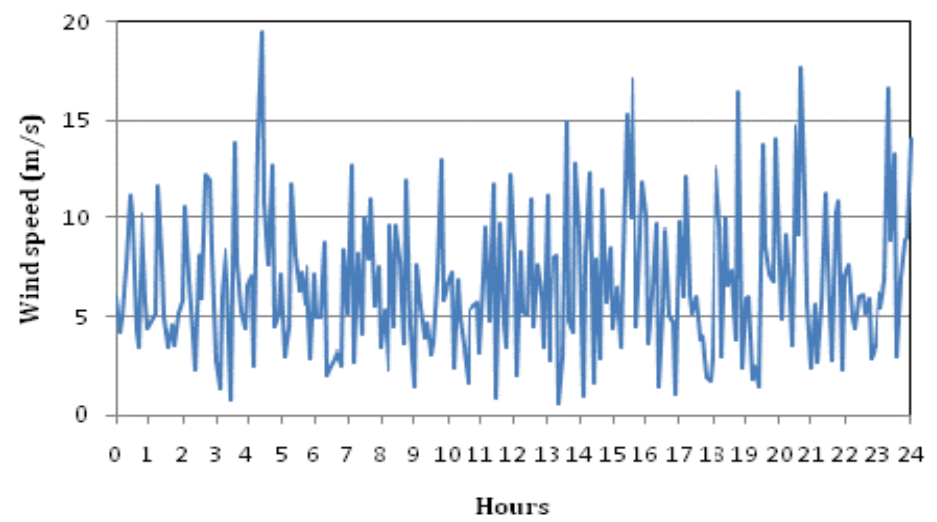

Figure A.3: Distribution of simulated wind speed

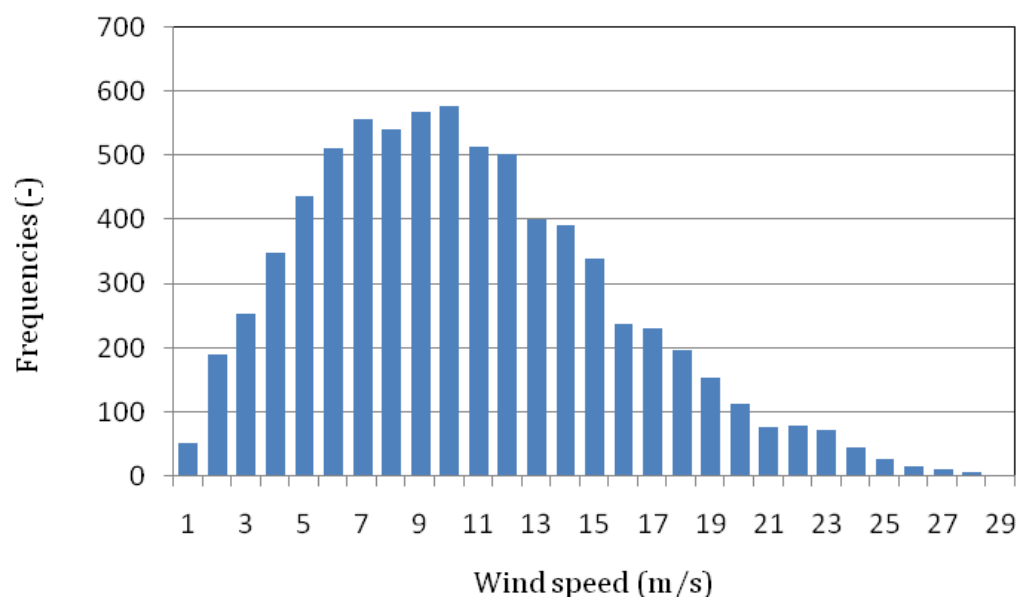




\section{Wind turbine operation model}

The output of the wind power was estimated as:

$$
P_{w}=\frac{C_{w} \rho A}{2} V^{3}=\frac{C_{w} \rho \pi R^{2}}{2} V^{3}
$$

where $A$ is the cross-sectional area of the individual wind turbine, $\rho$ is the density of the air, $C_{w}$ is the efficiency, $R$ is the radius of the wind turbine, and $V$ is the wind speed. In actual operation, the output is usually regulated when wind speeds exceed a set cut-out speed limit. Due to fluctuation of the wind speed, actual wind power is usually lower than the theoretical output. The ratio of actual power output to theoretical output throughout a year is called the capacity factor, which is typically $20 \%$ to $40 \%$. In this simulation, the estimated capacity factor was approximately $35 \%$, which approximates observed values.

To simulate the actual wind power output observed, the following operation curve was applied (Figure A.4):

$$
\begin{aligned}
& 0<\mathrm{V}<\text { Cut-in speed: } f_{w}=0 \\
& \text { Cut-in speed }<\mathrm{V}<\text { Base load speed: } f_{w}=C_{0} \cdot V^{3} \\
& \text { Base load speed }<\mathrm{V}<\text { Cut-out speed: } f_{w}=C_{\text {base }}
\end{aligned}
$$

Figure A.4: Normalised operational curve for wind power model

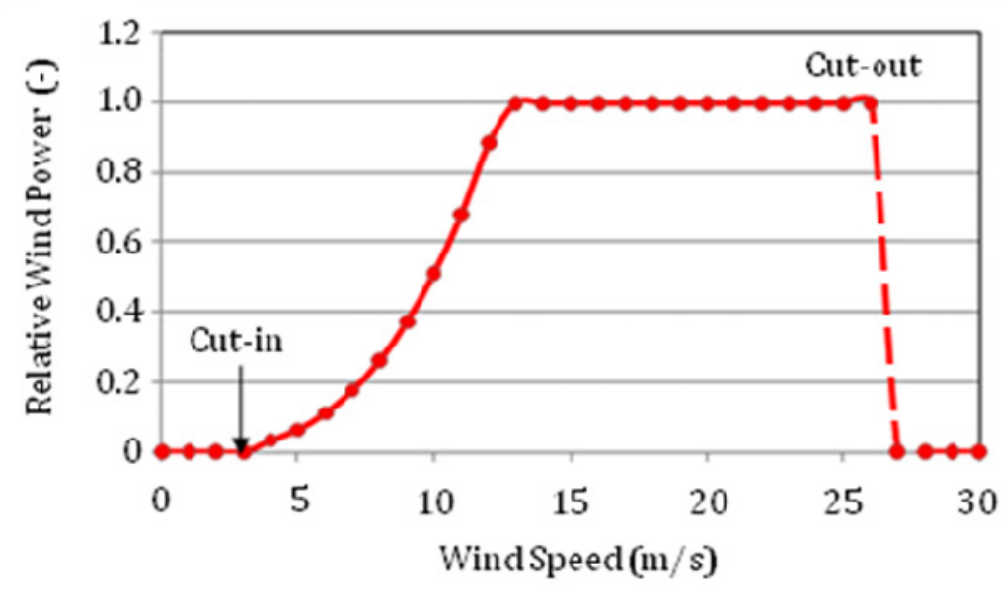

In Equation A.6, the following should be satisfied:

$$
C_{0} \cdot\left(V_{\text {base }}\right)^{3}=C_{\text {base }}
$$

where $V_{\text {base }}$ is the minimum speed in the regulation operation. 


\section{Annex 2: Power grids and smart grids}

This annex provides additional information about power grids and smart grids that informs the discussion of vehicle-to-grid (V2G) applications described in this paper.

\section{Electricity quality loss due to variation of renewable generation}

Daily and annual electricity power demands vary with time. The actual demand variations consist of the superposition of the short-term and long-term variations, and actual demand depends on each user's situation. Without balance of demand and supply, the power system frequency is never stabilised. Frequency falls when demand exceeds supply and, conversely, rises when supply exceeds demand.

Middle-load power plants employ a control system to minimise the frequency change. To balance supply and demand, operators of hydroelectric and thermal power plants modify their output through governor-free (GF) control for short-cycle demand fluctuation. For intermediate-cycle fluctuations, a load frequency control (LFC) system is used (Figure A.5). In addition, for long-cycle fluctuations, an economic load dispatching control (EDC) system controls the balance. Electric frequency is controlled within a small deviation: for example, in Japan the limit is $0.2 \mathrm{~Hz}$ to $0.3 \mathrm{~Hz}$; in the United States, it is $0.018 \mathrm{~Hz}$ to $0.0228 \mathrm{~Hz}$; and in the European UCTE, it is $0.04 \mathrm{~Hz}$ to $0.06 \mathrm{~Hz}$. As the share of variable renewable power increases, so does the potential for a fatal frequency change to occur in small capacity grids, particularly since renewable generators rarely have control systems for frequency change and produce large variations of output due to weather conditions.

Figure A.5: Comparison of frequency controllers
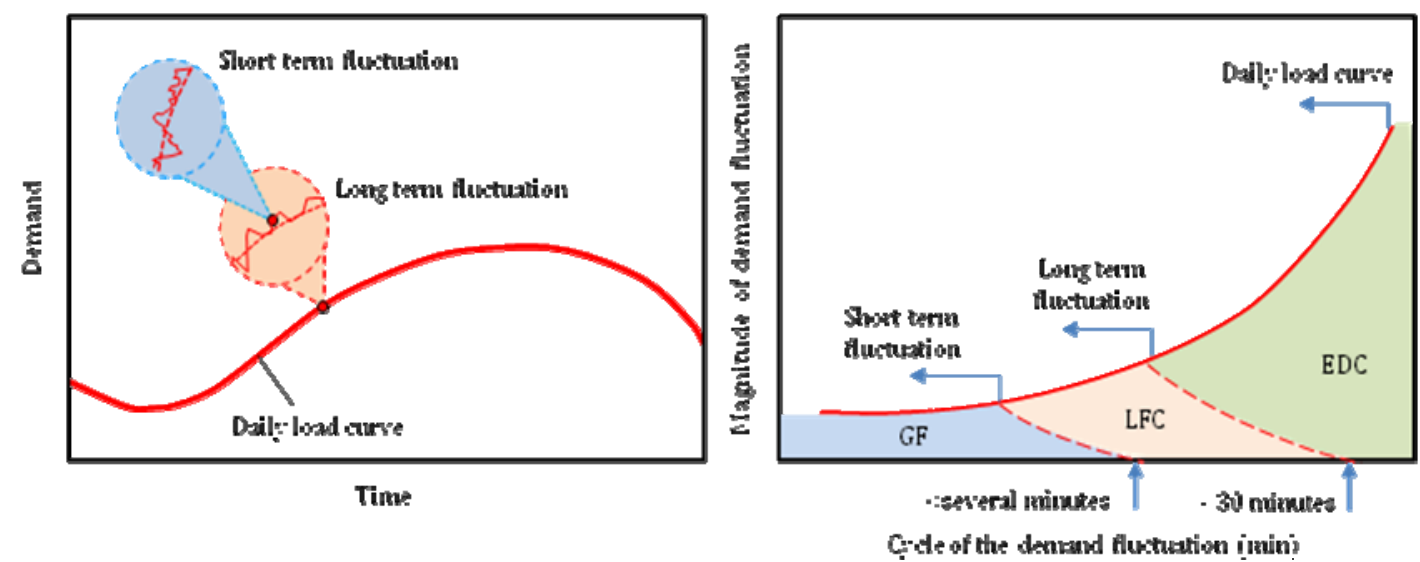

\section{Cascading accidents}

All grids consist of power generation units, transmission lines, substations and customers. The system consists of segments with different voltages that are connected through substations, which transform the voltage and frequency. On the power production side of the grid, the input voltage depends on the type of generation unit. Large-scale power generation units such as nuclear power plants provide power at less than $500 \mathrm{kV}$. Other smaller scale thermal powers are 
connected to the grid at less than $77.22 \mathrm{kV}$. Depending on the transportation distance and age of the capital stock, electricity transmission lines operate at $100 \mathrm{kV}$ to $1000 \mathrm{kV}$. The substations consist of several components like transformer, and circuit breaker, etc. They are classified as first, second or third substations based on the voltage level.

Grids may be divided into three types: radial, ring and mesh (Figure A.6). The different grid structures have consequences for grid stability and methods to enhance grid stability. Western and Central Europe represent a mesh type grid because the countries are interconnected. In contrast, Japan exemplifies a radial type grid, which has the advantage of easy control of power flow. However, the ring or mesh type grids are more reliable because they have several grid connections between the generation units and the customers, and can continue to operate in case one connection fails. Consequently, it is more difficult to control the power flow in each line. This can lead to a cascading accident. A comparison of selected characteristics of radial and mesh (ring) type grids is shown in Table A.1.

Figure A.6: Types of grid systems

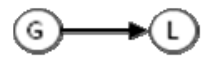

a) Radial type

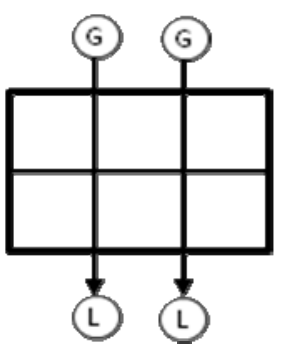

b) Ring type

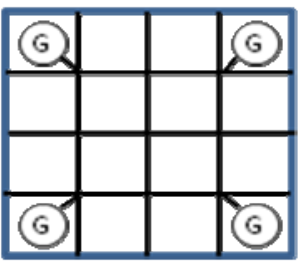

c) Mesh type

Table A.1: Comparison of radial type and mesh (ring) type

\begin{tabular}{|l|c|c|c|c|c|}
\hline \multicolumn{1}{|c|}{$\begin{array}{c}\text { Supply } \\
\text { Type }\end{array}$} & \multicolumn{1}{c}{$\begin{array}{c}\text { Power quality } \\
\text { control }\end{array}$} & Grid tracking & \multicolumn{1}{c|}{$\begin{array}{c}\text { Blackout by } \\
\text { local defect }\end{array}$} & Cascading \\
\hline Mesh & Large & Difficult & Difficult & No potential & Potential \\
\hline Radial & Small & Easy & Easy & Potential & No potential \\
\hline
\end{tabular}

Grid interconnections are classified into five types (Figure A.7). In separated grids, an accident on one grid line never spreads to other separated grids. The looped and interzonal types of grid are most common in the United States, Western Europe and Central Europe. 
Figure A.7: Classification of interconnections

Page $\mid 66$
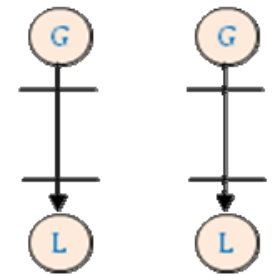

ai Separated grids

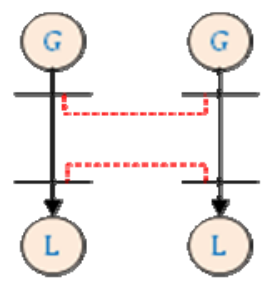

dj Looped grids

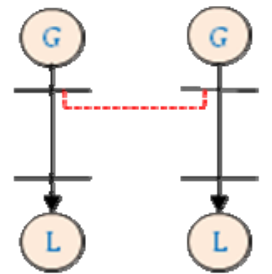

bị Upstrean interoonuected gide

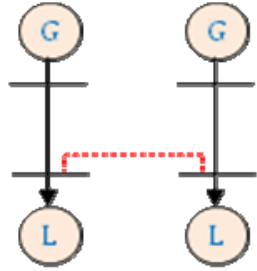

ci Downstrean interconnected gids

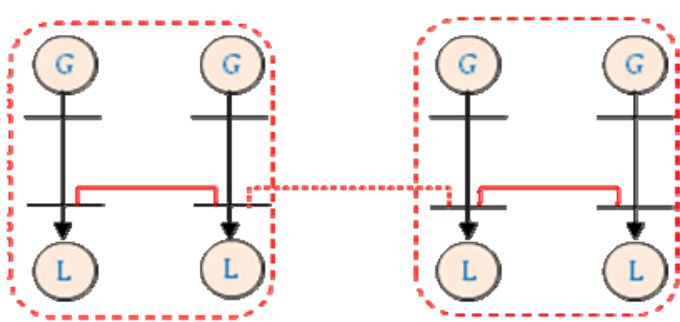

ei htersonal gids

In interconnected grids, an initial grid line accident can spread to another interconnected grid, causing a cascading accident. The concept of the cascading accident in simple interconnected grids is shown in Figure A.8. The potential for such an accident depends on the total electric supply and demand in the overall grid and the capacity of each grid line. In the case of a cascading accident, the grids fail in increasing order of capacity.

Grid reliability refers to the risk of a blackout. As a basic principle, the power grid is usually operated with " $(\mathrm{N}-1)$ rule". The grid system is a huge network that includes many components such as generation units, transmission lines, and substations. Here, $\mathrm{N}$ is the total number of components. A situation of $(\mathrm{N}-1)$ means that one component is out of order in the grid system. The $(\mathrm{N}-1)$ rule guarantees the stable electric transmission under even the $(\mathrm{N}-1)$ situation. An $(\mathrm{N}-2)$ situation may result in a blackout but should be extremely rare. The progress of such an accident is quite rapid, and is usually completed within several seconds or minutes. One example of a typical cascading accident was an extensive blackout in Europe on 4 November 2006.

There are two measures to prevent a cascading accident: 1) preliminary predictions from numerical simulations under varying conditions, and 2) instant load rejection technology based on measurements of power supply from generators and numerical results, which should be simulated within $200 \mathrm{~ms}$ to $250 \mathrm{~ms}$. 
Figure A.8: Concept of cascading accident

\begin{tabular}{|l|l|}
\hline Situations & Events and effects \\
Situation: Normal operation & $\begin{array}{l}\text { 1) Capacities of each grid: } \\
\text { Grid-1: 2P, grid-2: 1.2P, grid-3: 1.2P } \\
\text { 2) Loads of each grid: } \\
\text { Grid-1: 1P, grid-2: 1P, grid-3: 1P }\end{array}$ \\
\hline Situation: Domino effect to grid-2 & $\begin{array}{l}\text { Event: } \\
\text { Grid accident in grid-3 } \\
\text { Effects: } \\
\text { All of the power in grid-3 flows to grid-1 and grid-2. } \\
\text { Namely, power of 1.5P flows to grid-1 and grid-2, } \\
\text { respectively. 1.5P in grid-2 exceeds the capacity of } \\
\text { grid-2. }\end{array}$ \\
\hline Event: \\
Domino effects to grid-2 \\
Effects: \\
Due to the exceeded capacity in grid-2, it breaks \\
down immediately. Then, all the power of 3P flow \\
into grid-1. 3P exceeds the capacity of grid-1.
\end{tabular}

\section{Change of load curve and investments for peak load}

Figure A.9 shows the influence of PV penetration on the demand-supply balance. The system load varies with time. The middle load, which mainly consists of thermal power generators, plays an important role in balancing the system demand and supply. In addition, PV supplies power from 06:00 to 18:00, with output dependent on weather. As PV output is never controllable, the points of the minimum and maximum middle-load capacities are shifted as shown. In particular, as PV power increases, the difference between maximum and minimum capacities increases. In such a case, daily start and stop (DSS) operation of the middle load will be required more than it would be without a high share of PV generation. At the point of 
minimum capacity (indicated by the lowest dashed circle), middle-load generation capacity is almost unnecessary. To make effective use of the middle load, the difference between the maximum and minimum capacities of the middle load should be reduced.

Figure A.9: Influence of PV penetration on demand-supply balance
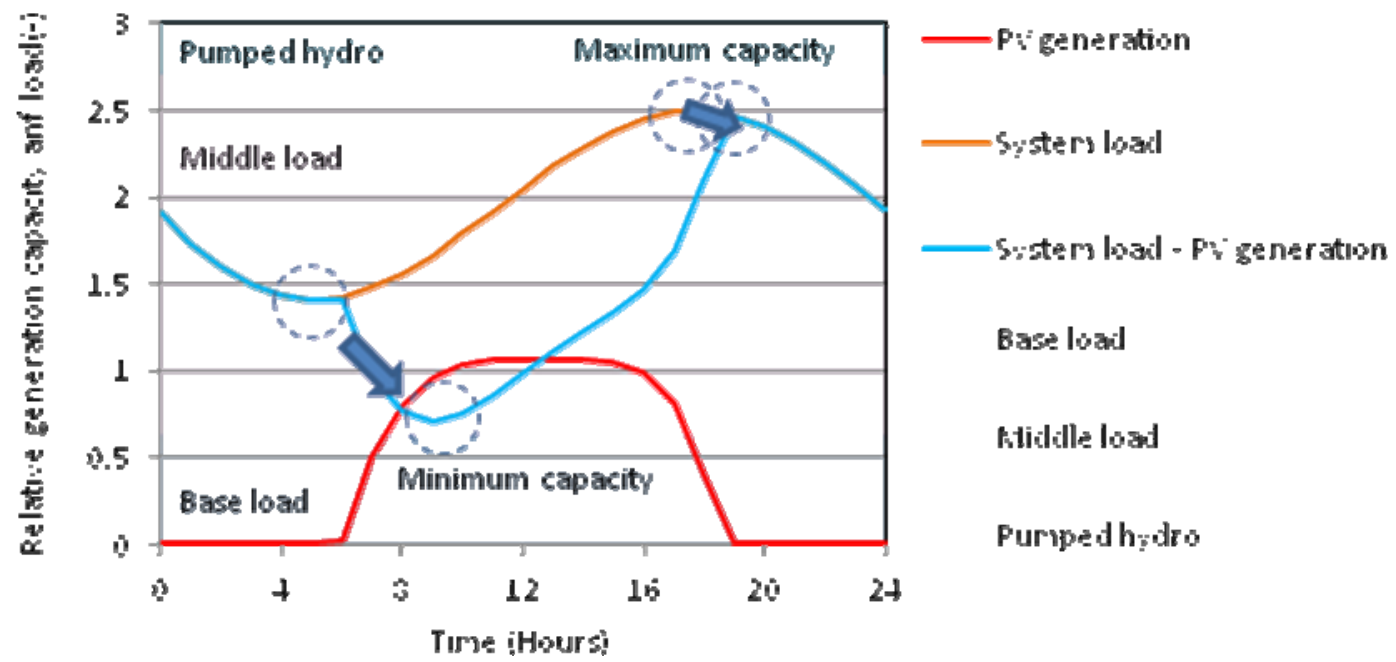

ntidille lost

Purpedhedo dro

Figure A.10 shows the trends for peak demand load and load factor experienced by the US utility Southern California Edison. The data indicate that the peak load is increasing year by year. With increasing peak load, the load factor, which is equivalent to the margin of the power output for the peak load, has been decreasing since 2001. This means that investments in power facilities have not followed the peak demand.

Figure A.10: Trends of peak demand and load factor

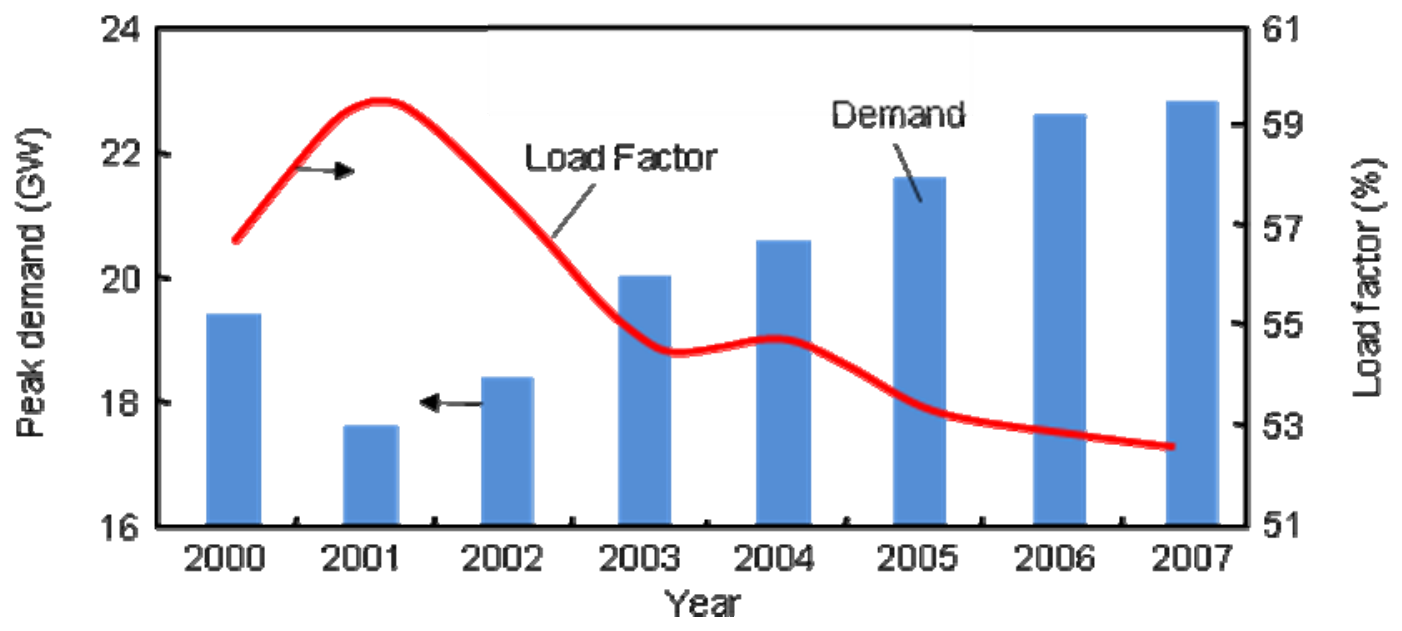

Source: Southern California Edison.

Figure A.11 shows the typical annual trend of peak demand for residences serviced by Southern California Edison. While several maximum peak loads appeared in the summer season, the period was quite short. The overall capacity of supply should be determined by the peak demand. Therefore, load shifting and demand-side management are expected to reduce the standby power needed and defer expensive capital investments that would otherwise be required. 
Figure A.11: Typical annual trend of residential peak demand for Southern California Edison

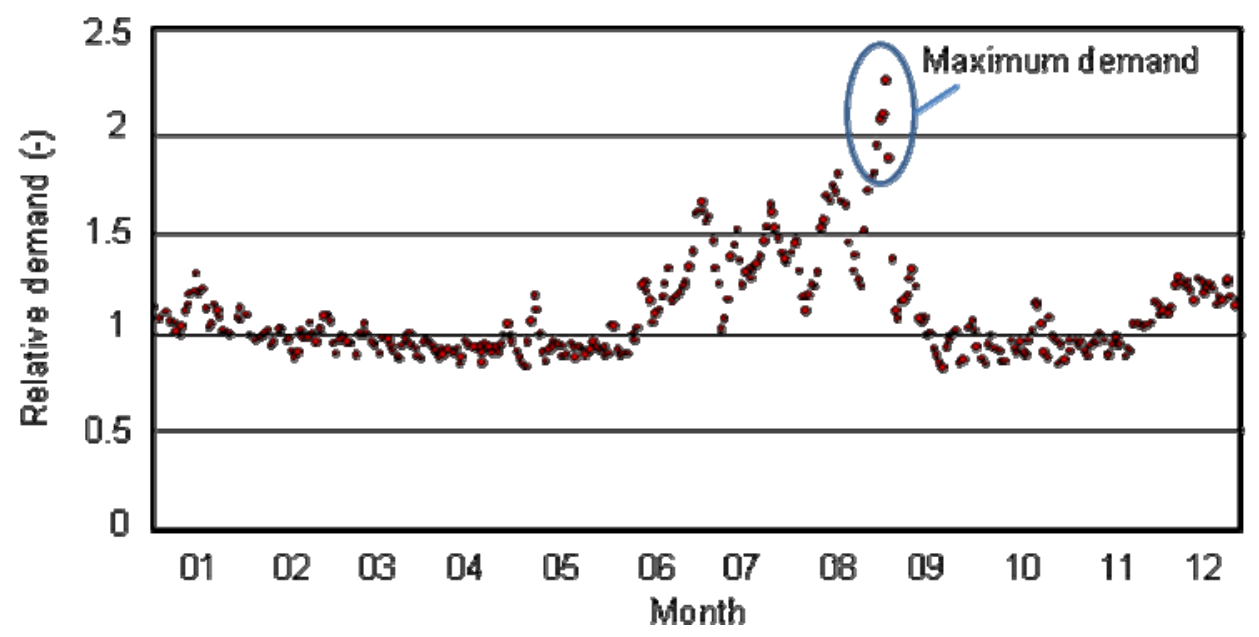

Page | 69

Source: Southern California Edison.

Figure A.12 shows the trend of transmission investment in the United States. Since 1975, investments have been decreasing year by year. On the other hand, according to DOE, the losses due to huge blackout in the United States are becoming massive, as seen for the following occurrences:

- A rolling blackout across Silicon Valley totalled USD 75 million in losses.

- In 2000, a one-hour outage that hit the Chicago Board of Trade resulted in USD 20 trillion in trades being delayed.

- Sun Micro Systems estimates that a blackout costs the company USD 1 million every minute that it continues.

- The 2003 blackout that hit the northeastern United States resulted in a USD 6 billion economic loss to the region.

After reflecting on these experiences, USD 4.5 billion of the USD 787-billion American Recovery and Reinvestment Act (ARRA) economic stimulus package of 2009 was specifically marked for power grids.

Figure A.12: Decrease in grid investments in the United States

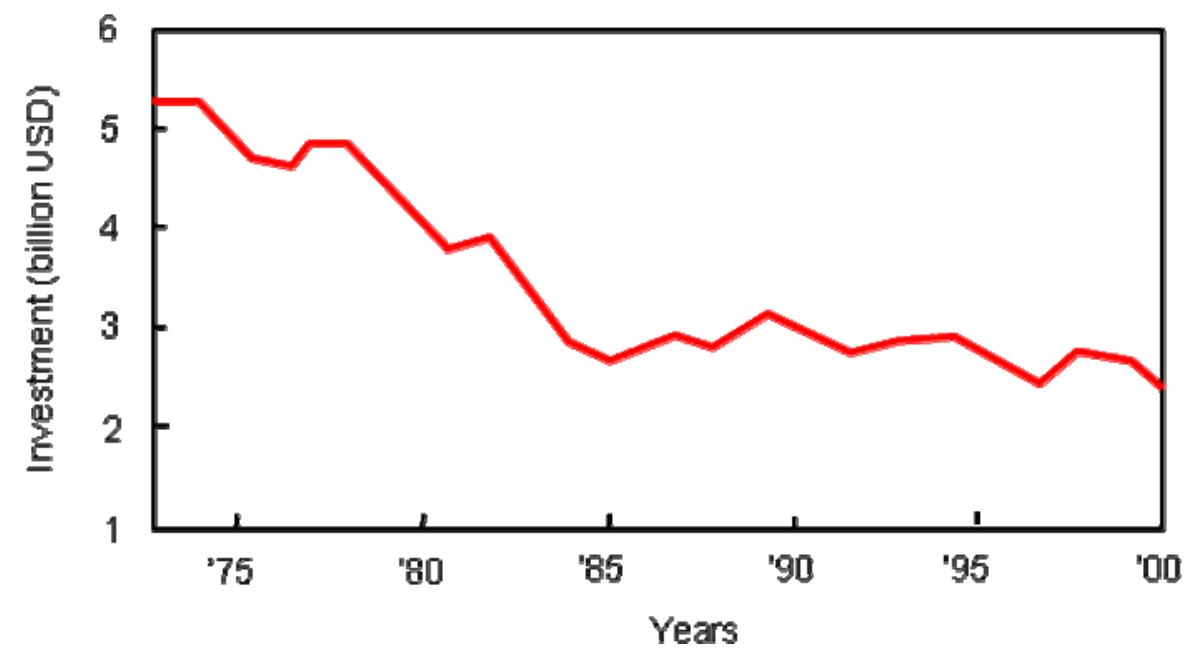

Source: DOE (2009), The SMART GRID: An Introduction. 


\section{Grid efficiency}

In 2007 India's power supply totalled 800 TWh, placing it fifth after the United States, China, Japan and Russia (Figure A.13). While India has achieved economic growth of $5 \%$ to $8 \%$ per year continuously, increases of the power supply are not keeping up with the increasing of power demand due to economic growth. Therefore, new and upgraded power generation and grid facilities are urgently needed. The Indian government estimates that approximately 100 new generation facilities of $1000 \mathrm{MW}$ capacity each are needed. One problem with quickly growing a nation's electricity infrastructure is the fact that, since expansion of transmission/distribution system is generally a running rate, grid losses due to overload operation are significant. In fact, grid losses in India have reached more than $26 \%$ of the total power generated (Figure A.14), placing an enormous financial burden on the country.

Figure A.13: Comparison of national electric power supplies in 2007

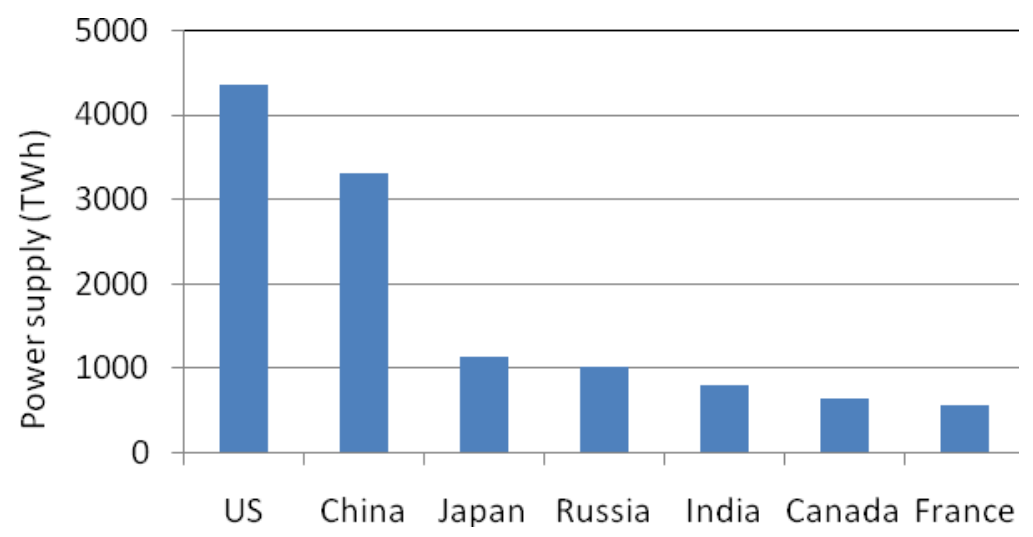

Source: IEA (2009), Electricity Information.

Figure A.14: Comparison of national grid losses in 2007

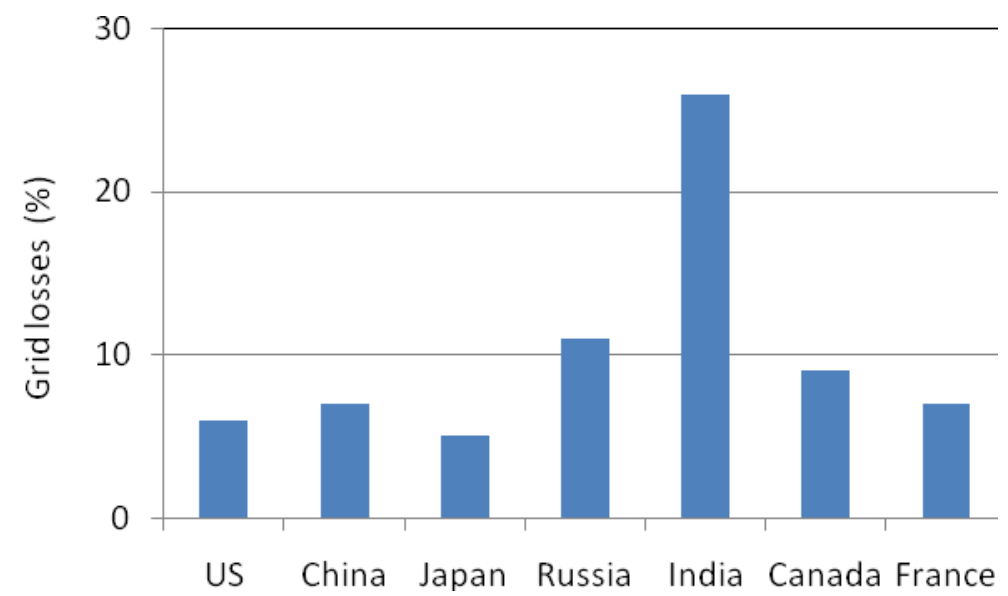

Source: IEA (2009), Electricity Information.

Grid losses can be classified as either technical or commercial losses. Technical losses are the result of overload operations, maintenance failures, and other physical or equipment-related causes, while commercial losses are derived from power user problems, meter interpolation, measuring errors and other process causes. 
In India, fees are charged for only $55 \%$ of the total power provided, and only $40 \%$ are collected. In other words, $60 \%$ of the fees are unrealised. Of these lost fees, $10 \%$ are due to supplying power to non-registered users while $50 \%$ are caused by grid losses. This percentage is much higher than the $8 \%$ to $12 \%$ experienced in China, Thailand, and South Korea. Furthermore, $75 \%$ to $80 \%$ of the grid losses are attributable to commercial losses. It is estimated that a reduction of just $1 \%$ in Indian grid losses would yield increased income of USD 70 million to USD 80 million.

To reduce commercial losses, improving the measurement efficiency of electric meter in addition to introducing appropriate accounting, auditing, charging and collecting of electricity fees would be effective.

The number of plug-in EVs in India is expected to grow so that approximately $200 \mathrm{TWh}$ will be required to charge them in 2050. Reducing grid loss is a key to the effective utilisation of EVs for both transportation and as distributed energy storage resources. 



\section{iea}

\section{International Energy Agency}
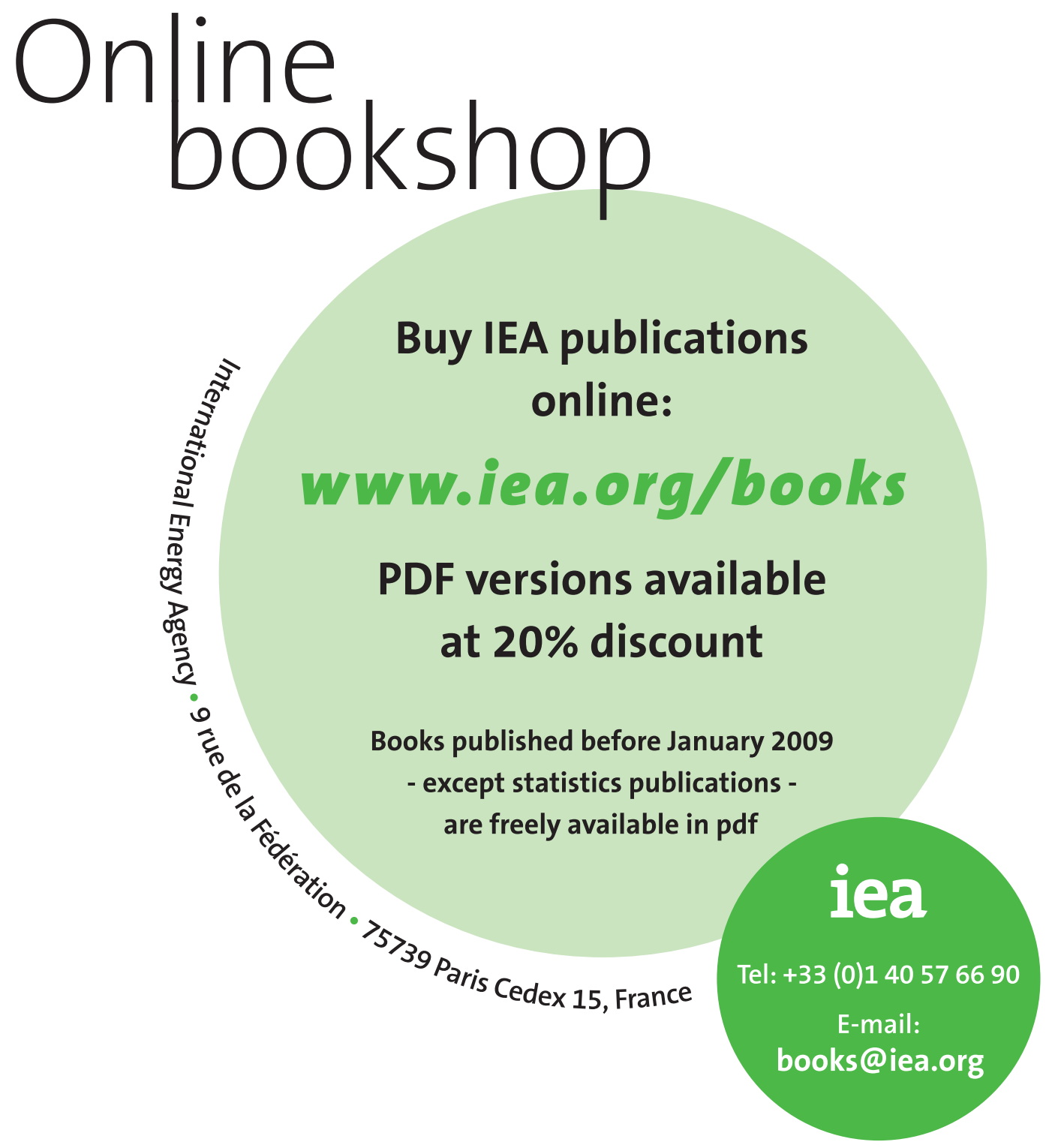
